\title{
EFICIÊNCIA AGRONÔMICA DE FONTES NITROGENADAS NA CULTURA DA CANA-DE-AÇÚCAR EM SISTEMA DE COLHEITA SEM DESPALHA A FOGO
}

\section{MÍRIAN CRISTINA GOMES COSTA}

\begin{abstract}
Dissertação apresentada à Escola Superior de Agricultura "Luiz de Queiroz”, Universidade de São Paulo, para obtenção do título de Mestre em Agronomia, Área de Concentração: Solos e Nutrição de Plantas.
\end{abstract}

P I R A C I C A B A

Estado de São Paulo - Brasil

Novembro de 2001 


\title{
EFICIÊNCIA AGRONÔMICA DE FONTES NITROGENADAS NA CULTURA DA CANA-DE-AÇÚCAR EM SISTEMA DE COLHEITA SEM DESPALHA A FOGO
}

\author{
MÍRIAN CRISTINA GOMES COSTA
}

Engenheiro Agrônomo

Orientador: Prof. Dr. GODOFREDO CESAR VITTI

Dissertação apresentada à Escola Superior de Agricultura "Luiz de Queiroz", Universidade de São Paulo, para obtenção do f́tulo de Mestre em Agronomia, Área de Concentração: Solos e Nutrição de Plantas.

P I R A C I C A B A

Estado de São Paulo - Brasil

Novembro de 2001 


\section{Dados Internacionais de Catalogação na Publicação (CIP)}

DIVISÃo DE BIBLIOTECA E DOCUMENTAÇÃO - ESALQ/USP

\section{Costa, Mírian Cristina Gomes}

Eficiência agronômica de fontes nitrogenadas na cultura da canade-açúc ar em sistema de colheita sem despalha a fogo / Mírian Cristina Gomes Costa. - - Pirac ic aba, 2001.

79 p. : il.

Dissertação (mestrado) - - Escola Superior de Agricultura Luiz de Queiroz, 2001.

Bibliografia.

1. Cana-de-açúcar 2. Colheita 3. Fertilizantes nitrogenados 4. Palhada-cana-d e-açúcar 5. Vola tilização I. Título

CDD 633.61

\section{"Permitida a cópia total ou parcial deste documento, desde que citada a fonte - $\mathbf{O}$ autor"}


À Deus, pela preciosa vida

OFEREÇO.

Aos meus pais,

Maria e Erasmo, por todo amor e confiança;

Aos meus irmãos,

Célia, Valter, Selma, Erasmo e Márcia, pelos bons exemplos, amizade e incentivo 


\section{AGRADECIMENTOS}

Ao Prof. Dr. Godofredo Cesar Vitti, pela amizade e ensinamentos;

Ao Dr. Heitor Cantarella, pela contribuição na realização deste trabalho;

Aos Professores Dr. Paulo Cesar Ocheuze Trivelin, Dr. Jairo Antônio Mazza e Dr. Pablo Vidal, pelas críticas e sugestões apresentadas no exame de qualificação;

À Prof ${ }^{a}$. Dra. Sônia Maria De Stefano Piedade, pelo auxílio nas análises estatísticas;

À bibliotecária Eliana Maria Garcia Sabino, pelas correções bibliográficas;

À Márcia Maria Gomes Costa pelas correções ortográficas e gramaticais;

À ESALQ/USP, especialmente ao Departamento de Solos e Nutrição de Plantas, pela oportunidade de treinamento;

À CAPES e à FAPESP, pela concessão de bolsa de estudos nos períodos de 02/2000 à 01/2001 e 02/2001 à 02/2002, respectivamente;

À SN-Centro, pelo financiamento de parte do projeto;

Ao Grupo COSAN/Usina Santa Helena, pela concessão da área experimental e pelo apoio na condução do experimento;

Ao técnico Dorival Grisotto, pelo apoio nas práticas de campo;

Aos técnicos dos laboratórios de solo, planta e adubos do Departamento de Solos e Nutrição de Plantas da ESALQ/USP, pela colaboração no desenvolvimento deste trabalho;

Aos funcionários e professores do Departamento de Solos e Nutrição de Plantas da ESALQ/USP, pelo convívio e respeito;

Aos colegas pós-graduandos, pela amizade e incentivo; 
Ao GAPE, pelo agradável convívio e por todas oportunidades de aprender e ensinar;

Ao Alf, pelas alegrias e tranquilidade que ajudaram a superar momentos difíceis.

No transcorrer deste curso e nas etapas anteriores, recebi muitas orientações e ajudas, mesmo aquelas consideradas pequenas, foram fundamentais em minha vida. A todos aqueles que, de alguma forma, contribuíram com meu crescimento pessoal e profissional, 


\section{SUMÁRIO}

\begin{tabular}{|c|c|}
\hline \multicolumn{2}{|l|}{ 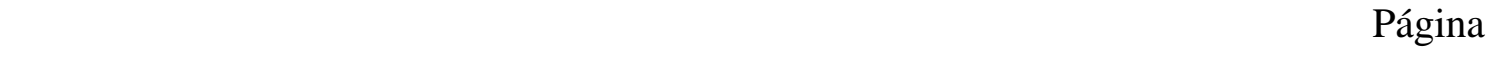 } \\
\hline LISTA DE FIGURAS & vii \\
\hline LISTA DE TABELAS & viii \\
\hline ESUMO ..... & $\mathrm{x}$ \\
\hline UMMARY.. & xii \\
\hline INTRODUÇÃO... & 1 \\
\hline 2 REVISÃO DE LITERATURA... & 3 \\
\hline 2.1 Aspectos importantes do nitrogênio $(\mathrm{N})$ na agricultura.. & 3 \\
\hline 2 Características de importantes fontes nitrogenadas.. & 5 \\
\hline 2.3 Matéria orgânica como fonte de nitrogênio..... & 7 \\
\hline 2.4 Perda gasosa de nitrogênio $\left(\mathrm{N}-\mathrm{NH}_{3}\right)$ por volatilização......... & 10 \\
\hline 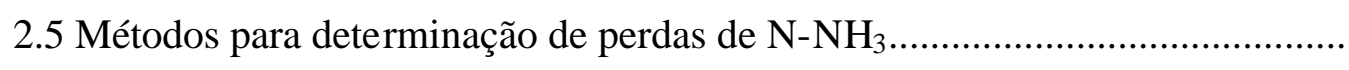 & 12 \\
\hline 2.6 Importância da cana-de-açúcar no Brasil.... & 13 \\
\hline 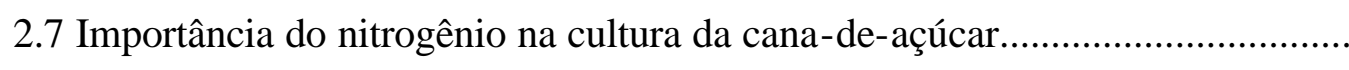 & 14 \\
\hline 2.8 Adubação nitrogenada no sistema de colheita de cana crua........ & 16 \\
\hline MATERIAL E MÉTODOS.. & 20 \\
\hline
\end{tabular}

3.1 Localização da área experimental, variedade de cana-de-açúcar e tipo de

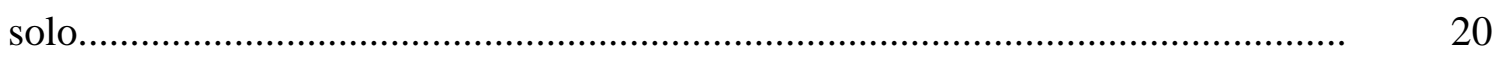

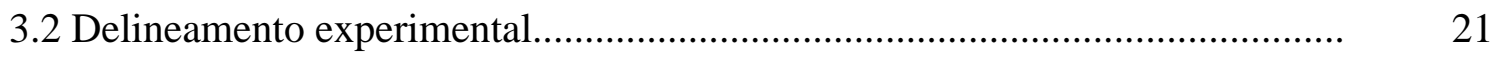

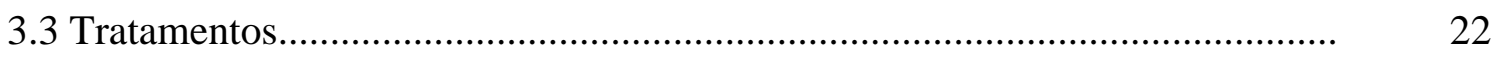

3.4 Adubação convencional e tratos culturais das soqueiras de cana-deaçúcar. 
3.5 Instalação do experimento.............................................................................. 24

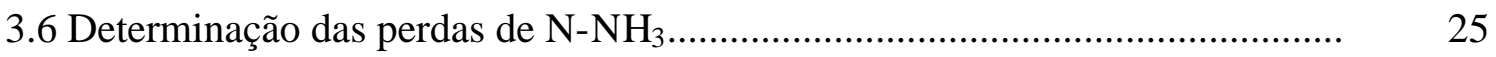

3.7 Amostragem e análise de folhas................................................................... 27

3.8 Amostragens e análises de solo.................................................................... 28

3.9 Amostragens e análises da palhada.............................................................. 28

3.10 Determinação de produtividade e qualidade tecnológica.................................. 29

3.11 Análise estatística...................................................................................... 30

4 RESULTADOS E DISCUSSÃO............................................................. 31

4.1 Perda acumulada de $\mathrm{N}-\mathrm{NH}_{3}$ das fontes nitrogenadas..................................... 31

4.2 Avaliação do estado nutricional da cana-de-açúcar........................................... 35

4.2.1 Teores foliares de macronutrientes.............................................................. 35

4.2.2 Teores foliares de micronutrientes............................................................ 36

4.3 Avaliação de atributos químicos do solo............................................................ 38

4.3.1 Amostragem realizada três meses após adubação.......................................... 38

4.3.2 Amostragem realizada cinco meses após adubação......................................... 46

4.3.3 Variações nos atributos químicos do solo nas diferentes épocas e profundidades de amostragem........................................................................ 52

4.4 Avaliação da produtividade e dos atributos qualitativos da cana-de-

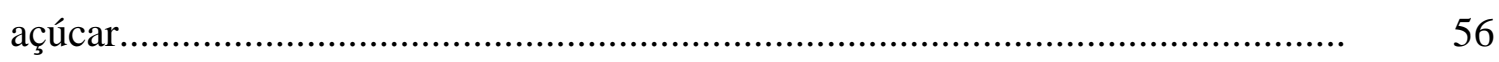

4.5 Estudo da decomposição da palha sem influência da adubação nitrogenada........................................................................................ 58

5 CONCLUSÕES

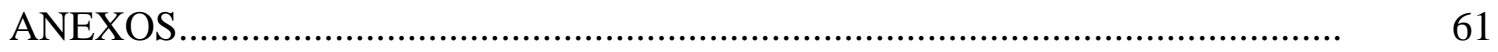

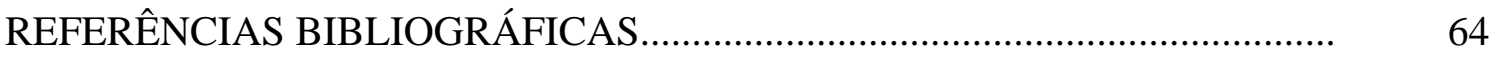




\section{LISTA DE FIGURAS}

1 Coletores de amônia instalados no campo.............................................. $\quad 25$

2 Detalhe das bases para mudança de posição dos coletores........................... 25

3 Detalhe das espumas coletoras embebidas em solução de ácido

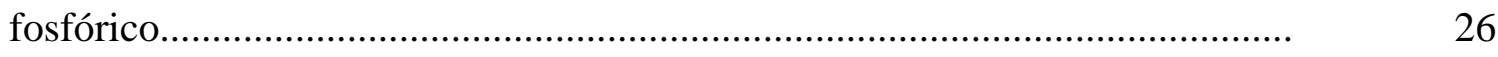

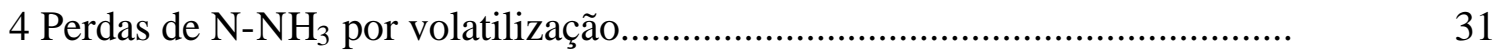

5 Umidade do solo nas datas de coleta das espumas................................... 33

6 Precipitação ocorrida no período em que a volatilização foi avaliada............. 33 


\section{LISTA DE TABELAS}

Página

1 Caracterização química do solo da área experimental...................................... 20

2 Caracterização química do solo da área experimental - micronutrientes............ 21

3 Caracterização física do solo da área experimental - Análise

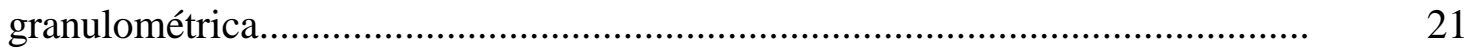

4 Descrição dos tratamentos....................................................................... 22

5 Caracterização química do resíduo orgânico líquido Ajifer............................... 23

6 Perda acumulada de $\mathrm{N}-\mathrm{NH}_{3}\left(\mathrm{~kg} \mathrm{ha}^{-1}\right)$ proveniente de diferentes fontes nitrogenadas aplicadas na superfície da palha de cana-de-açúcar................... $\quad 32$

7 Teores foliares de macronutrientes........................................................... 36

8 Teores foliares de micronutrientes............................................................. 37

9 Atributos químicos do solo amostrado três meses após aplicação dos tratamentos na profundidade de $0-5 \mathrm{~cm}$.................................................... 40

10 Teores de micronutrientes no solo amostrado três meses após aplicação dos tratamentos na profundidade de $0-5 \mathrm{~cm}$......................................................

11 Teores de carbono, nitrogênio total e relação $\mathrm{C} / \mathrm{N}$ do solo amostrado três meses após aplicação dos tratamentos na profundidade de $0-5 \mathrm{~cm}$...................

12 Atributos químicos do solo amostrado três meses após aplicação dos

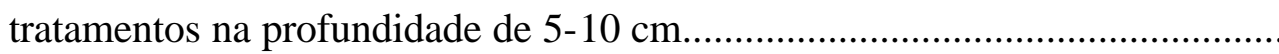

13 Teores de micronutrientes no solo amostrado três meses após aplicação dos tratamentos na profundidade de $5-10 \mathrm{~cm}$ 
14 Teores de carbono, nitrogênio total e relação $\mathrm{C} / \mathrm{N}$ do solo amostrado três meses após aplicação dos tratamentos na profundidade de $5-10 \mathrm{~cm}$...........

15 Atributos químicos do solo amostrado cinco meses após aplicação dos tratamentos na profundidade de $0-5 \mathrm{~cm}$.

16 Teores de micronutrientes no solo amostrado cinco meses após aplicação dos tratamentos na profundidade de $0-5 \mathrm{~cm}$.

17 Teores de carbono, nitrogênio total e relação $\mathrm{C} / \mathrm{N}$ do solo amostrado cinco meses após aplicação dos tratamentos, na profundidade de $0-5 \mathrm{~cm}$..................

18 Atributos químicos do solo amostrado cinco meses após aplicação dos tratamentos na profundidade de $5-10 \mathrm{~cm}$.

9 Teores de micronutrientes no solo amostrado cinco meses após aplicação dos tratamentos na profundidade de $5-10 \mathrm{~cm}$.

20 Teores de carbono, nitrogênio total e relação $\mathrm{C} / \mathrm{N}$ do solo amostrado cinco meses após aplicação dos tratamentos, na profundidade de $5-10 \mathrm{~cm}$.

21 Valores de pH, M.O., P, S, V e m\% do solo em duas profundidades e épocas de amostragem

22 Valores de $\mathrm{K}, \mathrm{Ca}, \mathrm{Mg}, \mathrm{Al}, \mathrm{H}+\mathrm{Al}, \mathrm{SB}$ e $\mathrm{T}$ do solo em duas profundidades e épocas de amostragem.

23 Produtividade e atributos qualitativos obtidos em cada

tratamento

24 Teores iniciais e finais de macronutrientes na palha

25 Teores iniciais e finais de micronutrientes na palha.

26 Precipitação diária e acumulada da Fazenda São José da Jibóia - 2000 


\title{
EFICIÊNCIA AGRONÔMICA DE FONTES NITROGENADAS NA CULTURA DA CANA-DE-AÇÚCAR EM SISTEMA DE COLHEITA SEM DESPALHA A FOGO
}

\author{
Autora: MÍRIAN CRISTINA GOMES COSTA
}

Orientador: Prof. Dr. GODOFREDO CESAR VITTI

RESUMO

O presente trabalho foi desenvolvido a partir de um experimento de campo, conduzido no período de setembro de 2000 a maio de 2001, na região canavieira de Piracicaba (SP), com a terceira soca da variedade SP 80-1842, cultivada em ARGISSOLO VERMELHO-AMARELO distrófico arenoso e colhida sem queima e mecanicamente. $\mathrm{O}$ objetivo deste estudo foi avaliar a eficiência agronômica de diferentes fontes nitrogenadas em sistema de colheita de cana crua por meio de: a) medidas das perdas de nitrogênio por volatilização da amônia; b) avaliação do estado nutricional das plantas; c) avaliação de atributos químicos do solo; d) avaliação da produção de colmos e de açúcar; e) ava liação de atributos tecnológicos do caldo. A dose de nitrogênio foi $100 \mathrm{~kg} \mathrm{ha}^{-1}$ de $\mathrm{N}$ em todos tratamentos, que também receberam $150 \mathrm{~kg}$ $\mathrm{ha}^{-1}$ de $\mathrm{K}_{2} \mathrm{O}$ aplicados como $\mathrm{KCl}$. Utilizoutse o delineamento experimental em blocos completos casualizados, com sete níveis de fator em cinco repetições. Os fatores foram: T0- testemunha, T1- uréia, T2 - uran, T3- uréia + sulfato de amônio, T4 - Ajifer, T5uréia + gesso aplicados na superfície e T6 - Uréia incorporada. Perdas por volatilização 
de amônia foram avaliadas em T0, T1, T2, T3 e T4 por meio de coletores semi-aberto estáticos colocados em cada uma das parcelas em que estudou-se a volatilização. Foram colocadas seis bases distintas para cada coletor, onde aplicou-se as fontes nitrogenadas na dose de $100 \mathrm{~kg} \mathrm{ha}^{-1}$ de N. O N-NH$H_{3}$ volatilizado foi retido em espumas embebidas em solução ácida e extraído com solução de $\mathrm{KCl}$ para posterior quantificação das perdas. Avaliações do estado nutricional das plantas, de atributos químicos do solo, de produtividade e qualidade foram efetuadas em todos tratamentos. A avaliação do estado nutricional foi feita pela análise química dos teores de nutrientes nas folhas que foram amostradas quatro meses após brotação das soqueiras. Atributos químicos do solo foram avaliados por meio de análises laboratoriais de amostras coletadas nas camadas de 0 a 5 e 5 a $10 \mathrm{~cm}$ de profundidade, aos três e cinco meses após aplicação dos tratamentos. A produção de colmos por hectare foi avaliada por ocasião da colheita, da mesma forma que atributos tecnológicos do caldo. Analisou-se teores de nutrientes na palha que foi amostrada aleatoriamente fora das parcelas em que aplicoutse a adubação nitrogenada. Os resultados mostraram que os tratamentos $\mathrm{T} 1$ e $\mathrm{T} 3$ apresentaram perdas por volatilização de aproximadamente $35 \%$ do $\mathrm{N}$ aplicado e que os tratamentos T2 e T4 apresentaram perdas de aproximadamente $15 \%$ e $9 \%$ do $\mathrm{N}$ aplicado, respectivamente. Teores foliares de $\mathrm{N}$ foram inversamente proporcionais às perdas por volatilização. $\mathrm{A}$ adubação nitrogenada e presença de palha aumentaram o teor de matéria orgânica nos 10 primeiros centímetros de solo. Sem a influência da adubação nitrogenada, ocorreu redução de 50\% na massa seca da palhada. Não houve liberação de N e S mas a redução nas relações $\mathrm{C} / \mathrm{N}$ e $\mathrm{C} / \mathrm{S}$ indicou possibilidade de mineralização de nitrogênio e enxofre do resíduo vegetal. As soqueiras responderam em produtividade à adubação nitrogenada e às perdas ocorridas por volatilização de $\mathrm{N}-\mathrm{NH}_{3}$. 


\title{
AGRONOMIC EFFICIENCY OF NITROGEN SOURCES IN SUGARCANE WITH GREEN HARVEST SYSTEM
}

\author{
Author: MÍRIAN CRISTINA GOMES COSTA \\ Adviser: Prof. Dr. GODOFREDO CESAR VITTI
}

\section{SUMMARY}

The present work was advanced by a field experiment that was conducted from September 2000 to May 2001 in Piracicaba cane region with the variety SP 80-1842 in the third sugarcane cut, tilled in Arenic Kanhaplodults and with mechanical harvest without burning. The aim of this study was to evaluate the agronomic efficiency from nitrogen sources in sugarcane harvest system without burning. The efficiency was evaluated through: a) measure of $\mathrm{N}_{-} \mathrm{NH}_{3}$ losses, b) plant nutritional condition evaluations, c) soil chemical attribute evaluations, d) stem and sugar productions, e) sugarcane juice technological attribute evaluations. The nitrogen dose was standardized in $100 \mathrm{~kg} \mathrm{ha}^{-1}$ in every treatment and in the same way to potassium fertilizer which dose was standardized in $150 \mathrm{~kg}^{-1}$ of $\mathrm{K}_{2} \mathrm{O}$ supplied by $\mathrm{KCl}$. The experimental design was in complete randomized blocks with seven factor levels in five replications. The factors were: T0 - Control, T1 - Urea, T2 - Uan, T3 - Urea + ammonia sulfate, T4 - Ajifer, T5

- Urea + gypsum, T6 - Incorporated urea. Losses by ammonia volatilization were evaluated in the treatments $\mathrm{T} 0, \mathrm{~T} 1, \mathrm{~T} 2, \mathrm{~T} 3$ and $\mathrm{T} 4$ by static semi-open $\mathrm{NH}_{3}$ collectors that were set in each experimental plot where $\mathrm{N}-\mathrm{NH}_{3}$ losses were measured. Six different bases were set to each collector, which were applied dose to fit $100 \mathrm{~kg} \mathrm{ha}^{-1}$ of nitrogen by different sources. The $\mathrm{N}-\mathrm{NH}_{3}$ was collected by foam absorbers soaked in 
acid solution after that was extracted by $\mathrm{KCl}$ solution to be quantified later. Plant nutritional conditions, soil chemical attributes, productivity and quality were evaluated in every treatment. The plant nutritional conditions were evaluated by leaf chemical analysis and the leaves were sampled four months after the sugarcane sprout. Soil chemical attributes were evaluated by samples laboratories analyses and the samples were collected in 0-5 and 5-10 cm of depth four and six months after treatments application. The stem and sugar productivity and juice technological attributes were measured after the harvest. The straw was randomized sampled outside experimental plots and its nutrients content was determinate. The results showed that $\mathrm{N}^{-\mathrm{NH}_{3}}$ losses were nearly $35 \%$ of the nitrogen applied to T1 and T3 and losses in T2 and T4 were low, nearly $15 \%$ and $9 \%$. The leaf diagnosis showed that leaves nitrogen content in treatments with low nitrogen losses was bigger than treatments where nitrogen losses were high. Nitrogen sources applied over the straw resulted in organic matter increase at the soil surface. It didn't happen straw nitrogen and sulfur liberation but the decrease in $\mathrm{C} / \mathrm{N}$ and $\mathrm{C} / \mathrm{S}$ relation indicated the possibility to happen nitrogen and sulfur liberation from the vegetal residue. The stalks of sugarcane answered in productivity to nitrogen fertilizer and to nitrogen losses. 


\section{INTRODUÇÃO}

A cultura da cana-de-açúcar (Saccharum spp) apresenta grande importância na economia brasileira, contribuindo para a geração de divisas. Cultivando área de aproximadamente cinco milhões de hectares, o Brasil destaca-se na produção mundial dessa cultura. Cerca de 70\% da produção nacional na safra 99/00 concentrou-se na região centro-sul, sendo que o Estado de São Paulo responsabilizou-se por mais da metade de toda produção brasileira.

Durante muito tempo quase toda área cultivada com cana-de-açúcar no Brasil esteve submetida à queima prévia para facilitar procedimentos de corte e carregamento. Entretanto, o Decreto $\mathrm{n}^{\mathrm{o}} 42.056$ de 06/08/97 estabeleceu que a colheita de cana queimada deveria ser substituída gradualmente pela colheita de cana sem despalha a fogo e, atualmente no Estado de São Paulo, 20\% da área cultivada tem sido colhida sem a queima prévia.

A colheita da cana sem queima faz com que espessa camada de palha seja depositada na superfície do solo, trazendo vantagens e desvantagens. As alterações no agroecossistema provocadas pela presença da palha exigem reformulação nas tecnologias de manejo da cultura. Com relação ao manejo da adubação nitrogenada, a maior problemática é quanto ao uso de nitrogênio na adubação de soqueiras. A principal fonte utilizada nessa adubação é a uréia que, quando aplicada sobre a palha, sofre perda de nitrogênio por volatilização de amônia $\left(\mathrm{NH}_{3}\right)$.

Além da problemática da volatilização, há necessidade de se conhecer melhor as variações em atributos da fertilidade do solo proporcionadas pela deposição da palha. $\mathrm{Na}$ fase inicial de instalação do sistema de colheita de cana crua, ocorre imobilização de nutrientes por microrganismos. A elevada relação $\mathrm{C} / \mathrm{N}$ do resíduo vegetal favorece a imobilização, limitando a disponibilidade de nutrientes para a cultura. 
Entretanto, após estabelecimento do sistema, o resíduo vegetal depositado sobre o solo atua como importante fonte de nutrientes para as soqueiras de cana-de-açúcar.

No presente trabalho, estudoutse a eficiência agronômica de diferentes fontes nitrogenadas utilizadas na cultura da cana-de-açúcar, colhida sem queima prévia. Tal estudo foi realizado por meio de medidas das perdas de nitrogênio por volatilização, avaliação do estado nutricional das plantas, avaliação de atributos químicos do solo e avaliação de produção de colmos e atributos qualitativos. Além disso, estudou-se os teores de nutrientes da palha de cana no período entre dois cortes, para avaliar possível liberação de nutrientes do resíduo vegetal durante um ciclo da cultura. 


\section{REVISÃO DE LITERATURA}

\subsection{Aspectos importantes do nitrogênio (N) na agricultura}

O Nitrogênio (N) é essencial para o crescimento das plantas, sendo exigido em grandes quantidades para possibilitar o crescimento normal dos vegetais. Mediante deficiência de nitrogênio, as plantas apresentam sintomas típicos, como clorose de folhas velhas em função de quantidades reduzidas de clorofila, além de redução no crescimento (Melgar et al., 1999).

No que se refere à exigência pelas culturas, de modo geral, o $\mathrm{N}$ é o nutriente mineral exigido em maior quantidade. Esse fato é refletido no consumo mundial do elemento em fertilizantes, superando as quantidades utilizadas de fósforo ou potássio (Raij, 1991).

Por ser exigido em grandes quantidades pelas culturas e por apresentar elevado custo de obtenção, o $\mathrm{N}$, junto com o fósforo $(\mathrm{P})$ e o potássio (K), é denominado macronutriente primário ou nobre. Entretanto, o custo de obtenção do $\mathrm{N}$ é praticamente cinco vezes maior do que o custo de obtenção de Pe oito vezes maior do que o custo de obtenção do K (Vitti et al., 2001a).

As quantidades de $\mathrm{N}$ no solo, na forma disponível para as plantas, são pequenas. Quantidades muito baixas encontram-se em rochas e em minerais que formarão os solos (Melgar et al., 1999). Devido à alta solubilidade e instabilidade química dos compostos nitrogenados minerais, o $\mathrm{N}$ não figura como constituinte de rochas terrestres, pois é facilmente lavado. A ocorrência de nitrogênio em rochas é verificada somente em certas regiões áridas do Chile, Bolívia e Peru, onde é encontrado 
como salitre do Chile $\left(\mathrm{NaNO}_{3}\right)$, ou nos desertos da Índia e Egito, onde é encontrado como salitre de Bengala $\left(\mathrm{KNO}_{3}\right)$ (Vitti et al., 1984).

Quase todo $\mathrm{N}$ do solo provém da atmosfera, que contém reserva inesgotável desse elemento, porém, o $\mathrm{N}$ atmosférico está como gás inerte que deve combinar-se com outros elementos antes que as plantas possam usá-lo (Melgar et al., 1999). Segundo Epstein (1975), a principal fonte de $\mathrm{N}$ é a atmosfera, que possui 78\% desse elemento em volume, na forma de gás inerte $\left(\mathrm{N}_{2}\right)$. Para possibilitar o uso do $\mathrm{N}$ na agricultura, há necessidade de fixação, que pode ocorrer por meio de processos biológicos e/ou industriais. Além dos processos de fixação, existe, também, a possibilidade do uso de resíduos orgânicos como fonte de $\mathrm{N}$.

No solo, o nitrogênio pode estar na forma mineral ou orgânica e a quantidade de $\mathrm{N}$ orgânico é maior em relação à quantidade de $\mathrm{N}$ inorgânico (Melgar et al., 1999). Entretanto, existe grande número de processos que resultam em transformações das formas orgânicas em inorgânicas e vice-versa, e que podem redundar em ganhos ou perdas do sistema como um todo (Raij, 1991).

Os mecanismos de adição de nitrogênio ao solo podem ser resumidos em fixação biológica, adição de matéria orgânica, aplicação de adubos orgânicos ou minerais e adições pelas águas pluviais. Já os mecanismos de perda de nitrogênio do solo podem ser resumidos em remoção pelas colheitas, lixiviação, erosão e volatilização (Melo, 1978).

$\mathrm{O}$ manejo adequado do $\mathrm{N}$ na agricultura é fundamental para que não haja prejuízos na relação custo/benefício, para o meio ambiente e para a nutrição das plantas. Considerando que o $\mathrm{N}$ é o elemento mais utilizado, extraído e exportado pelas culturas, sendo o mais empregado na adubação e, considerando, ainda, que sua dinâmica no solo é muito intensa, envolvendo processos de adição e perda, reforça-se a necessidade de estudos que viabilizem o manejo adequado da adubação nitrogenada nos diferentes sistemas de cultivo. 


\subsection{Características de importantes fontes nitrogenadas}

No Brasil, cerca de 52\% do N consumido no ano de 2000 foi na forma de uréia, 19\% como sulfato de amônio e 12,1\% como nitrato de amônio (Monesmith, 2001). Em determinadas condições, o uso de misturas entre fontes, bem como o uso de resíduos, podem tornar-se mais viáveis.

A uréia $\left[\mathrm{CO}\left(\mathrm{NH}_{2}\right)_{2}\right]$ é caracterizada como fertilizante sólido granulado de maior concentração de N (45\%) que está na forma amídica. Dentre as vantagens da uréia, além da elevada concentração de $\mathrm{N}$, pode-se mencionar o menor custo com transporte, armazenagem e aplicação, alta solubilidade, baixa corrosividade e facilidade de mistura com outras fontes (Melgar et al., 1999).

Como desvantagens da uréia, ressalta-se sua elevada higroscopicidade e maior susceptibilidade à volatilização. Se houver umidade, ocorre degradação e dissolução do grânulo de uréia aplicado ao solo. Ao entrar em contato com a urease presente no solo e em resíduos vegetais, a uréia sofre hidrólise, produzindo carbonato de amônio $\left[\left(\mathrm{NH}_{4}\right)_{2}\right.$ $\mathrm{CO}_{3}$ ]. $\mathrm{O}$ acúmulo de carbonato de amônio causa aumento no $\mathrm{pH}$ e esse evento pode ser acompanhado pela emissão de $\mathrm{NH}_{3}$ (Melgar et al., 1999).

A fonte denominada uran é caracterizada por ser solução nitrogenada que contém $32 \%$ de $\mathrm{N}\left(14 \% \mathrm{NH}_{2}, 9 \% \mathrm{NH}_{4}\right.$ e $\left.9 \% \mathrm{NO}_{3}{ }^{-}\right)$e densidade de 1,33 . A solução é formada pela mistura de $35,4 \%$ de uréia com $44,3 \%$ de nitrato de amônio $\left(\mathrm{NH}_{4} \mathrm{NO}_{3}\right)$ e $20,3 \%$ de água.

O uran é produzido a partir da mistura líquida de seus componentes, sem que esses tenham passado pelo processo de granulação. A solução resultante apresenta maior concentração de $\mathrm{N}$ do que as soluções saturadas de seus componentes individuais. Quando aplicado ao solo, o uran torna-se sujeito a processos de transformação habituais do N, incluindo volatilização do N da uréia (Achorn, 2000).

$\mathrm{O}$ sulfato de amônio [( $\left.\left.\mathrm{NH}_{4}\right)_{2} \mathrm{SO}_{4}\right]$ é uma fonte de $\mathrm{N}$ que, mundialmente, tem sido menos utilizada que a uréia, o nitrato de amônio e o uran (Byrnes, 2000). Sua produção dá-se a partir de subprodutos da indústria (aço, metalúrgica, produção de nylon), sendo a caprolactama (subproduto da indústria de nylon) importante fonte para 
sua produção. A partir de uma tonelada de caprolactama é possível obter até quatro toneladas de sulfato de amônio. Também é possível obter sulfato de amônio através de síntese direta $\left(\mathrm{NH}_{3}+\mathrm{H}_{2} \mathrm{SO}_{4}\right)$, entretanto essa forma de obtenção não é tão viável como a citada anteriormente (Monesmith, 2001).

Dentre as principais vantagens do sulfato de amônio, cita-se sua baixa higroscopicidade, boas propriedades físicas, estabilidade química, boas características agronômicas, potencial de oferta de enxofre (24\%), além do N (21\%) (Byrnes, 2000).

Alguns autores mencionam que, como desvantagem, o sulfato de amônio apresenta no solo uma reação fortemente ácida, fato esse que, em solos de regiões tropicais, pode tornar-se problemático (Kunz, 2001). Além disso, possui apenas $21 \%$ de $\mathrm{N}$, aumentando o custo de aplicação, estocagem e transporte, de maneira tal que, o custo por unidade de $\mathrm{N}$ seja bem maior em relação à uréia. Por outro lado, o uso do sulfato de amônio será considerado vantajoso se o custo de obtenção for baixo, a distância de transporte for curta e se a fonte for empregada com objetivo de fornecer $\mathrm{S}$, além do $\mathrm{N}$ (Byrnes, 2000).

A mistura de uréia com sulfato de amônio apresenta boa eficiência agronômica, com menores taxas de volatilização devido à menor quantidade de uréia, bem como pelo efeito acidificante do sulfato de amônio (Vitti, 2001b). O entendimento da forma pela qual a mistura possibilita redução na volatilização é facilitado pelas equações químicas a seguir:

$$
\begin{aligned}
& \text { a1) } \mathrm{CO}\left(\mathrm{NH}_{2}\right)_{2}+{ }_{2} \mathrm{H}_{2} \mathrm{O} \stackrel{\text { Urease }}{\longrightarrow}\left(\mathrm{NH}_{4}\right)_{2} \mathrm{CO}_{3} \\
& \text { a2) }\left(\mathrm{NH}_{4}\right)_{2} \mathrm{CO}_{3} \longrightarrow{ }_{2} \mathrm{NH}_{3}+\mathrm{H}_{2} \mathrm{CO}_{3} \\
& \text { a3) } \mathrm{H}_{2} \mathrm{CO}_{3} \longrightarrow \mathrm{CO}_{2}+\mathrm{H}_{2} \mathrm{O} \\
& \text { a4) } \mathrm{NH}_{3}+\mathrm{H}_{2} \mathrm{O} \longrightarrow \mathrm{NH}_{4}^{+}+\mathrm{OH}^{-} \\
& \text {b) }\left(\mathrm{NH}_{4}\right)_{2} \mathrm{SO}_{4} \longrightarrow \mathrm{NH}_{4}^{+}+{ }_{2} \mathrm{SO}_{4}^{--}
\end{aligned}
$$


c) ${ }_{2} \mathrm{NH}_{4}{ }^{+}+{ }_{3} \mathrm{O}_{2} \longrightarrow{ }_{2} \mathrm{NO}_{2}{ }^{-}+{ }_{4} \mathrm{H}^{+}+{ }_{2} \mathrm{H}_{2} \mathrm{O}$

Como consequiência do uso da mistura, tem-se:

2) $\mathrm{H}^{+}$(reação c) + OH (reação a4) $\longrightarrow \mathrm{H}_{2} \mathrm{O}$

Vitti et al. (2001b) estudaram o efeito da adição de sulfato de amônio em mistura com uréia sobre a volatilização de $\mathrm{N}-\mathrm{NH}_{3}$, assumindo a hipótese de que, devido à redução da forma amídica de $\mathrm{N}$ e ao efeito acidificante do sulfato de amônio, a mistura proporcionaria menores taxas de volatilização. Ao misturar uréia e sulfato de amônio nas proporções de $50 \%$ e $50 \%$, os autores observaram menores perdas de $\mathrm{N}-\mathrm{NH}_{3}$ por volatilização.

Resíduos orgânicos também são considerados importantes fontes de nitrogênio. A utilização do resíduo denominado Ajifer faz parte do conceito de bio-integração entre lavouras, usinas e fábricas. Esse resíduo é obtido a partir do processo industrial de fermentação glutâmica do melaço de cana-de-açúcar. Após fermentação, cristais são separados do líquido final, que volta para a lavoura como resíduo orgânico contendo nitrogênio e outros nutrientes. Em sua composição, o Ajifer apresenta 3\% de nitrogênio amoniacal, $2 \%$ de nitrogênio orgânico e $4 \%$ de enxofre.

\subsection{Matéria orgânica como fonte de nitrogênio}

A matéria orgânica pode fornecer nitrogênio e outros nutrientes. Como definição, tem-se que substância orgânica é aquela que apresenta carbono tetracovalente com ligações completadas por átomos de hidrogênio, oxigênio, nitrogênio, enxofre, dentre outros. Vegetais e animais apresentam em sua composição substâncias orgânicas de natureza diversa. Admite-se que os tecidos vegetais são constituídos por carboidratos ( 1 a $5 \%$ de açúcares e amido, 10 a $28 \%$ de hemicelulose e 20 a $50 \%$ de celulose), $1,8 \%$ de gorduras, ceras e taninos, 10 a 30\% de ligninas e 1 a 15\% de proteínas (Melo, 1978). 
Segundo Oliveira (1987), a decomposição da matéria orgânica do solo é fundamental para o desenvolvimento vegetal pois, mediante esse processo, ocorre o fornecimento de macro e micronutrientes para as plantas. Da decomposição de resíduos orgânicos que chegam ao solo, resulta a liberação para os vegetais de N, P, K e S.

$\mathrm{O}$ processo que converte as formas orgânicas de $\mathrm{N}$ à formas inorgânicas denomina-se mineralização e ocorre à medida que os microrganismos do solo decompoem a matéria orgânica para obter energia. As diferentes fases que envolvem as transformações do $\mathrm{N}$ no solo são esquematizadas da seguinte forma:

a) Amonificação

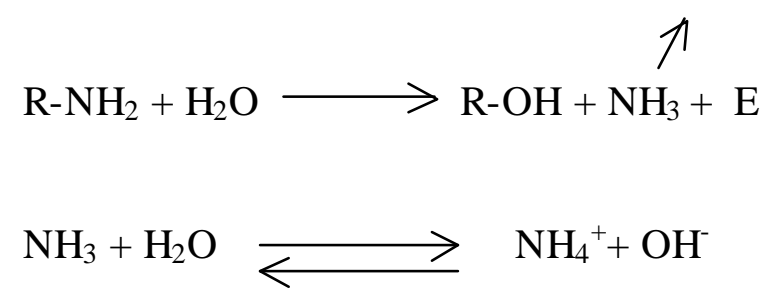

b) Nitrificação

b1) Nitritação

$2 \mathrm{NH}_{4}{ }^{+}+3 \mathrm{O}_{2} \stackrel{\text { Nitrosomonas }}{\longrightarrow} 2 \mathrm{NO}_{2}^{-}+2 \mathrm{H}_{2} \mathrm{O}+4 \mathrm{H}^{+}+\mathrm{E}$

b2) Nitratação

$$
2 \mathrm{NO}_{2}^{-}+\mathrm{O}_{2} \stackrel{\text { Nitrobacter }}{\longrightarrow} 2 \mathrm{NO}_{3}{ }^{-}+\mathrm{E}
$$

Após a amonificação, o primeiro produto resultante da decomposição da matéria orgânica é o amônio $\left(\mathrm{NH}_{4}^{+}\right)$, proveniente da decomposição de proteínas, aminoácidos e outros compostos. Em condições favoráveis para o crescimento das plantas, a maior 
parte do $\mathrm{NH}_{4}{ }^{+}$do solo se converte em nitrato $\left(\mathrm{NO}_{3}{ }^{-}\right)$pela ação de bactérias nitrificantes. Esse processo denomina-se nitrificação e produz acidez no solo devido à liberação de íons $\mathrm{H}^{+}$(Melgar et al., 1999).

Além dos processos citados, também é importante mencionar a desnitrificação. Tal processo envolve a conversão de nitrato em formas gasosas, cujas principais são $\mathrm{N}_{2} \mathrm{O}$ e $\mathrm{N}_{2}$. Os gases resultantes da desnitrificação são liberados para a atmosfera e, junto ao dióxido e monóxido de carbono e o metano, são considerados gases de efeito estufa. Mediante anaerobiose e presença de microrganismos anaeróbios facultativos ou obrigatórios, ocorre a desnitrificação.

O cultivo dos solos sem adição de resíduos orgânicos propicia, em geral, redução nos teores de matéria orgânica com o passar dos anos. Essa redução pode ser favorecida pela prática de queimadas e pelo revolvimento do solo. Assim, ocorre queda exponencial do teor total de nitrogênio no solo, mais rápida no início e em proporção cada vez menor com o passar do tempo, até que seja atingido novo teor de equilíbrio, o que pode demorar muitas décadas para acontecer (Raij, 1991).

Com os sistemas de cultivo que envolvem manutenção de palha na superfície do solo, o acúmulo de matéria orgânica é favorecido. O resíduo vegetal remanescente no solo atua como fonte potencial de nitrogênio, enxofre e outros nutrientes para as culturas (Furlani Neto, 1997; Gava, 1999) e precisa sofrer mineralização para que os nutrientes nele contidos sejam disponibilizados para as plantas. Wood (1991) verificou elevação do teor de carbono orgânico de $0,6 \%$ a $1 \%$, e do N-total de 0,06 a 0,08\% na camada de 10 cm de solo, após cinco anos de cultivo com presença de palha.

Dependendo da composição do resíduo vegetal, a taxa de mineralização durante o ano agrícola pode ser muito baixa (Melo, 1978; Kiehl, 1987). Vitti (1998) relatou que a adição ao solo de resíduos vegetais de cana-de-açúcar com elevada relação $\mathrm{C} / \mathrm{N}$, provocou imobilização líquida da fonte nitrogenada aplicada. Weng \& Li (1992) constataram imobilização biológica do $\mathrm{N}$ mediante uso de resíduos de cana-de-açúcar com elevada relação $\mathrm{C} / \mathrm{N}$.

Em função da relação $\mathrm{C} / \mathrm{N}$ do resíduo vegetal, pode ocorrer mineralização ou imobilização dos nutrientes através da ação de microrganismos. Se a relação $\mathrm{C} / \mathrm{N}$ do 
resíduo é elevada (> 30:1), microrganismos possuem sobra de energia e assimilam todo $\mathrm{N}$ mineral que passa a ser orgânico, ficando temporariamente indisponível às plantas. Mediante redução na relação $\mathrm{C} / \mathrm{N}$, em determinado momento há diminuição na oferta de energia para os microrganismos e estes sofrem decomposição, liberando o $\mathrm{N}$ que estava assimilado em suas estruturas. Ao adicionar-se $\mathrm{N}$ mineral em solo com resíduo de elevada relação $\mathrm{C} / \mathrm{N}$, inicialmente ocorre competição entre as raízes das plantas e os microrganismos do solo pelo N aplicado (Kiehl, 1987; Jingguo \& Bakken, 1997).

Sabe-se que resíduos orgânicos depositados na superfície do solo são fontes potenciais de nutrientes, principalmente nitrogênio. Entretanto, com os processos de mineralização e imobilização e com toda complexa dinâmica do $\mathrm{N}$, fica difícil avaliar precisamente a disponibilidade desse nutriente nos diferentes resíduos vegetais (Oliveira, 1987).

\subsection{Perda gasosa de nitrogênio $\left(\mathrm{N}-\mathrm{NH}_{3}\right)$ por volatilização}

Nem sempre o $\mathrm{N}$ aplicado ao solo será totalmente absorvido pelas plantas. Parte dele poderá ser imobilizada por microrganismos ou, ainda, ser perdida do sistema solo por diversos mecanismos (Byrnes, 2000). Como importante meio de perda do $\mathrm{N}$ aplicado, tem-se a forma gasosa, ou seja, $\mathrm{NH}_{3}, \mathrm{~N}_{2}, \mathrm{~N}_{2} \mathrm{O}, \mathrm{NO}$.

$\mathrm{O} N-\mathrm{NH}_{3}$ perdido por volatilização será proveniente da mineralização da M.O. ou do fertilizante aplicado, sendo esse o fenômeno mais intenso mediante aumento no pH do solo (Melo, 1978).

Devido à ocorrência de perdas, a eficiência de aproveitamento de $\mathrm{N}$ pelas plantas é de $40 \%$ a $50 \%$. Tem-se pesquisado meios para reduzir perdas e aumentar a eficiência de uso do N, como, por exemplo, controle na época de aplicação, uso de revestimentos nos fertilizantes para controlar liberação de $\mathrm{N}$, além de melhorias nos métodos de aplicação. Para fontes nitrogenadas mais susceptíveis às perdas, a prática de incorporação possibilita considerável redução na volatilização (Espironello, 1987; Lara Cabezas, 1987; Subirós \& Bertsch, 1998; Cantarella et al., 1999). 
A eficiência é afetada pela forma de $\mathrm{N}$ aplicada na adubação; então, estudos com diferentes fontes de $\mathrm{N}$ passaram a ser realizados, com objetivo de reduzir perdas e aumentar a eficiência. A uréia, que é uma das fontes nitrogenadas mais utilizadas na agricultura brasileira, por apresentar elevada concentração de $\mathrm{N}$ e baixo custo por unidade de nitrogênio, apresenta grande susceptibilidade de perda de amônia $\left(\mathrm{NH}_{3}\right)$ por volatilização. Tal fenômeno tem sido considerado um dos principais motivos pelos quais a eficiência desse fertilizante em fornecer nitrogênio às culturas está abaixo da esperada (Kiehl, 1989).

De modo geral, diferentes fontes são equivalentes quando aplicadas adequadamente, não apresentando diferenças significativas quanto às perdas de $\mathrm{N}-\mathrm{NH}_{3}$ por volatilização (Byrnes, 2000). Entretanto, fontes nitrogenadas amídicas, em determinadas condições, têm maior disposição para a perda de $\mathrm{N}$ por volatilização. Scharf \& Alley (1988) sugeriram a aplicação do fertilizante nitrogenado misturado a um doador de $\mathrm{H}^{+}$. Dessa forma, Lara Cabezas (1994) constatou que, onde fez-se mistura de vinhaça com uréia, ocorreram perdas de $16 \%$ do $\mathrm{N}$ aplicado em solo com maior teor de argila, ao passo que as perdas foram de de $26 \%$ em solos com menor teor de argila.

$\mathrm{O}$ processo de volatilização de $\mathrm{N}-\mathrm{NH}_{3}$ aplicando-se uréia envolve, inicialmente, a hidrólise da fonte nitrogenada por meio da urease. A urease é uma enzima extracelular produzida por bactérias, actinomicetos e fungos do solo ou, ainda, de origem em restos vegetais. Como resultado da hidrólise tem-se a formação de carbonato de amônia e, em função das características da urease, fatores que influenciam a atividade dos microrganismos também influenciam a hidrólise da uréia, promovendo grande variação na taxa de hidrólise para diferentes solos (Reynolds \& Wolf, 1987).

Segundo Volk (1959), a hidrólise da uréia ocorre em solos com vários teores de umidade. Quanto mais rápida a hidrólise, maior o potencial de perda de $\mathrm{NH}_{3}$. A adição de água tem influência direta sobre a hidrólise e atua diretamente, promovendo aumento da difusão da uréia e, consequentemente, maior contato com a urease no solo (Savant et al., 1987). A uréia aplicada é rapidamente hidrolisada em 2 ou 3 dias e a taxa de hidrólise depende da temperatura do solo, umidade, quantidade e forma pela qual a uréia é aplicada (Byrnes,2000). 
O carbonato de amônio resultante da hidrólise da uréia não é estável e desdobra-se em $\mathrm{NH}_{3}, \mathrm{CO}_{2}$ e água (Volk, 1959). Parte do $\mathrm{NH}_{3}$ formado reage com íons $\mathrm{H}^{+}$da solução do solo e com íons $\mathrm{H}^{+}$dissociáveis do complexo coloidal, resultando no cátion $\mathrm{NH}_{4}{ }^{+}$. Entretanto, a neutralização da acidez potencial determina a elevação do $\mathrm{pH}$, que pode atingir valores acima de 7 na região próxima aos grânulos do fertilizante aplicado. Na camada próxima à aplicação do fertilizante, constatou-se aumento do $\mathrm{pH}$ em água, de 6,9 para 8,7 (Rodrigues \& Kiehl, 1992).

Diversos fatores afetam a volatilização de $\mathrm{N}-\mathrm{NH}_{3}$, como temperatura, umidade, trocas gasosas, taxa de evaporação da água, conteúdo de água no solo, pH, poder tampão, capacidade de troca catiônica, classe textural e atividade da urease. Valores elevados de $\mathrm{pH}$ conduzem à volatilização de $\mathrm{N}^{-\mathrm{NH}_{3}}$ da uréia aplicada em superfície. Entretanto, fontes como sulfato de amônio, diamônio fosfato e nitrato de amônio, são menos susceptíveis às perdas por volatilização, pois não possuem característica de aumentar o pH do local onde são aplicados (Freney et al., 1985; Hargrove, 1988; Byrnes, 2000; Penatti, 2001).

\subsection{Métodos para determinação de perdas de $\mathrm{N}-\mathrm{NH}_{3}$}

Lara Cabezas \& Trivelin (1990) realizaram levantamento de literatura e encontraram que, entre os métodos apresentados para estimar perdas por volatilização de amônia do solo, provenientes da aplicação de fertilizantes nitrogenados, os micrometeorológicos (métodos diretos) e os métodos por balanço isotópico de ${ }^{15} \mathrm{~N}$ (método indireto) são os únicos que permitem quantificar o processo sem influenciar na atmosfera próxima à superfície do solo, bem como nas propriedades químicas e biológicas deste.

Métodos diretos necessitam de aparelhos específicos, que podem dificultar sua prática (Lara Cabezas \& Trivelin, 1990). Já os métodos indiretos, que consistem na determinação da amônia volatilizada pela diferença entre o $\mathrm{N}$-fertilizante aplicado e o residual no solo, somado ao retirado pelas plantas e descontando-se o nativo, podem ser 
efetuados usando-se fertilizante isotopicamente marcado $\left({ }^{15} \mathrm{~N}\right)$ (Nönmik, 1973; Rashid, 1977; Moraghan et al., 1984; San, 1986).

Determinações estabelecidas pelo método ${ }^{15} \mathrm{~N}$ apresentam alto custo e têm sido empregadas em estudos de balanço nitrogenado no sistema solo-planta-atmosfera, onde pode-se quantificar perdas, bem como na calibração de métodos diretos que utilizam-se de câmaras coletoras (Lara Cabezas \& Trivelin, 1990).

Medidas pelo critério direto podem ser realizadas no laboratório, casa de vegetação ou no campo por meio dos sistemas fechado-estático, fechado-dinâmico e semi-aberto estático. O sistema fechado-estático isola o solo do ar atmosférico. No sistema fechado dinâmico faz-se circulação forçada de ar (Rodrigues \& Kiehl, 1986; Reynolds \& Wolf, 1987). Tais sistemas fechados podem impossibilitar a obtenção de observações da volatilização que ocorreria em condições naturais, pois modificam o ambiente na superfície do solo (Lara Cabezas \& Trivelin, 1990).

Em contra-partida, os coletores descritos por Nönmik (1973), com sistema semi-aberto estático, são utilizados para estudos de campo. Possuem abertura permanente que possibilita o equilíbrio da atmosfera interna do aparelho com o ar exterior, minimizando interferências na determinação da amônia volatilizada.

O coletor semi-aberto estático, no entanto, também apresenta limitações. Essas limitações foram avaliadas por Lara Cabezas \& Trivelin (1990), na quantificação do N$\mathrm{NH}_{3}$ volatilizado de adubos nitrogenados aplicados ao solo. Os autores observaram que a presença do sistema coletor semi-aberto estático influiu significativamente, reduzindo a porcentagem e quantidade de amônia volatilizada do fertilizante. Assim, verifica-se a importância do uso de fatores de correção para determinar, pelo coletor semi-aberto estático, o N- $\mathrm{NH}_{3}$ volatilizado. 


\subsection{Importância da cana-de-açúcar no Brasil}

A cultura da cana-de-açúcar apresenta grande importância na economia brasileira, contribuindo para a geração de divisas. Tal importância é atribuída à sua múltipla utilização, podendo ser empregada in natura, sob a forma de forragem para alimentação animal ou como matéria prima para a fabricação de rapadura, melado, aguardente, açúcar e álcool.

O Brasil destaca-se no cenário mundial como produtor de cana-de-açúcar, possuindo cerca de cinco milhões de hectares cultivados com essa cultura. A produção brasileira na safra 1999/2000 foi de 324 milhões de toneladas, com destaque para a região centro-sul, que produziu aproximadamente 220 milhões de toneladas, das quais 189 milhões foram produzidas no Estado de São Paulo (Agrianual, 2001).

Para a colheita 2000/2001, 36\% da safra de cana-de-açúcar da região centro-sul do país já havia sido processada até agosto de 2001, num total de 81,6 milhões de toneladas. Em 2000/2001, a região centro-sul apresentou 219 unidades produtoras, com previsão de término da safra com produção maior que 200 milhões de toneladas de cana (Jonalcana, 2001).

Devido ao elevado nível tecnológico, a média de produtividade da região centro-sul é de aproximadamente $90 \mathrm{t} \mathrm{ha}^{-1}$, sendo considerada alta em relação à média de outras regiões do país, responsáveis pela média nacional estar na faixa de 60-70 t ha ${ }^{-1}$ (Agrianual, 2001).

\subsection{Importância do nitrogênio na cultura da cana-de-açúcar}

Diversos trabalhos encontrados na literatura mostram a importância do $\mathrm{N}$ na cultura da cana-de-açúcar. Mesmo estando em apenas 1\% da matéria seca total da canade-açúcar, havendo deficiência de $\mathrm{N}$ a planta apresenta redução na síntese de clorofila, de aminoácidos essenciais e da energia necessária à produção de carboidratos e esqueletos carbônicos (Dillewijn, 1952; Malavolta \& Haag, 1964; Alexander, 1973; Epstein, 1975 e Silveira, 1980). 
Elevando-se o teor de nirogênio, a cana-de-açúcar responde produzindo mais fitomassa, e o aumento no conteúdo desse nutriente nas folhas e entrenós está correlacionado com o aumento de seu conteúdo no solo (Clements, 1941; Bolton \& Brown, 1980). No quarto mês do ciclo, as quantidades de $\mathrm{N}$ extraídas do solo por colmos e folhas já são elevadas, sugerindo a necessidade de adição de N no solo logo no início do ciclo de produção (Orlando Filho et al., 1980).

Segundo Das (1936), o N aumenta o comprimento dos colmos da cana-deaçúcar, o que provoca redução na espessura da parede celular, podendo levar à redução na porcentagem de fibras na planta. Existem relatos de que ocorre aumento linear na quantidade de açúcar produzida por hectare com as doses de N, apesar de resultar, também, em elevação no teor de umidade de colmos, levando à redução no teor de sacarose (Clements et al., 1941; Korndorfer et al., 1992).

$\mathrm{Na}$ ordem de extração de nutrientes pela cultura, verifica-se que o potássio é extraído em maior quantidade que o nitrogênio $(\mathrm{K}>\mathrm{N}>\mathrm{Ca}>\mathrm{Mg}>\mathrm{P})$. O mesmo é constatado na exigência de macronutrientes para produzir 100 toneladas de cana, onde são necessários 143 kg de N, 174 de K, 87 de Ca, 49 de Mg, 44 de S e 19 de P. (Orlando Filho et al., 1980).

Sabe-se que a cana-planta é mais eficiente na utilização de $\mathrm{N}$ que a cana-soca. Estudos realizados no Hawai mostraram que a cana-planta necessitou de $0,9 \mathrm{~kg}$ de $\mathrm{N}$ para cada tonelada produzida, ao passo que a cana-soca necessitou de $1,3 \mathrm{~kg}$ de $\mathrm{N}$ (Dillewijn, 1952). Assim, a cana-soca apresenta maior resposta à adubação nitrogenada em relação à cana-planta. Dentre as possíveis causas da ausência de resposta da canaplanta à adubação nitrogenada, ressalta-se a maior fixação biológica e a maior disponibilidade de $\mathrm{N}$ proporcionada pela mineralização do resíduo vegetal resultante da reforma do canavial (Zambello Jr. et al., 1981; Carnaúba, 1990).

Döbereiner (1972) demonstrou a possibilidade de haver fixação biológica não simbiótica do $\mathrm{N}_{2}$ em cana-de-açúcar na presença de grande quantidade de bactérias do gênero Beijerinckia nas proximidades das touceiras de cana-de-açúcar. Ruschel \& Vose, (1982) citados por Carnaúba (1990), mencionam que a rotação com leguminosas poderia aumentar a fixação biológica do nitrogênio, fazendo com que a resposta da cana- 
planta à adubação mineral nitrogenada seja reduzida. Segundo citações de Carnaúba (1990), a fixação biológica do nitrogênio em cana-de-açúcar pode ser influenciada por fatores genéticos e climáticos. Além disso, a energia fornecida pelos toletes de cana no plantio permite o desenvolvimento do microrganismo fixador de nitrogênio.

Espironelo (1989) cita trabalhos em que não encontrourse resposta da canaplanta à adubação nitrogenada, sendo que a menor necessidade de nitrogênio foi encontrada em solos que já haviam sido cultivados com cana. Tal observação foi explicada pelo maior teor de matéria orgânica do solo, decorrente do acúmulo de raízes da própria cana de cultivos anteriores, associado ao maior número de bactérias fixadoras de nitrogênio atmosférico.

A adubação nitrogenada em cana-planta é viável, aplicando-se no sulco de plantio de cana de ano e meio cultivada em área que não recebeu leguminosa e em cana de ano, $30 \mathrm{~kg} \mathrm{ha}^{-1}$ de $\mathrm{N}$. Em cobertura é possível aplicar até $60 \mathrm{~kg} \mathrm{ha}^{-1}$ de $\mathrm{N}$, mas somente em cana de ano (Vitti et al., 2001 a).

\subsection{Adubação nitrogenada no sistema de colheita de cana crua}

Durante muito tempo, quase toda área cultivada com cana-de-açúcar no Brasil esteve submetida à queima prévia, devido à necessidade de limpeza parcial do canavial, visando facilitar operações de corte e carregamento (Ripoli et al., 1987).

Entretanto, a partir do decreto $n^{0} 42.056$ de 06/08/97, a agroindústria sucroalcooleira no Estado de São Paulo precisou adaptar seu sistema para praticar colheita de cana sem queima prévia. Fortalecendo a Lei de 1997, o Decreto n 45.869 de 22/06/2001 regulamentou a Lei 10.547/2000, segundo a qual, “a partir do ano de 2001 não se efetuará a queima da palha da cana-de-açúcar em percentual correspondente a 25\% das áreas mecanizáveis e 13,35\% das áreas não mecanizáveis”.

Com a colheita da cana sem queima, espessa camada de palha fica sobre o solo. Estima-se que, no Estado de São Paulo, a massa de palha que fica no solo após a colheita da cana crua, varia de 13 a 20 t ha $^{-1}$ de matéria seca (Herman et al., 1977, Ng kee Kwong et al, 1987 e Siqueira e Franco, 1988). Abramo Filho et al. (1993) determinaram, para a variedade SP 71 - 6163, que o material residual seco da pós colheita (ponteiro e palhas) 
que ficou no solo foi de aproximadamente $15 \mathrm{t} \mathrm{ha}^{-1}$. Segundo Cantarella (1998), a palha depositada sobre o solo, após a colheita da cana sem queima prévia, está na faixa de 10 a $15 \mathrm{t} \mathrm{ha}^{-1}$.

Alguns aspectos positivos da presença de palha de cana sobre o solo podem ser considerados do ponto de vista da fertilidade do solo e da nutrição das plantas. Segundo Sampaio (1991), a queima da palha pode levar à redução no teor de matéria orgânica do solo, o que é agravado pela diminuição na qualidade dessa matéria orgânica.

A palha possibilita menor temperatura e maiores teores de umidade e de matéria orgânica no solo (Abramo Filho et al., 1993). A biodegradação da palha, fornece substâncias agregantes ao solo, tornando-o grumoso, com bioestrutura estável, aumentando a capacidade de troca catiônica e o poder tampão (Primavesi, 1987).

Como a cana-de-açúcar é considerada cultura smi-perene, a qual, na fase inicial de desenvolvimento bem como no início de cada ciclo, deixa exposto o solo cultivado, a presença da palha pode atuar na proteção desse solo. A cobertura do solo com restos de cultura (palha) é uma das mais eficientes práticas de controle de erosão, protegendo o solo contra a ação direta dos ventos e impedindo o transporte de partículas (erosão eólica), agindo, ainda, como protetor contra a erosão causada pela chuva (Sallaway, 1979).

Segundo Furlani Neto et al. (1997), além de promover controle de plantas invasoras, permitindo redução e economia no uso de herbicidas, a palha de cana deixada no campo proporciona retorno de nutrientes (principalmente $\mathrm{N}$ e $\mathrm{S}$ ). A palha possui cerca de 40 a $80 \mathrm{~kg} \mathrm{ha}^{-1}$ de $\mathrm{N}$ e metade desses valores como $\mathrm{S}$ que, junto com outros nutrientes, poderiam ser disponibilizados à cultura por ação de microrganismos do solo.

Segundo Cantarella (1998), a palha depositada sobre o solo contém de 50 a 100 $\mathrm{kg} \mathrm{ha}^{-1}$ de $\mathrm{N}$, entretanto a contribuição inicial do $\mathrm{N}$ do resíduo é pequena, devido à baixa taxa de mineralização. Dessa maneira, nos primeiros anos sob sistema de cana crua, não deve haver redução na necessidade de adubação nitrogenada em relação à cana queimada. Com diminuição nas perdas de solo por erosão e aumento contínuo na palha, ocorrerão aumentos nos teores de matéria orgânica e nitrogênio do solo, podendo representar menor necessidade nas doses de $\mathrm{N}$ após alguns anos de implantação. 
A presença da palha de cana-de-açúcar na superfície do solo também pode ter aspectos negativos. Abramo Filho et al.(1993) relata possível aumento de pragas e retardamento da brotação de soqueiras. Buzolin (1997) constatou que áreas com cobertura de palha sobre o solo foram mais afetadas pela ocorrência de geada em relação às áreas cultivadas sem a presença de palha.

A palha resultante da colheita de cana crua provoca mudanças no agroecossistema, exigindo reformulação na tecnologia até então empregada no manejo da cana colhida queimada. Tendo em vista que a prática da colheita de cana crua pode alterar significativamente a fertilidade dos solos, em função do material orgânico deixado na superfície, há necessidade de estudo do potencial de mineralização.

Do ponto de vista da fertilidade do solo e da nutrição das plantas, com relação ao manejo da adubação, a maior problemática é quanto ao uso do nitrogênio na adubação de soqueiras. A adubação dessas áreas com $\mathrm{N}$ em superfície, leva à imobilização do nutriente devido a elevada relação C/N da palha (Gava, 1999). Como outro problema, tem-se que a uréia é a fonte nitrogenada mais utilizada na cultura e, quando aplicada sobre a palha, apresenta elevadas taxas de perda de $\mathrm{N}-\mathrm{NH}_{3}$ por volatilização, devido ação da urease do solo e da palha.

Como meio para reduzir perdas por volatilização de fontes nitrogenadas aplicadas na cana-de-açúcar na presença de palha, tem-se a possibilidade de incorporar o fertilizante nitrogenado. Willcox (1990) sugere que, para cana colhida crua, a melhor localização do fertilizante na soqueira é sob a palha, na subsuperfície do solo, ao lado da linha de plantio. A aplicação do fertilizante sob a palha reduziu em $30 \%$ as perdas por volatilização (Prammanee et al., 1988).

Entretanto, a incorporação da fonte nitrogenada em solos com espessa camada de palha, pode ser de difícil operacionalidade. Para adubação nitrogenada de soqueiras colhidas sem queima, constata-se a necessidade de uso de fontes nitrogenadas que apresentem menores perdas do elemento por volatilização pois, com a palha, há dificuldade de incorporação do adubo (Trivelin et al., 1997).

Outra possibilidade para reduzir perdas por volatilização seria garantir a presença de componente acidificante do meio. Em alguns casos, a mistura da fonte 
nitrogenada com vinhaça mostrou-se eficiente para reduzir perdas por volatilização de $\mathrm{N}-\mathrm{NH}_{3}$. Gava et al. (2001) estudaram perda de amônia proveniente da mistura vinhaça e ureía aplicada ao solo com e sem cobertura de palha de cana e constataram que, perdas por volatilização do $\mathrm{N}$-fertilizante foram de $16 \%$ e $2 \%$ nos solos com e sem palha, respectivamente. Outra possibilidade para reduzir as perdas seria a adição de sais solúveis, como $\mathrm{CaCb}, \mathrm{CaNO}_{3}$ e $\mathrm{MgSO}_{4}$ (Fenn et al.,1981).

A utilização de fontes nitrogenadas que apresentem o $\mathrm{N}$ em outras formas também tem-se mostrado eficiente para reduzir perdas por volatilização de $\mathrm{N}^{-N_{3}}$. Cantarella et al. (1999) constataram que perdas de $\mathrm{NNH}_{3}$ foram controladas mediante uso da fonte nitrato de amônio. Fontes de nitrogênio, como nitrato de amônio, nitrato de cálcio e sulfato de amônio, não estão sujeitas

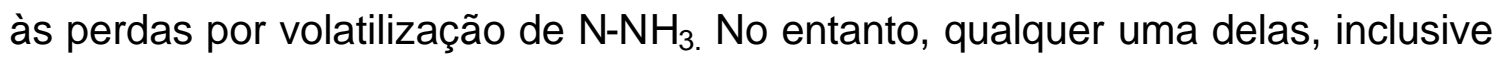
a uréia, pode sofrer outro tipo de perda gasosa via desnitrificação, em função da diminuição da aeração, pela maior umidade e/ou por problemas de compactação e mediante presença de compostos de carbono solúveis (Cantarella, 1998). 


\section{MATERIAL E MÉTODOS}

\subsection{Localização da área experimental, variedade de cana-de-açúcar e tipo de solo}

O estudo foi conduzido em área de campo comercial localizada na Fazenda São José da Jibóia, no município de Anhumas, SP, pertencente à Usina Santa Helena (Rio das Pedras, SP). A cultivar utilizada foi SP $80-1842$ em terceira soca que havia sido colhida sem queima prévia e mecanicamente em 16/07/2000. No manejo de corte das safras anteriores, a cana havia sido colhida manualmente após despalha a fogo.

O solo da área foi classificado como ARGISSOLO VERMELHO-AMARELO distrófico arenoso (Embrapa, 1999) cujas características químicas e físicas constam das Tabelas 1,2 e 3.

Tabela 1. Caracterização química do solo da área experimental.

\begin{tabular}{cccccccccccccc}
\hline $\begin{array}{c}\text { Prof. } \\
---\mathrm{cm}---\end{array}$ & $\begin{array}{c}\mathrm{pH} \\
\mathrm{CaCl}_{2}\end{array}$ & $\begin{array}{c}\mathrm{M} . \mathrm{O} . \\
\mathrm{g} \mathrm{dm}^{-3}\end{array}$ & $\begin{array}{c}\mathrm{P} \\
---\mathrm{m} \mathrm{dm}^{-3}--\end{array}$ & $\begin{array}{c}\mathrm{S} \\
---\end{array}$ & $\mathrm{K}$ & $\mathrm{Ca}$ & $\mathrm{Mg}$ & $\mathrm{Al}$ & $\begin{array}{c}\mathrm{H}+\mathrm{Al} \\
\mathrm{mmol}_{\mathrm{c}} \mathrm{dm}^{-3}\end{array}$ & $\mathrm{SB}$ & $\mathrm{T}$ & $\mathrm{V}$ & $\mathrm{m}$ \\
\hline $0-10$ & 4,3 & 17 & 5 & 18 & 1,6 & 7 & 3 & 6 & 52 & 11,6 & 63,6 & 18 & 34 \\
$10-20$ & 4,7 & 16 & 3 & 14 & 0,7 & 18 & 5 & 1 & 31 & 23,7 & 54,7 & 43 & 4 \\
$20-40$ & 4,3 & 14 & 3 & 25 & 0,5 & 13 & 6 & 9 & 80 & 19,5 & 99,5 & 20 & 32 \\
\hline
\end{tabular}

Prof. - Profundidade em cm.

$\mathrm{pH}-\mathrm{CaCl}_{2}$ 0,01 mol L ${ }^{-1}$ (Raij et al., 1987).

M.O. - Matéria orgânica, método colorimétrico (Raij et al., 1987).

$\mathrm{P}$ - Extração por resina trocadora de íons e determinação por colorimetria (Raij et al., 1987).

$\mathrm{S}=\mathrm{NH}_{4}$ Oac $0,5 \mathrm{~N}$ em HOAc $0,25 \mathrm{~N}$ (Vitti, 1988)

$\mathrm{K}$ - Extração por resina trocadora de íons e determinação por fotometria de chama (Raij et al., 1987).

Ca e Mg - extração por resina trocadora de íons e determinação por espectrometria de absorção atômica

(Raij et al., 1987).

H+Al - determinação potenciométrica em solução tampão SMP (Raij et al., 1987).

$\mathrm{Al}-\mathrm{KCl} 1 \mathrm{~N}$ 
Tabela 2. Caracterização química do solo da área experimental - micronutrientes.

\begin{tabular}{cccccc}
\hline $\begin{array}{c}\text { Prof. } \\
\mathrm{cm}----\end{array}$ & $\mathrm{B}$ & $\mathrm{Cu}$ & $\mathrm{Fe}$ & $\mathrm{Mn}$ & $\mathrm{Zn}$ \\
\hline $0-10$ & 0,06 & 0,1 & 47 & 2,4 & 0,2 \\
$10-20$ & 0,04 & 0,2 & 43 & 1,2 & 0,3 \\
$20-40$ & 0,07 & 0,1 & 35 & 0,8 & 0,2 \\
\hline
\end{tabular}

Prof. - Profundidade em cm.

$\mathrm{B}=\mathrm{BaCl}_{2} \cdot 2 \mathrm{H}_{2} \mathrm{O}$ 0,125\% microondas (10 ml TFSA/20 $\mathrm{ml} \mathrm{BaCl}_{2}$ 0,125\%) (Raij et al., 1987)

$\mathrm{Cu}, \mathrm{Fe}, \mathrm{Mn}, \mathrm{Zn}$ - DTPA-TEA pH 7,3 (Raij et al., 1987)

Tabela 3. Caracterização física do solo da área experimental - Análise granulométrica.

\begin{tabular}{ccccc}
\hline $\begin{array}{c}\text { Prof. } \\
\text { cm }\end{array}$ & Areia total & Silte & Argila total & Classe de textura \\
\hline $0-10$ & 86 & $\%$ & & \\
\hline $10-20$ & 86 & 6 & 6 & Arenosa \\
$20-40$ & 80 & 10 & 10 & Arenosa \\
\hline
\end{tabular}

Método do densímetro (Bouyoucos, 1927)

\subsection{Delineamento experimental}

Empregou-se o delineamento em blocos completos inteiramente casualizados, com sete tratamentos e cinco repetições, formando 35 parcelas experimentais. Cada bloco representou uma repetição e apresentou sete parcelas nas quais os tratamentos foram distribuídos aleatoriamente.

Cada parcela experimental constituiu-se de sete linhas de cana com 1,4 metros de espaçamento e 10 metros de comprimento, totalizando área de $98 \mathrm{~m}^{2}$. As avaliações foram realizadas nas cinco linhas centrais, sendo que uma linha em cada lateral da parcela foi considerada bordadura. 


\subsection{Tratamentos}

Os tratamentos avaliados no experimento foram de caráter qualitativo. Trabalhou-se com diferentes fontes de nitrogênio aplicadas na dose correspondente a $100 \mathrm{~kg} \mathrm{ha}^{-1}$ de $\mathrm{N}$. Os tratamentos empregados no experimento são visualizados na Tabela 4.

Tabela 4. Descrição dos tratamentos.

\begin{tabular}{|c|c|c|c|c|c|}
\hline Tratamento & $\mathrm{N}_{\text {total }}$ & $\mathrm{N}_{\text {amídico }}$ & $\mathrm{N}_{\text {nítrico }}$ & $\mathrm{N}_{\text {amoniacal }}$ & $\mathrm{N}_{\text {orgânico }}$ \\
\hline T0 - Testemunha & - & - & - & - & - \\
\hline T1- Uréia em superfície & 45 & 45 & - & - & - \\
\hline T2- Uran em superfície & 32 & 14 & 9 & 9 & - \\
\hline $\mathrm{T} 3-\mathrm{U}+\mathrm{SA}{ }^{(1)}$ em superfície & 32 & 22 & - & 10 & - \\
\hline T4- Ajifer em superfície & 5 & - & - & 3 & 2 \\
\hline T5- Uréia + Gesso em superfície & 45 & 45 & - & - & - \\
\hline T6- Uréia incorporada & 45 & 45 & - & - & - \\
\hline
\end{tabular}

(1) U + SA: Mistura Uréia + Sulfato de amônio

Na Tabela 5 visualiza-se os resultados da análise química do resíduo Ajifer que foi utilizado no tratamento T4. 
Tabela 5. Caracterização química do resíduo orgânico líquido Ajifer.

\begin{tabular}{|c|c|}
\hline Determinação & Resultados \\
\hline Indice $\mathrm{pH}$ & 3,20 \\
\hline Densidade & $1,17 \mathrm{~g} \mathrm{ml}^{-1}$ \\
\hline Matéria orgânica total (combustão) & $315,35 \mathrm{~g} \mathrm{~L}^{-1}$ \\
\hline Carbono total (orgânico e mineral) & $175,19 \mathrm{~g} \mathrm{~L}^{-1}$ \\
\hline Nitrogênio total & $50 \mathrm{~g} \mathrm{~L}^{-1}$ \\
\hline Fósforo $\left(\mathrm{P}_{2} \mathrm{O}_{5}\right)$ total & $2,48 \mathrm{~g} \mathrm{~L}^{-1}$ \\
\hline Potássio $\left(\mathrm{K}_{2} \mathrm{O}\right)$ & $11,80 \mathrm{~g} \mathrm{~L}^{-1}$ \\
\hline Cálcio (Ca) & $0,33 \mathrm{~g} \mathrm{~L}^{-1}$ \\
\hline Magnésio (Mg) & $0,69 \mathrm{~g} \mathrm{~L}^{-1}$ \\
\hline Enxofre (S) & $47,27 \mathrm{~g} \mathrm{~L}^{-1}$ \\
\hline Cobre $(\mathrm{Cu})$ & 2,0 ppm \\
\hline Manganês (Mn) & $19,0 \mathrm{ppm}$ \\
\hline Zinco (Zn) & 3,00 ppm \\
\hline Ferro $(\mathrm{Fe})$ & $122,0 \mathrm{ppm}$ \\
\hline Relação C/N (C total e $\mathrm{N}$ total) & $6 / 1$ \\
\hline
\end{tabular}

Avaliações de volatilização de $\mathrm{N}-\mathrm{NH}_{3}$ foram realizadas nos tratamentos $\mathrm{T} 0, \mathrm{~T} 1$, T2, T3 e T4. Os resultados de T0 foram utilizados para descontar possível liberação de $\mathrm{N}-\mathrm{NH}_{3}$ nativo do solo e/ou proveniente da fotodecomposição das espumas, permitindo determinação da volatilização das fontes utilizadas em T1, T2, T3 e T4. O tratamento T5 foi utilizado para avaliar possíveis efeitos do fornecimento de enxofre, também proporcionado pelos tratamentos $\mathrm{T} 3 \mathrm{e} \mathrm{T} 4$, na produtividade e qualidade. $\mathrm{O}$ tratamento T6 foi utilizado com objetivo de constatar se existe relação entre menores perdas de nitrogênio por volatilização e produtividade e qualidade. 


\subsection{Adubação convencional e tratos culturais das soqueiras de cana-de-açúcar}

Além da adubação nitrogenada, que foi objeto de estudo deste trabalho, realizou-se adubação potássica de cobertura nas soqueiras de cana-de-açúcar. Aplicou-se

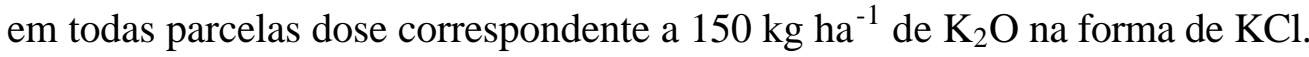

Observou-se desenvolvimento de plantas daninhas mesmo com a influência da palha, porém não foi utilizado nenhum método para controle pois o mato surgiu em pontos isolados.

Durante o período de condução do experimento no campo, apenas realizou-se limpezas nos espaços existentes entre as parcelas de cada bloco, formando pequenos "carreadores" que facilitaram a locomoção entre as parcelas durante as avaliações.

\subsection{Instalação do experimento}

A instalação do experimento foi realizada em 04 de setembro de 2000. As soqueiras apresentavam pequeno tamanho pois sofreram ligeiro atraso na brotação devido à presença da palha.

Nos tratamentos em que determinou-se perdas por volatilização de $\mathrm{N}_{-} \mathrm{NH}_{3}$, primeiramente enterrou-se e cobriu-se com lona as bases dos coletores de amônia. Posteriormente aplicou-se o adubo nitrogenado, manualmente e de forma localizada em cada parcela, procurando-se colocar as fontes a $25 \mathrm{~cm}$ de distância das linhas de cana. Em T5 o gesso foi aplicado após a uréia e em T6 abriu-se sulcos de aproximadamente 10 centímetros de profundidade que, após aplicação da uréia, foram fechados.

Para viabilizar a determinação da amônia volatilizada por meio dos coletores, buscou-se máxima uniformidade de aplicação das fontes nitrogenadas. Aplicou-se nas bases dos coletores quantidades previamente pesadas ou medidas das fontes sólidas e fluídas. Fontes sólidas foram aplicadas nas bases dos coletores junto com o adubo potássico; na aplicação de fontes fluídas, o $\mathrm{KCl}$ foi aplicado logo em seguida. Tal procedimento visou uniformizar os tratamentos para possível influência do $\mathrm{KCl}$ que, na adubação geral das parcelas, foi aplicado junto com as fontes nitrogenadas. 
No mesmo dia em que as fontes nitrogenadas foram aplicadas, instalou-se os coletores semi-aberto estáticos para determinação das perdas gasosas de $\mathrm{N}-\mathrm{NH}_{3}$.

\subsection{Determinação das perdas de $\mathrm{N}-\mathrm{NH}_{3}$}

No período de 04 de setembro a 11 de outubro de 2000, quantificou-se as perdas de $\mathrm{N}-\mathrm{NH}_{3}$ por volatilização por meio do coletor semi-aberto descrito por Lara Cabezas et al. (1999). Cada parcela dos tratamentos T0, T1, T2, T3 e T4 apresentou um coletor com seis bases distintas nas quais aplicourse as fontes nitrogenadas na dose de $100 \mathrm{~kg} \mathrm{ha}^{-1}$ de N (Figuras 1 e 2).

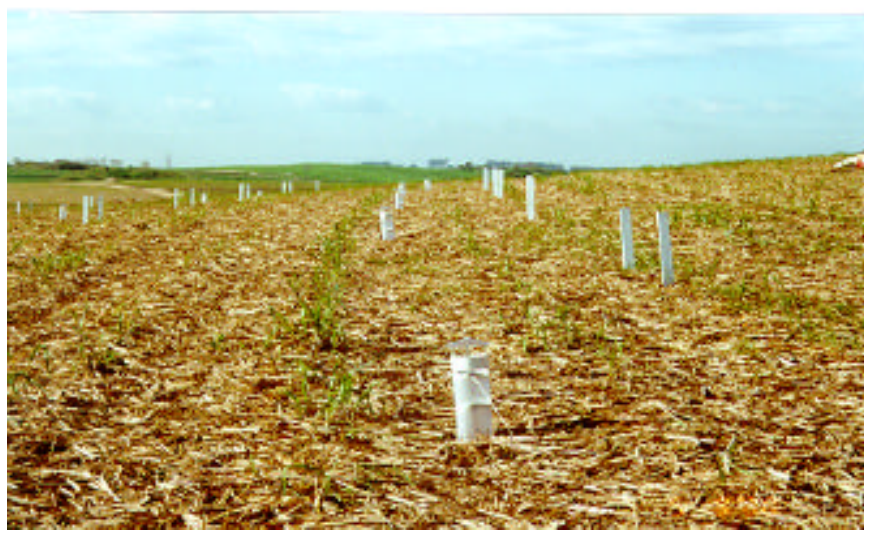

Figura 1 - Coletores de amônia instalados no campo.

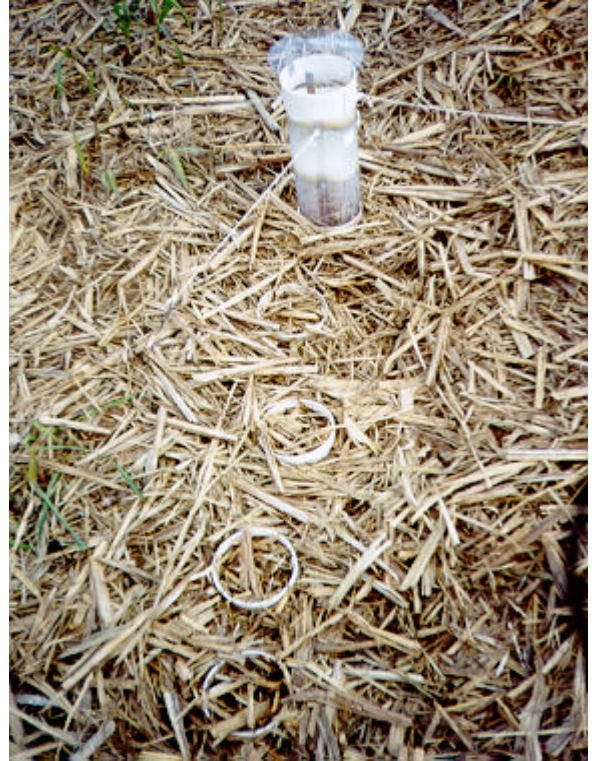

Figura 2 - Detalhe das bases para mudança de posição dos coletores. 
Cada coletor apresentou duas espumas absorventes embebidas em ácido fosfórico e glicerina (Figura 3). A espuma inferior foi utilizada para determinar a amônia proveniente do solo e das fontes nitrogenadas e a espuma superior foi utilizada para isolar a inferior da atmosfera. Coletas e trocas de espumas foram efetuadas aos 2, 6, 9, 13, 16, 20, 23, 33 e 38 dias após aplicação dos tratamentos. A cada coleta e troca, os coletores foram transferidos para as bases subseqüentes, de modo que, a determinação de cada período foi realizada considerando-se as influências de mudanças climáticas ocorridas (chuva, orvalho, vento, temperatura).

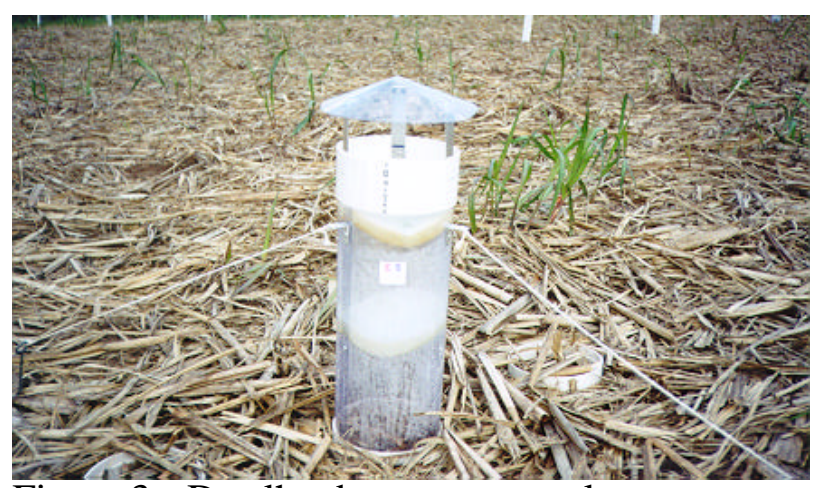

Figura 3 - Detalhe das espumas coletoras embebidas em solução de ácido fosfórico.

Tanto para preparo ou extração no laboratório, quanto para coleta e troca no campo, o manuseio das espumas foi extremamente cuidadoso, utilizando-se sacos plásticos para isolar as espumas da atmosfera e luvas de borracha, com objetivo de minimizar riscos de contaminação. Com objetivo de minimizar erros ocorridos por contaminação, também fez-se determinações em espumas que não foram levadas ao campo, que atuaram como provas em branco.

A extração do $\mathrm{N}-\mathrm{NH}_{3}$ retido nas espumas foi realizada com solução de $\mathrm{KCl}$, sendo que as espumas sofreram quatro lavagens consecutivas com a solução para completa remoção do nitrogênio amoniacal retido. $\mathrm{O}$ volume de $\mathrm{KCl}$ utilizado foi suficiente para completar balões volumétricos de $500 \mathrm{ml}$.

Do extrato tomourse alíquota de $50 \mathrm{ml}$ que foi transferida para balão de destilação onde adicionourse $\mathrm{NaOH}$ para elevar o pH da solução até 7,5. O destilado foi 
recolhido em Erlenmeyer contendo $10 \mathrm{ml}$ de solução de ácido bórico mais indicador e, posteriormente, foi titulado com ácido sulfúrico $0,0025 \mathrm{~mol} \mathrm{~L}^{-1}$.

Tendo-se em mãos os valores do volume de ácido sulfúrico gasto na titulação, das provas em branco e das amostras, calculourse o nitrogênio amoniacal volatilizado pela equação $\mathrm{N}=(\mathrm{V} \mathrm{a}-\mathrm{V}$ b) $\mathrm{x}$ f, de modo que:

$\mathrm{N}=\mathrm{mg}$ de nitrogênio por câmara;

$\mathrm{V} \mathrm{a}=$ Volume de ácido gasto na titulação da amostra;

$\mathrm{V} \mathrm{b}=$ Volume de ácido gasto na titulação do branco;

$\mathrm{f}=0,7$ (fator referente à molaridade do ácido, volume da alíquota e do extrato no balão volumétrico).

Os resultados obtidos foram corrigidos de acordo com a equações propostas por Lara Cabezas et al. (1999).

\subsection{Amostragem e análise de folhas}

Realizou-se amostragem de folhas quatro meses após brotação das soqueiras. Coletou-se o terço médio sem a nervura central da primeira folha com aurícula visível, sendo que uma amostra de cada parcela foi composta por três folhas.

De acordo com a metodologia de preparo de material descrita por Malavolta et al. (1997), as folhas amostradas foram armazenadas em sacos de papel identificados e levadas para o laboratório. As folhas frescas foram lavadas em água destilada com pequena quantidade de detergente e enxaguadas em água destilada até plena remoção do detergente, sendo posteriormente secas em papel absorvente. Procedeu-se a secagem das folhas em estufa com circulação forçada de ar na temperatura de $65^{\circ} \mathrm{C}$ e moagem em moinhos do tipo Wiley com peneira de 20 mesh.

Após secagem, o material foi moído e analisado para determinação de macro e micronutrientes. O N foi extraído pela digestão sulfúrica; $\mathrm{P}, \mathrm{K}, \mathrm{Ca}, \mathrm{Mg}, \mathrm{S}, \mathrm{Cu}, \mathrm{Fe}, \mathrm{Mn}$ e Zn foram extraídos pela digestão nítrico-perclórica e o B foi extraído por meio de

digestão seca. As determinações analíticas foram realizadas de acordo com as metodologias descritas por Malavolta et al. (1997). 


\subsection{Amostragens e análises de solo}

Além das amostragens de solo realizadas antes da instalação do experimento, para caracterização física e química da área experimental, foram realizadas duas amostragens de solo, uma em 02/12/00 e outra em 06/02/01. Essas amostragens foram feitas em todas parcelas, nas profundidades de 0-5 e 5-10 cm e a $25 \mathrm{~cm}$ das linhas de cana. Tomou-se três sub-amostras por parcela para formação de uma amostra composta.

As amostras foram acondicionadas em sacos plásticos, identificadas e encaminhadas para o laboratório, onde foram secas em estufa de circulação forçada, com temperatura não superior a $40^{\circ} \mathrm{C}$. Após secagem, foram feitas determinações de $\mathrm{pH}$, M.O., $\mathrm{K}, \mathrm{Ca}, \mathrm{Mg}, \mathrm{H}+\mathrm{Al}$ e micronutrientes conforme metodologias propostas por Raij et al. (1987). Também foram realizadas determinações de teores de enxofre (S) no solo, conforme metodologia descrita por Vitti (1988).

Além das determinações acima citadas, também foram feitas determinações de N-total e C-orgânico. Para determinação do N-total nas amostras de solo, utilizourse o método de Kjeldahl citado por Tedesco et al. (1995). A determinação do C-orgânico foi feita pela divisão dos valores de M.O. obtidos por 1,72 (fator de Van Bemmelen).

\subsection{Amostragens e análises da palha}

Amostras de palha foram coletadas fora das parcelas experimentais, em áreas que não receberam adubação nitrogenada. Coletourse palha de cinco pontos aleatórios por meio de amostradores de madeira de $0,25 \mathrm{~m}^{2}$. Determinoutse peso úmido e peso seco da palha amostrada, a secagem foi realizada em estufa de circulação forçada a 65 ${ }^{\circ} \mathrm{C}$ durante 72 horas. Após secagem, o material foi moído e analisado para determinação de macro e micronutrientes. $\mathrm{O} \mathrm{N}$ foi extraído pela digestão sulfúrica; $\mathrm{P}, \mathrm{K}, \mathrm{Ca}, \mathrm{Mg}, \mathrm{S}$, $\mathrm{Cu}, \mathrm{Fe}, \mathrm{Mn}$ e $\mathrm{Zn}$ foram extraídos pela digestão nítrico-perclórica e o B foi extraído por meio da digestão seca. As determinações analíticas foram realizadas de acordo com a metodologia descrita por Malavolta et al. (1997). A determinação de C orgânico na palha foi feita pela metodologia descrita por Tedesco et al. (1995). 


\subsection{Determinação de produtividade e qualidade tecnológica}

A colheita do experimento foi efetuada em 30/05/01 em função do cronograma de atividades da usina e da chegada da frente de colheita no talhão em que o ensaio foi instalado. Para determinação da produtividade, colheu-se as cinco linhas centrais de cada parcela manualmente e sem queima, posteriormente os colmos foram pesados com garra acoplada à célula de carga. Tendo em mãos a produção de colmos de cana na área ocupada pelas cinco linhas centrais de cada parcela, calculoutse a produção de colmos por hectare.

Por ocasião da colheita também foi realizada amostragem para avaliação da qualidade tecnológica da cana. A amostragem para análises tecnológicas constou de 10 canas contíguas da linha central de cada parcela, conforme descrito por Espironello et al. (1987). As amostras foram analisadas no laboratório da Usina Santa Helena, determinando-se:

- Brix $(\%)$ e Pol (\%) via refratometria à $20^{\circ} \mathrm{C}$ e dosado pelo método de Schimitz sem diluição (Schneider, 1979);

- Pureza pela relação [Pol (\%)/Brix (\%)] x 100;

- Açúcares redutores (\%) pelo do método volumétrico de Lane \& Eynon (1934);

- Pol (\%) cana e Fibra (\%) cana, segundo ATO nº 32/89 - IAA (1989);

- Produção de açúcar provável por hectare $(\mathrm{TAH})=(\mathrm{TCH} \times \mathrm{ATR}) / 100$ onde $\mathrm{ATR}=$ açúcares totais recuperáveis e $\mathrm{TCH}=$ tonelada cana $\mathrm{ha}^{-1}$.

- Açúcares Totais Recuperáveis (ATR), segundo CONSECANA (1999).

\subsection{Análise estatística}

Os resultados das avaliações, com exceção daqueles referentes às amostras de palha, foram submetidos à análise de variância $\left(\mathrm{SAS}^{\circledR}\right)$, utilizando-se o teste $\mathrm{F}$ de Fisher \& Snedecor, ao nível de $95 \%$ de confiança. Para as causas de variação em que F 
apresentou valor significativo, realizou-se o teste de Tukey para comparação das médias entre tratamentos, ao nível de $5 \%$ de probabilidade. 


\section{RESULTADOS E DISCUSSÃO}

\subsection{Perda acumulada de $\mathrm{N}-\mathrm{NH}_{3}$ das fontes nitrogenadas}

$\mathrm{Na}$ Figura 4 e Tabela 6, verifica-se que perdas de $\mathrm{N}-\mathrm{NH}_{3}$ ocorreram até os seis primeiros dias após aplicação dos tratamentos. Gava (1999) encontrou perdas nos 11 primeiros dias após aplicação de vinhaça + uréia sobre a palha de cana-de-açúcar.

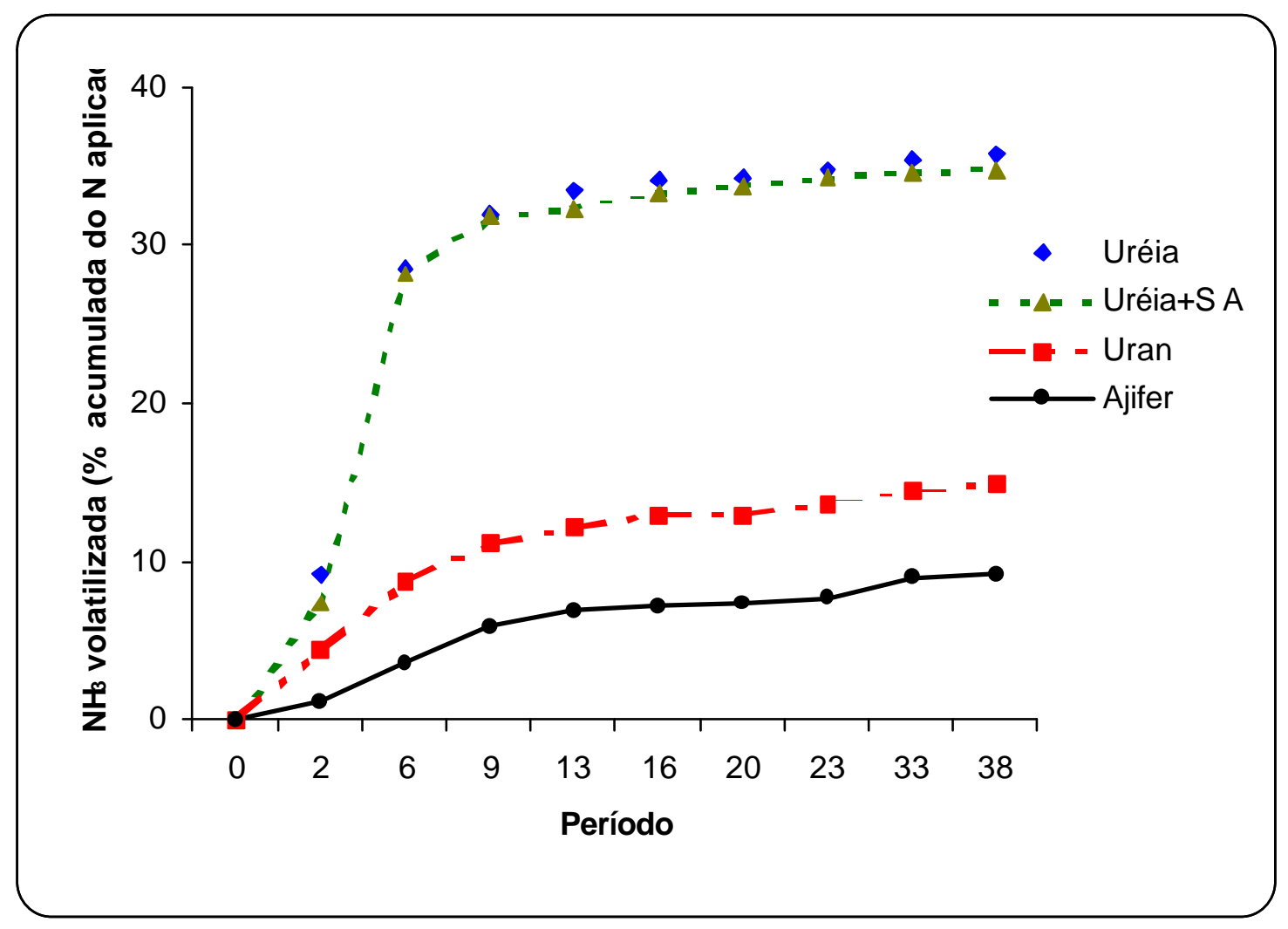

Figura 4 - Perdas de $\mathrm{N}-\mathrm{NH}_{3}$ por volatilização. 
Tabela 6. Perda acumulada de $\mathrm{N}-\mathrm{NH}_{3} \quad\left(\mathrm{~kg} \mathrm{ha}^{-1}\right)$ proveniente de diferentes fontes nitrogenadas aplicadas sobre a palha de cana-de-açúcar.

\begin{tabular}{|c|c|c|c|c|c|c|c|c|c|}
\hline \multirow[t]{2}{*}{ Tratamento } & $\mathbf{0 - 2}$ & $\overline{0-6}$ & 0-9 & $\mathbf{0 - 1 3}$ & 0-16 & $\mathbf{0 - 2 0}$ & $\mathbf{0 - 2 3}$ & $\mathbf{0 - 3 3}$ & $\mathbf{0 - 3 8}$ \\
\hline & \multicolumn{9}{|c|}{ 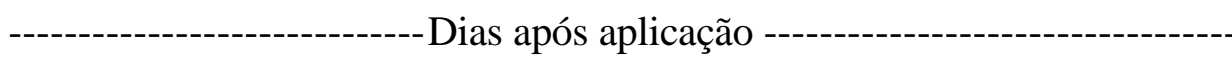 } \\
\hline $\mathrm{T} 1$ & $9 \mathrm{a}$ & $28 \mathrm{a}$ & $32 \mathrm{a}$ & $34 \mathrm{a}$ & $34 \mathrm{a}$ & $34 \mathrm{a}$ & $35 \mathrm{a}$ & $36 \mathrm{a}$ & $36 \mathrm{a}$ \\
\hline $\mathrm{T} 2$ & $4 \mathrm{ab}$ & $8 \mathrm{~b}$ & $11 \mathrm{~b}$ & $12 \mathrm{~b}$ & $13 \mathrm{~b}$ & $13 \mathrm{~b}$ & $14 \mathrm{~b}$ & $14 \mathrm{~b}$ & $15 \mathrm{~b}$ \\
\hline $\mathrm{T} 3$ & $7 \mathrm{ab}$ & $28 \mathrm{a}$ & $32 \mathrm{a}$ & $32 \mathrm{a}$ & $33 \mathrm{a}$ & $34 \mathrm{a}$ & $34 \mathrm{a}$ & $35 \mathrm{a}$ & $35 \mathrm{a}$ \\
\hline $\mathrm{T} 4$ & $1 \mathrm{~b}$ & $4 \mathrm{~b}$ & $6 \mathrm{~b}$ & $7 \mathrm{~b}$ & $7 \mathrm{~b}$ & $7 \mathrm{~b}$ & $8 \mathrm{~b}$ & $9 \mathrm{~b}$ & $9 \mathrm{~b}$ \\
\hline Valor F & $9 * *$ & $16 * *$ & $18^{* *}$ & $16 * *$ & $17^{* *}$ & $18^{* *}$ & $17 * *$ & $15 * *$ & $15 *$ \\
\hline $\mathrm{CV}(\%)$ & 48 & 42 & 36 & 36 & 34 & 34 & 34 & 34 & 33 \\
\hline DMS & 5 & 14 & 14 & 14 & 14 & 14,0 & 14 & 15 & 15 \\
\hline
\end{tabular}

T1: Uréia, T2: Uran, T3: Uréia + Sulfato de amônio, T4: Ajifer.

Médias de cinco repetições contidas em colunas, seguidas de mesma letra não diferem entre si pelo teste de Tukey.

* e**: nível de significância de 5 e $1 \%$ respectivamente. ns: não significativo.

A umidade do solo influenciou a volatilização de $\mathrm{N}-\mathrm{NH}_{3}$ (Figura 5). As chuvas de 58 e 22 mm ocorridas na área em 01/09 e em 02/09/00 fizeram com que a palha e o solo apresentassem considerável umidade por ocasião da instalação do experimento (Figura 6).

A segunda avaliação foi influenciada pela chuva de oito milímetros ocorrida um dia após aplicação dos tratamentos (Figura 6). Assim, resultados de volatilização no período da segunda avaliação foram acentuados. Cantarella et al. (1999) observaram que a ocorrência de chuvas manteve baixo o nível de volatilização, e concluíram que as taxa de perda acentua-se após chuvas que não sejam suficientes para solubilizar a uréia. 


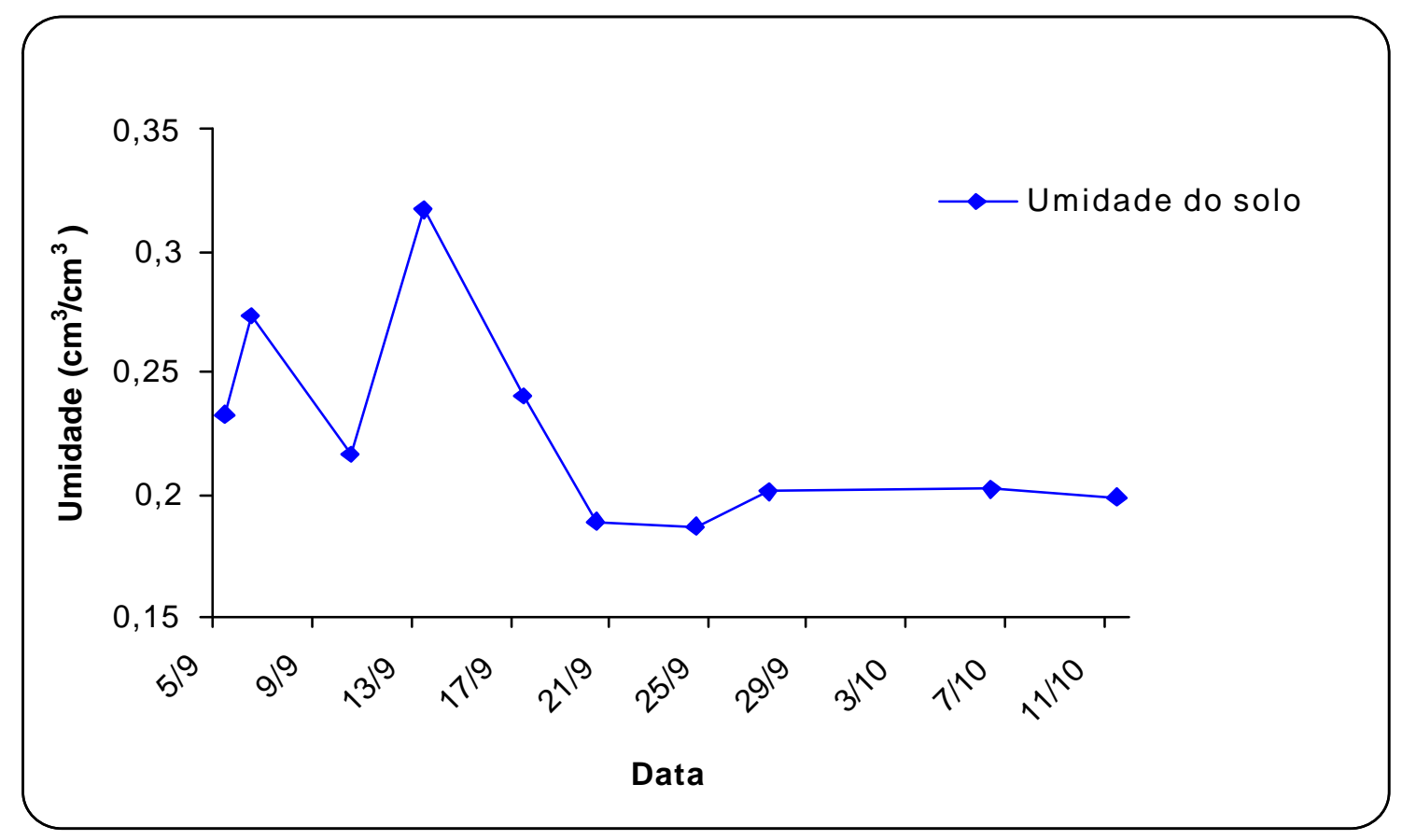

Figura 5 - Umidade do solo nas datas de coleta das espumas.

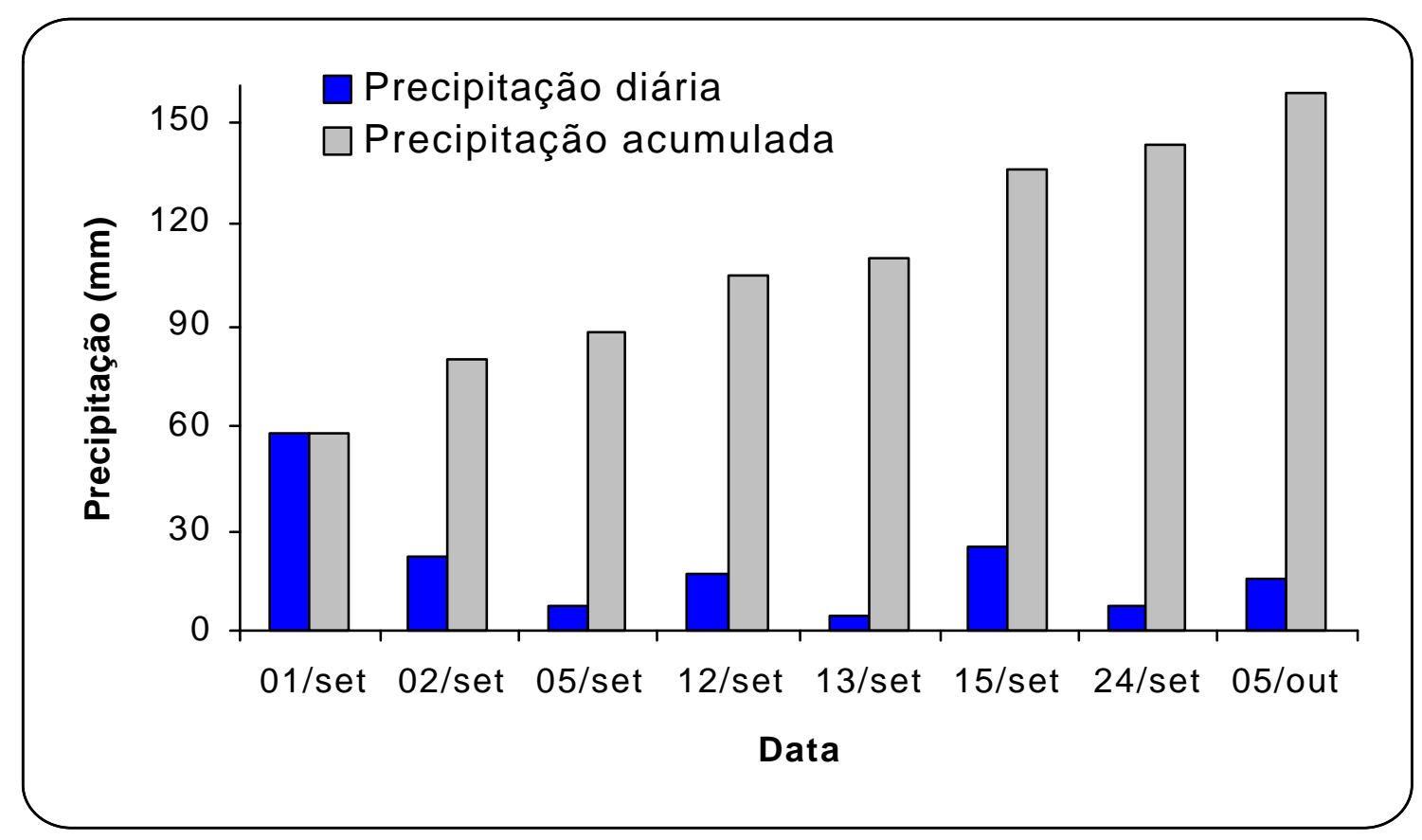

Figura 6 - Precipitação ocorrida no período em que a volatilização foi avaliada. 
Ao final do período de avaliação, observoutse que T1 e T3 não diferiram entre si e apresentaram maior perda acumulada de $\mathrm{N}^{-\mathrm{NH}_{3}}$ (36 e $35 \%$ respectivamente). Os valores de volatilização obtidos em T1 deveram-se à susceptibilidade de perda da fonte utilizada, aos efeitos da urease tanto da palha como do solo e à baixa capacidade de retenção de amônia da palha (Freney et al., 1992). Quando a uréia é aplicada na superfície da palha, 30 a 94\% do nitrogênio é perdido por volatilização de N-NH3 (Deanmead et al., 1990; Wood et al., 1991; Freney et al., 1992; Oliveira et al., 1997).

No tratamento T3 deste trabalho, a aplicação da mistura entre uréia e sulfato de amônio sobre a palha, e não sobre o solo, causou elevação do pH que deslocou o equilíbrio químico entre amônia e o íon amônio $\left(\mathrm{NH}_{3}+\mathrm{H}_{2} \mathrm{O} \Leftrightarrow \mathrm{NH}_{4}{ }^{+}+\mathrm{OH}^{-}\right)$para a esquerda, favorecendo a volatilização de $\mathrm{N}^{-\mathrm{NH}_{3}}$. Vitti et al. (2001b) realizaram experimento em laboratório e observaram que a mistura de $50 \%$ de uréia com $50 \%$ de sulfato de amônio aplicada ao solo, resultou em menor volatilização de amônia em relação às misturas com menores quantidades de sulfato de amônio e à aplicação exclusiva de uréia. Os mesmos autores atribuíram a menor perda ao efeito de controle de elevação de $\mathrm{pH}$ e à redução na quantidade de $\mathrm{N}$-amídico proporcionados pela mistura.

Os tratamentos T2 e T4 também não diferiram estatisticamente entre si e apresentaram menores perdas (15 e 9\% respectivamente). A menor volatilização encontrada no tratamento T2 ocorreu devido à substituição de parte do N-amídico por Namoniacal e nítrico. Trivelin et al. (1996) atribuíram a menor perda total por volatilização de amônia do uran em relação à mesma dose de $\mathrm{N}$-uréia, à substituição do $\mathrm{N}$-amídico pelo N-nitrato de amônio.

As perdas ocorridas em T4 também foram consideradas baixas em relação às demais. Tal observação é resultado da característica qualitativa do resíduo utilizado que, além de nitrogênio e enxofre, possui cátions ( $\mathrm{K}, \mathrm{Ca}$ e $\mathrm{Mg}$ ) que podem contribuir para reduzir o potencial de volatilização (Fenn \& Myamoto, 1981; Fenn \& Richards, 1984; Sengik \& Kiehl, 1995). 


\subsection{Avaliação do estado nutricional da cana-de-açúcar}

\subsubsection{Teores foliares de macronutrientes}

$\mathrm{Na}$ Tabela 7 verifica-se que houve diferença significativa para teores foliares de nitrogênio $(\mathrm{N})$, fósforo $(\mathrm{P})$ e enxofre $(\mathrm{S})$. Teores foliares de $\mathrm{N}$ foram menores em $\mathrm{T} 0 \mathrm{e}$ maiores em T2, T4 e T6 que não diferiram entre si. Os tratamentos T1, T3 e T5 apresentaram teores foliares de $\mathrm{N}$ intermediários aos demais, sem diferir estatisticamente entre si. Nos tratamentos em que avaliou-se perdas de $\mathrm{N}_{-} \mathrm{NH}_{3}$ por volatilização, o teor foliar de $\mathrm{N}$ foi inversamente proporcional às perdas ocorridas. Analisando o teor foliar de $\mathrm{N}$ em T6 supõe-se que, devido a incorporação da uréia, esse tratamento apresentou taxa de volatilização semelhante àquelas encontradas em T2 e T4. Esses resultados mostram que o teor de $\mathrm{N}$ nas folhas sofre influência das perdas por volatilização do $\mathrm{N}$ aplicado.

O teor foliar de P foi maior em T2 e menor em T5. Orlando Filho et al. (1998) verificaram que valores de $\mathrm{P}$ no solo acompanharam aumentos da matéria orgânica, de modo que maiores teores foliares poderiam estar relacionados com maiores teores de M.O. no solo, fato que não foi constatado neste trabalho.

O tratamento 44 apresentou maior teor foliar de S, seguido pelos tratamentos T3 e T5. Tais resultados são justificados pela presença de enxofre nas fontes utilizadas nesses tratamentos. 
Tabela 7. Teores foliares de macronutrientes.

\begin{tabular}{ccccccc}
\hline Tratamento & $\mathbf{N}$ & $\mathbf{P}$ & $\mathbf{K}$ & $\begin{array}{c}\text { Ca } \\
\mathrm{kg}\end{array}$ & $\mathbf{M g}$ & $\mathbf{S}$ \\
& ---------------------------------- & $\mathrm{g}^{-1}$ & \\
\hline T0 & $15,8 \mathrm{~b}$ & $2,0 \mathrm{ab}$ & $13,8 \mathrm{a}$ & $1,5^{\mathrm{a}}$ & $1,6 \mathrm{a}$ & $1,5 \mathrm{~b}$ \\
$\mathrm{~T} 1$ & $17,4 \mathrm{ab}$ & $1,9 \mathrm{ab}$ & $13,2 \mathrm{a}$ & $1,9^{\mathrm{a}}$ & $1,7 \mathrm{a}$ & $1,5 \mathrm{~b}$ \\
$\mathrm{~T} 2$ & $18,7 \mathrm{a}$ & $2,1 \mathrm{a}$ & $14,5 \mathrm{a}$ & $1,6^{\mathrm{a}}$ & $1,7 \mathrm{a}$ & $1,6 \mathrm{~b}$ \\
$\mathrm{~T} 3$ & $17,7 \mathrm{ab}$ & $2,0 \mathrm{ab}$ & $14,0 \mathrm{a}$ & $1,7 \mathrm{a}$ & $1,7 \mathrm{a}$ & $1,8 \mathrm{ab}$ \\
$\mathrm{T} 4$ & $18,8 \mathrm{a}$ & $1,9 \mathrm{ab}$ & $14,3 \mathrm{a}$ & $1,9 \mathrm{a}$ & $1,7 \mathrm{a}$ & $2,0 \mathrm{a}$ \\
$\mathrm{T} 5$ & $17,2 \mathrm{ab}$ & $1,8 \mathrm{~b}$ & $13,0 \mathrm{a}$ & $1,8 \mathrm{a}$ & $1,6 \mathrm{a}$ & $1,8 \mathrm{ab}$ \\
$\mathrm{T} 6$ & $18,2 \mathrm{a}$ & $1,8 \mathrm{ab}$ & $13,5 \mathrm{a}$ & $1,5 \mathrm{a}$ & $1,5 \mathrm{a}$ & $1,5 \mathrm{~b}$ \\
Valor F & $6,3 * *$ & $3,2^{*}$ & $0,9 \mathrm{~ns}$ & $0,8 \mathrm{~ns}$ & $1,0 \mathrm{~ns}$ & $9,4 * *$ \\
CV $(\%)$ & 5,2 & 6,9 & 9,7 & 23,0 & 10,8 & 9,5 \\
DMS & 2,3 & 0,3 & 2,7 & 0,8 & 0,4 & 0,4 \\
\hline
\end{tabular}

T0: Testemunha, T1: Uréia, T2: Uran, T3: Uréia + Sulfato de amônio, T4: Ajifer, T5: Uréia + Gesso, T6: Uréia incorporada.

Médias de cinco repetições contidas em colunas, seguidas de mesma letra não diferem entre si pelo teste de Tukey. $*$ e **: nível de significância de 5 e $1 \%$ respectivamente. ns: não significativo.

\subsubsection{Teores foliares de micronutrientes}

Somente houve diferença entre tratamentos para teores de boro (Tabela 8). Os tratamentos T0 e T6 apresentaram maiores teores de B nas folhas, enquanto que T1 e T2 apresentaram menores teores. O boro pode estar na solução do solo (disponível para as plantas) ou pode estar na matéria orgânica. O teor foliar do nutriente encontrado no tratamento T0 poderia ser resultado de maior disponibilidade no solo em função do menor teor de matéria orgânica nesse tratamento. Entretanto, teores foliares encontrados em T6 não permitem justificar tal comportamento a partir do teor de matéria orgânica do solo. 
Tabela 8. Teores foliares de micronutrientes.

\begin{tabular}{|c|c|c|c|c|c|}
\hline Tratamento & $\overline{\mathbf{B}}$ & $\overline{\mathrm{Cu}}$ & $\mathbf{F e}$ & $\overline{M n}$ & $\overline{Z n}$ \\
\hline T0 & $\overline{5,2 a}$ & $4,8 \mathrm{a}$ & $58,8^{\mathrm{a}}$ & $67,0 a$ & $13,8 \mathrm{a}$ \\
\hline $\mathrm{T} 1$ & $3,8 \mathrm{c}$ & $5,4 a$ & $61,0^{\mathrm{a}}$ & $83,2 \mathrm{a}$ & $14,4 a$ \\
\hline $\mathrm{T} 2$ & $3,4 \mathrm{c}$ & $5,6 a$ & $61,0^{\mathrm{a}}$ & $89,0 \mathrm{a}$ & $15,2 \mathrm{a}$ \\
\hline $\mathrm{T} 3$ & 4,2abc & $5,4 \mathrm{a}$ & $62,8^{\mathrm{a}}$ & $94,0 \mathrm{a}$ & $14,4 \mathrm{a}$ \\
\hline $\mathrm{T} 4$ & 4,6abc & $6,2 \mathrm{a}$ & $57,8^{\mathrm{a}}$ & $91,4 \mathrm{a}$ & $14,8 \mathrm{a}$ \\
\hline $\mathrm{T} 5$ & 4,6abc & $5,6 a$ & $57,2^{\mathrm{a}}$ & $85,2 \mathrm{a}$ & $13,8 \mathrm{a}$ \\
\hline T6 & $5,0 \mathrm{ab}$ & $5,2 \mathrm{a}$ & $59,0^{\mathrm{a}}$ & $96,6 a$ & $13,6 \mathrm{a}$ \\
\hline Valor F & $7,1 * *$ & $1,9 \mathrm{~ns}$ & $0,6 \mathrm{~ns}$ & $2,0 \mathrm{~ns}$ & $1,0 \mathrm{~ns}$ \\
\hline $\mathrm{CV}(\%)$ & 12,29 & 12,77 & 10,2 & 18,1 & 9,0 \\
\hline DMS & 1,34 & 1,41 & 12,4 & 31,9 & 2,6 \\
\hline
\end{tabular}

T0: Testemunha, T1: Uréia, T2: Uran, T3: Uréia + Sulfato de amônio, T4: Ajifer, T5: Uréia+Gesso, T6: Uréia incorporada.

Médias de cinco repetições contidas em colunas, seguidas de mesma letra não diferem entre si pelo teste de Tukey. * e **: nível de significância de 5 e $1 \%$ respectivamente. ns: não significativo.

Por meio da diagnose foliar, constatourse deficiência de cálcio, boro e zinco nos tratamentos. Segundo Malavolta (1994), a cana-de-açúcar apresenta sintomas de deficiência de cálcio quando o teor foliar desse nutriente é menor que $2,5 \mathrm{~g} \mathrm{~kg}^{-1}$. O mesmo autor menciona que sintomas de deficiência de boro e zinco surgem quando os teores desses nutrientes nas folhas estão na faixa de 1 a 5 e 10 a 15 ppm, respectivamente. 


\subsection{Avaliação de atributos químicos do solo}

\subsubsection{Amostragem realizada três meses após aplicação dos tratamentos}

A Tabela 9 mostra resultados analíticos de amostras retiradas na profundidade 0-5 cm. Verifica-se que houve diferença estatística significativa para matéria orgânica (M.O.), teores de magnésio ( $\mathrm{Mg}$ ), acidez potencial ( $\mathrm{H}+\mathrm{Al})$ e saturação por bases $(\mathrm{V} \%)$.

$\mathrm{O}$ tratamento T0 apresentou menor teor de M.O. Comparando tratamentos que receberam adubação nitrogenada, verifica-se que T3 e T4 não diferiram entre si e apresentaram maiores teores de M.O., enquanto que T1, T2, T5 e T6 apresentaram teores intermediários. Orlando Filho et al. (1998) verificaram que a adubação nitrogenada sobre a palha de cana-de-açúcar proporcionou maior teor de matéria orgânica no solo.

Fragmentos de raízes e biomassa microbiana fazem parte da matéria orgânica do solo, assim os teores de M.O. encontrados nos tratamentos são justificados pelo desenvolvimento de raízes e de microrganismos. Sem adição de nitrogênio, a formação de raízes e/ou radicelas em T0 provavelmente foi menor em relação aos demais tratamentos.

Considerando os microrganismos, as fontes nitrogenadas estimularam a decomposição dos carboidratos mais solúveis da palha, favorecendo a biomassa microbiana no solo por meio da disponibilidade de carbono e nitrogênio (Jenkinson \& Ayanaba, 1977; Martin \& Haider, 1980; Siqueira \& Franco, 1988; Killham, 1994; Oliveira et al., 1999). Mediante disponibilidade de substrato, há aumento na biomassa microbiana e no metabolismo dos microrganismos, principalmente se a fonte de carbono estiver prontamente disponível (Minhoni et al., 1990). Analisando a decomposição de palha, Sampaio et al., (1990) verificaram que um mês após adição do resíduo vegetal, maior parte da biomassa microbiana havia sido formada a partir de compostos provenientes da palha.

Segundo Alvarez et al. (1995), a matéria orgânica nos primeiros cinco centímetros de solo sob palha é composta por materiais de fácil decomposição que são 
mineralizados rapidamente em condições de laboratório. Campbell et al. (1989) verificaram que a palha proporcionou aumentos na quantidade de aminoácidos e amino açúcares na camada de 0-7,5 cm de solo.

Segundo Vargas \& Scholles (2000), a influência da disponibilidade de N sobre o crescimento microbiano também depende da disponibilidade de C. Assim, como neste estudo houve disponibilidade de $\mathrm{C}$, é possível que microrganismos tenham imobilizado o $\mathrm{N}$ adicionado.

Valores de $\mathrm{pH}$ não apresentaram diferença estatística entre tratamentos, porém valores médios estiveram baixos, o que pode ter contribuído para menor mineralização da matéria orgânica no solo. Freitas et al. (1988) utilizaram torta de filtro e verificaram que, na ausência de $\mathrm{N}$ mineral, aos 10 dias de incubação já havia ocorrido imobilização de $\mathrm{N}-\mathrm{NH}_{4}{ }^{+}$e $\mathrm{N}^{-\mathrm{NO}_{3}}{ }^{-}$. Com uso de calagem, a imobilização foi menor. Quando o pH é maior, tem-se maior atividade microbiológica e maior mineralização ( Edmeades et al., 1981). 
Tabela 9. Atributos químicos do solo amostrado três meses após aplicação dos tratamentos na profundidade de 0-5 cm.

\begin{tabular}{|c|c|c|c|c|c|c|c|c|c|c|c|c|c|}
\hline \multirow[t]{2}{*}{ Tratamento } & \multirow{2}{*}{$\begin{array}{c}\mathrm{pH} \\
\mathrm{CaCl}_{2}\end{array}$} & \multirow{2}{*}{$\begin{array}{l}\text { M.O. } \\
\mathrm{g} \mathrm{dm}^{3}\end{array}$} & $\mathrm{P}$ & $\mathrm{S}$ & \multirow[t]{2}{*}{$\bar{K}$} & \multirow[t]{2}{*}{$\mathrm{Ca}$} & \multirow[t]{2}{*}{$\mathrm{Mg}$} & \multirow{2}{*}{$\begin{array}{c}\mathrm{Al} \\
\mathrm{mmol}_{\mathrm{c}} \mathrm{dn}\end{array}$} & \multirow{2}{*}{$\mathrm{H}+\mathrm{Al}$} & \multirow[t]{2}{*}{ SB } & \multirow{2}{*}{$\begin{array}{r}\mathrm{T} \\
----\end{array}$} & \multirow{2}{*}{\multicolumn{2}{|c|}{$\begin{array}{ll}\mathrm{V} & \mathrm{m} \\
-\end{array}$}} \\
\hline & & & \multicolumn{2}{|c|}{$------\mathrm{mg} \mathrm{dm}^{-3}$} & & & & & & & & & \\
\hline T0 & $4,2 \mathrm{a}$ & $10,2 \mathrm{c}$ & $8,2 \mathrm{a}$ & $11,2 \mathrm{a}$ & $3,4 \mathrm{a}$ & $11,0 \mathrm{a}$ & $6,2 \mathrm{a}$ & $7,0 \mathrm{a}$ & $27,4 \mathrm{~b}$ & $20,6 \mathrm{a}$ & $48,0 \mathrm{a}$ & $42,0 \mathrm{a}$ & $27,4 \mathrm{a}$ \\
\hline $\mathrm{T} 1$ & $4,0 \mathrm{a}$ & $16,4 \mathrm{ab}$ & $7,0 \mathrm{a}$ & $11,6 \mathrm{a}$ & $3,3 \mathrm{a}$ & $7,8 \mathrm{a}$ & $3,6 a b$ & $11,2 \mathrm{a}$ & $40,8 \mathrm{a}$ & $14,7 \mathrm{a}$ & $55,5 \mathrm{a}$ & $26,0 \mathrm{~b}$ & $43,8 \mathrm{a}$ \\
\hline $\mathrm{T} 2$ & $4,1 \mathrm{a}$ & $16,0 \mathrm{~b}$ & $8,2 \mathrm{a}$ & $11,6 \mathrm{a}$ & $4,0 \mathrm{a}$ & $10,2 \mathrm{a}$ & $4,4 \mathrm{ab}$ & $9,0 \mathrm{a}$ & $34,2 \mathrm{ab}$ & $18,6 \mathrm{a}$ & $52,8 \mathrm{a}$ & $35,6 \mathrm{ab}$ & $32,6 \mathrm{a}$ \\
\hline $\mathrm{T} 3$ & $4,0 \mathrm{a}$ & $20,2 \mathrm{a}$ & $9,0 \mathrm{a}$ & $16,6 \mathrm{a}$ & $3,3 \mathrm{a}$ & $8,6 \mathrm{a}$ & $3,8 \mathrm{ab}$ & $10,2 \mathrm{a}$ & $35,2 \mathrm{ab}$ & $15,7 \mathrm{a}$ & $50,9 \mathrm{a}$ & $31,2 \mathrm{ab}$ & $39,4 \mathrm{a}$ \\
\hline $\mathrm{T} 5$ & $4,1 \mathrm{a}$ & $18,6 \mathrm{ab}$ & $7,8 \mathrm{a}$ & $14,0 \mathrm{a}$ & $3,5 \mathrm{a}$ & $9,0 \mathrm{a}$ & $4,0 \mathrm{ab}$ & $8,6 \mathrm{a}$ & $34,6 a b$ & $16,5 \mathrm{a}$ & $51,7 \mathrm{a}$ & $33,2 \mathrm{ab}$ & $34,4 \mathrm{a}$ \\
\hline T6 & $4,0 \mathrm{a}$ & $18,6 \mathrm{ab}$ & $8,6 \mathrm{a}$ & $11,6 \mathrm{a}$ & $3,9 \mathrm{a}$ & $7,2 \mathrm{a}$ & $3,2 \mathrm{~b}$ & $10,4 \mathrm{a}$ & $35,4 \mathrm{ab}$ & $14,3 \mathrm{a}$ & $49,7 \mathrm{a}$ & $29,0 \mathrm{ab}$ & $42,0 \mathrm{a}$ \\
\hline Valor F & $1,9 \mathrm{~ns}$ & $20,3 * *$ & $1,2 \mathrm{~ns}$ & $2,4 \mathrm{~ns}$ & $1,9 \mathrm{~ns}$ & $1,9 \mathrm{~ns}$ & $2,6 *$ & $1,3 \mathrm{~ns}$ & $2,7 *$ & $1,7 \mathrm{~ns}$ & $1,2 \mathrm{~ns}$ & $2,9 *$ & $1,6 \mathrm{~ns}$ \\
\hline $\mathrm{CV}(\%)$ & 3,8 & 9,7 & 16,2 & 35,9 & 21,4 & 21,4 & 33,2 & 28,9 & 17,2 & 22,8 & 11,7 & 22,1 & 27,6 \\
\hline
\end{tabular}

T0: Testemunha, T1: Uréia, T2: Uran, T3: Uréia + Sulfato de amônio, T4: Ajifer, T5: Uréia + Gesso, T6: Uréia incorporada. Médias de cinco repetições contidas em colunas, seguidas de mesma letra não diferem entre si pelo teste de Tukey. * e **: nível de significância de 5\% e $1 \%$ respectivamente. ns: não significativo. 
A acidez potencial foi diretamente proporcional ao teor de matéria orgânica. Pavan (1983) observou que valores de acidez potencial foram menores para os solos contendo menor teor de matéria orgânica. Orlando Filho et al. (1998) observaram que, em sistema de cana crua, maior valor de $\mathrm{H}+\mathrm{Al}$ indicou ligeira acidez proveniente da decomposição da palha.

Tabela 10. Teores de micronutrientes no solo amostrado três meses após aplicação dos tratamentos na profundidade de $0-5 \mathrm{~cm}$.

\begin{tabular}{|c|c|c|c|c|c|}
\hline Tratamento & $\bar{B}$ & $\mathbf{C u}$ & $\mathbf{F e}$ & Mn & $\mathbf{Z n}$ \\
\hline $\mathrm{T} 0$ & $0,31 \mathrm{e}$ & $0,2 \mathrm{a}$ & $52,2 \mathrm{~b}$ & $2,9 \mathrm{a}$ & $0,2 \mathrm{a}$ \\
\hline $\mathrm{T} 1$ & $0,35 \mathrm{~d}$ & $0,2 \mathrm{a}$ & $64,8 \mathrm{ab}$ & $3,0 \mathrm{a}$ & $0,2 \mathrm{a}$ \\
\hline $\mathrm{T} 2$ & $0,39 \mathrm{~d}$ & $0,2 \mathrm{a}$ & $60,0 \mathrm{ab}$ & $3,4 \mathrm{a}$ & $0,2 \mathrm{a}$ \\
\hline $\mathrm{T} 3$ & $0,45 \mathrm{c}$ & $0,2 \mathrm{a}$ & $69,0 \mathrm{ab}$ & $3,7 \mathrm{a}$ & $0,3 \mathrm{a}$ \\
\hline $\mathrm{T} 4$ & $0,47 \mathrm{bc}$ & $0,3 \mathrm{a}$ & $62,6 a b$ & $2,8 \mathrm{a}$ & $0,2 \mathrm{a}$ \\
\hline $\mathrm{T} 5$ & $0,49 a b$ & $0,2 \mathrm{a}$ & $69,0 \mathrm{ab}$ & $3,3 \mathrm{a}$ & $0,5 \mathrm{a}$ \\
\hline T6 & $0,53 \mathrm{a}$ & $0,2 \mathrm{a}$ & $72,8 \mathrm{a}$ & $3,6 \mathrm{a}$ & $0,2 \mathrm{a}$ \\
\hline Valor F & $92,53 * *$ & $1,6 \mathrm{~ns}$ & $3,0^{*}$ & $0,58 \mathrm{~ns}$ & $2,2 \mathrm{~ns}$ \\
\hline $\mathrm{CV}(\%)$ & 4,33 & 25,4 & 13,8 & 33,4 & 56,0 \\
\hline DMS & 0,04 & 0,1 & 18,0 & 2,2 & 0,3 \\
\hline
\end{tabular}

T0: Testemunha, T1: Uréia, T2: Uran, T3: Uréia + Sulfato de amônio, T4: Ajifer, T5: Uréia+Gesso, T6: Uréia incorporada.

Médias de cinco repetições contidas em colunas, seguidas de mesma letra não diferem entre si pelo teste de Tukey. ${ }^{*}$ e ${ }^{* *}$ : nível de significância de $5 \%$ e $1 \%$ respectivamente. ns: não significativo. 
$\mathrm{Na}$ Tabela 10, verifica-se que houve diferença para teores de boro (B) e ferro (Fe) no solo. O tratamento T0 apresentou menores médias para teores de B e Fe em relação aos demais tratamentos. Estudando a mineralização potencial de resíduos de cana-de-açúcar, Yaday et al. (1987) constataram aumento significativo na disponibilidade de macro e micronutrientes como $\mathrm{Zn}, \mathrm{Fe}, \mathrm{Mn}$ e $\mathrm{Cu}$ no solo, principalmente nas parcelas em que houve adição de nitrogênio.

Tabela 11. Teores de carbono, nitrogênio total e relação $\mathrm{C} / \mathrm{N}$ do solo amostrado três meses após aplicação dos tratamentos na profundidade de $0-5 \mathrm{~cm}$.

\begin{tabular}{|c|c|c|c|}
\hline Tratamento & $\mathbf{C}$ & $\mathbf{N}$ & $\mathrm{C} / \mathrm{N}$ \\
\hline T0 & $5,7 \mathrm{c}$ & $0,4 \mathrm{a}$ & $14,4 \mathrm{~b}$ \\
\hline $\mathrm{T} 1$ & $9,1 \mathrm{ab}$ & $0,4 \mathrm{a}$ & $22,1 \mathrm{a}$ \\
\hline $\mathrm{T} 2$ & $8,9 \mathrm{~b}$ & $0,4 \mathrm{a}$ & $21,9 \mathrm{a}$ \\
\hline $\mathrm{T} 3$ & $11,2 \mathrm{a}$ & $0,5 \mathrm{a}$ & 24,6 a \\
\hline $\mathrm{T} 4$ & $10,4 \mathrm{ab}$ & $0,4 \mathrm{a}$ & $25,2 \mathrm{a}$ \\
\hline T5 & $10,3 \mathrm{ab}$ & $0,4 \mathrm{a}$ & $27,1 \mathrm{a}$ \\
\hline T6 & $10,3 \mathrm{ab}$ & $0,4 \mathrm{a}$ & $24,2 \mathrm{a}$ \\
\hline Valor F & $20,3 * *$ & $1,7 \mathrm{~ns}$ & $10,7 * *$ \\
\hline $\mathrm{CV}(\%)$ & 9,7 & 9,6 & 12,3 \\
\hline DMS & 2,3 & 0,1 & 7,0 \\
\hline
\end{tabular}


A Tabela 11 mostra que houve diferença significativa para carbono $(C)$ e para relação $\mathrm{C} / \mathrm{N}$ no solo. Teores de $\mathrm{C}$ no solo nos tratamentos que receberam adubação nitrogenada, foram maiores em relação à testemunha, sendo que o tratamento T3 apresentou maior teor de C. Os tratamentos T1 e T2 apresentaram menores teores de C no solo em relação aos tratamentos T3, T4, T5 e T6. O tratamento T0, devido ao menor teor de $\mathrm{C}$ no solo, apresentou menor relação $\mathrm{C} / \mathrm{N}$ em relação aos demais tratamentos que, apesar de apresentarem maiores teores de $\mathrm{N}$-total, apresentaram maiores teores de C. Tais observações implicam em mudanças na população microbiana do solo pois fungos apresentam características favoráveis para decompor resíduos com elevada relação $\mathrm{C} / \mathrm{N}$ em detrimento a bactérias e actinomicetos. Com o predomínio de fungos sobre bactérias, tem-se aumento na eficiência de transformação do carbono da palha para $\mathrm{C}$ microbiano pois fungos requerem pouca energia em relação às bactérias e isto pode levar à formação de mais matéria or gânica humificada (Campbell et al., 1989; Alvarez et al., 1995). 
Tabela 12. Atributos químicos do solo amostrado três meses após aplicação dos tratamentos na profundidade de $5-10 \mathrm{~cm}$.

\begin{tabular}{|c|c|c|c|c|c|c|c|c|c|c|c|c|c|}
\hline \multirow[t]{2}{*}{ Tratamento } & \multirow{2}{*}{$\begin{array}{c}\mathrm{pH} \\
\mathrm{CaCl}_{2}\end{array}$} & \multirow{2}{*}{$\begin{array}{l}\text { M.O. } \\
\mathrm{g} \mathrm{dm}^{3}\end{array}$} & $\mathrm{P}$ & $\mathrm{S}$ & $\mathrm{K}$ & $\mathrm{Ca}$ & $\mathrm{Mg}$ & \multirow{2}{*}{$\begin{array}{c}\mathrm{Al} \\
\mathrm{mmol}_{\mathrm{c}} \mathrm{dm}\end{array}$} & $\mathrm{H}+\mathrm{Al}$ & \multirow{2}{*}{ SB } & \multirow[t]{2}{*}{$\mathrm{T}$} & \multirow[t]{2}{*}{$\mathrm{V}$} & \multirow[t]{2}{*}{$\mathrm{m}$} \\
\hline & & & \multicolumn{2}{|c|}{------mg d m${ }^{-3}----$} & \multicolumn{4}{|c|}{ - $\mathrm{mmol}_{\mathrm{c}} \mathrm{dm}^{-3}$} & & & & & \\
\hline T0 & $4,4 \mathrm{a}$ & $8,4 \mathrm{~b}$ & $6,6 \mathrm{a}$ & $18,8 \mathrm{a}$ & $1,4 \mathrm{a}$ & $15,0 \mathrm{a}$ & $6,8 \mathrm{a}$ & $5,2 \mathrm{a}$ & $31,2 \mathrm{a}$ & $23,2 \mathrm{a}$ & $54,4 \mathrm{a}$ & $42,6 \mathrm{a}$ & $18,6 \mathrm{a}$ \\
\hline $\mathrm{T} 1$ & $4,3 \mathrm{a}$ & $15,2 \mathrm{a}$ & $7,0 \mathrm{a}$ & $12,2 \mathrm{a}$ & $1,5 \mathrm{a}$ & $14,0 \mathrm{a}$ & $4,8 \mathrm{a}$ & $6,4 \mathrm{a}$ & $28,0 \mathrm{a}$ & $20,3 \mathrm{a}$ & $48,3 \mathrm{a}$ & $41,6 \mathrm{a}$ & $24,8 \mathrm{a}$ \\
\hline $\mathrm{T} 2$ & $4,3 \mathrm{a}$ & $17,6 \mathrm{a}$ & $8,4 \mathrm{a}$ & $11,6 \mathrm{a}$ & $2,3 \mathrm{a}$ & $14,8 \mathrm{a}$ & $5,8 \mathrm{a}$ & $6,2 \mathrm{a}$ & $29,8 \mathrm{a}$ & $22,9 \mathrm{a}$ & $52,7 \mathrm{a}$ & $43,2 \mathrm{a}$ & $23,0 \mathrm{a}$ \\
\hline T5 & $4,3 \mathrm{a}$ & $19,2 \mathrm{a}$ & $7,2 \mathrm{a}$ & $13,8 \mathrm{a}$ & $2,4 \mathrm{a}$ & $14,0 \mathrm{a}$ & $5,8 \mathrm{a}$ & $7,2 \mathrm{a}$ & $34,0 \mathrm{a}$ & $22,2 \mathrm{a}$ & $56,2 \mathrm{a}$ & $40,6 \mathrm{a}$ & $24,2 \mathrm{a}$ \\
\hline T6 & $4,3 \mathrm{a}$ & $17,0 \mathrm{a}$ & $7,0 \mathrm{a}$ & $11,4 \mathrm{a}$ & $1,8 \mathrm{a}$ & $13,0 \mathrm{a}$ & $4,6 \mathrm{a}$ & $7,2 \mathrm{a}$ & $30,2 \mathrm{a}$ & $19,4 \mathrm{a}$ & $49,6 \mathrm{a}$ & $39,6 \mathrm{a}$ & $26,0 \mathrm{a}$ \\
\hline Valor F & $0,32 \mathrm{~ns}$ & $16,2 * *$ & $0,3 \mathrm{~ns}$ & $2,2 \mathrm{~ns}$ & $2,5 \mathrm{~ns}$ & $0,5 \mathrm{~ns}$ & $1,7 \mathrm{~ns}$ & $0,4 \mathrm{~ns}$ & $0,6 \mathrm{~ns}$ & $0,8 \mathrm{~ns}$ & $1,4 \mathrm{~ns}$ & $0,2 \mathrm{~ns}$ & $0,4 \mathrm{~ns}$ \\
\hline $\mathrm{CV}(\%)$ & 4,8 & 12,9 & 43,7 & 30,8 & 31,6 & 17,9 & 23,4 & 45,9 & 22,9 & 16,5 & 11,4 & 19,8 & 42,2 \\
\hline
\end{tabular}

T0: Testemunha, T1: Uréia, T2: Uran, T3: Uréia + Sulfato de amônio, T4: Ajifer, T5: Uréia+Gesso, T6: Uréia incorporada.

Médias de cinco repetições contidas em colunas, seguidas de mesma letra não diferem entre si pelo teste de Tukey. * e **: nível de significância de $5 \%$ e $1 \%$ respectivamente. ns: não significativo 
Tabela 13. Teores de micronutrientes no solo amostrado três meses após aplicação dos tratamentos na profundidade de $5-10 \mathrm{~cm}$.

\begin{tabular}{|c|c|c|c|c|}
\hline Tratamento & $\bar{B}$ & $\mathbf{C u}$ & $\mathbf{F e}$ & Mn \\
\hline $\mathrm{T} 0$ & $0,28 \mathrm{f}$ & $\overline{0,2 \mathrm{a}}$ & $54,4 \mathrm{a}$ & $3,5 \mathrm{a}$ \\
\hline $\mathrm{T} 1$ & 0,34 ef & $0,2 \mathrm{a}$ & $68,6 \mathrm{a}$ & $3,4 \mathrm{a}$ \\
\hline $\mathrm{T} 2$ & $0,36 \mathrm{de}$ & $0,3 \mathrm{a}$ & $58,8 \mathrm{a}$ & $3,1 \mathrm{a}$ \\
\hline $\mathrm{T} 3$ & $0,41 \mathrm{~cd}$ & $0,2 \mathrm{a}$ & $68,2 \mathrm{a}$ & $3,6 \mathrm{a}$ \\
\hline $\mathrm{T} 4$ & $0,43 \mathrm{bc}$ & $0,4 \mathrm{a}$ & $62,6 \mathrm{a}$ & $3,0 \mathrm{a}$ \\
\hline $\mathrm{T} 5$ & $0,48 \mathrm{ab}$ & $0,4 \mathrm{a}$ & $70,2 \mathrm{a}$ & $3,2 \mathrm{a}$ \\
\hline T6 & $0,50 \mathrm{a}$ & $0,3 \mathrm{a}$ & $63,8 \mathrm{a}$ & $4,0 \mathrm{a}$ \\
\hline Valor F & $44,88^{* *}$ & $0,88 \mathrm{~ns}$ & $1,4 \mathrm{~ns}$ & $0,5 \mathrm{~ns}$ \\
\hline $\mathrm{CV}(\%)$ & 6,52 & 59,06 & 16,8 & 31,5 \\
\hline DMS & 0,06 & 0,34 & 21,8 & 2,2 \\
\hline
\end{tabular}

T0: Testemunha, T1: Uréia, T2: Uran, T3: Uréia + Sulfato de amônio, T4: Ajifer, T5: Uréia+Gesso, T6: Uréia incorporada.

Médias de cinco repetições contidas em colunas, seguidas de mesma letra não diferem entre si pelo teste de Tukey. ${ }^{*}$ e $* *$ : nível de significância de $5 \%$ e $1 \%$ respectivamente. ns: não significativo.

Resultados de análise de solo amostrado na camada de $5-10 \mathrm{~cm}$ podem ser visualizados nas Tabelas 12 e 13. Constata-se que também houve diferença significativa para teores de M.O. na camada de 5-10 cm, sendo que o tratamento T0 apresentou menores teores em relação aos demais.

Para micronutrientes, somente houve diferença significativa entre tratamentos para teores de boro (B), sendo que o tratamento T0 apresentou menor média e T6 maior média (Tabela 13).

$\mathrm{Na}$ Tabela 14, verifica-se as diferenças significativas ocorridas para teores de $\mathrm{C}$, $\mathrm{N}$-total e relação $\mathrm{C} / \mathrm{N}$ entre tratamentos. $\mathrm{O}$ tratamento $\mathrm{T} 0$ apresentou menores teores de $\mathrm{C}$ e N-total e maior relação $\mathrm{C} / \mathrm{N}$ em relação aos demais. 
Tabela 14. Teores de carbono, nitrogênio total e relação $\mathrm{C} / \mathrm{N}$ do solo amostrado três meses após aplicação dos tratamentos na profundidade de $5-10 \mathrm{~cm}$.

\begin{tabular}{cccc}
\hline Tratamento & $\mathbf{C}$ & $\mathbf{N}$ & $\mathbf{C} / \mathbf{N}$ \\
& $4,7 \mathrm{~b}$ & \\
\hline T0 & $8,4 \mathrm{a}$ & $0,3 \mathrm{~b}$ & $15,0 \mathrm{~b}$ \\
T1 & $9,8 \mathrm{a}$ & $0,6 \mathrm{a}$ & $14,0 \mathrm{a}$ \\
T2 & $10,9 \mathrm{a}$ & $0,7 \mathrm{a}$ & $14,0 \mathrm{a}$ \\
T3 & $10,0 \mathrm{a}$ & $0,8 \mathrm{a}$ & $14,0 \mathrm{a}$ \\
T4 & $10,7 \mathrm{a}$ & $0,7 \mathrm{a}$ & $14,0 \mathrm{a}$ \\
T5 & $9,4 \mathrm{a}$ & $0,7 \mathrm{a}$ & $14,0 \mathrm{a}$ \\
T6 & $16,2 * *$ & $0,6 \mathrm{a}$ & $14,0 \mathrm{a}$ \\
Valor F & 13,0 & $16,4 * *$ & $99999,99 * *$ \\
CV $(\%)$ & 2,9 & 13,1 & 0,00 \\
DMS & 0,2 & 0,00
\end{tabular}

T0: Testemunha, T1: Uréia, T2: Uran, T3: Uréia + Sulfato de amônio, T4: Ajifer, T5: Uréia+Gesso, T6: Uréia incorporada.

Médias de cinco repetições contidas em colunas, seguidas de mesma letra não diferem entre si pelo teste de Tukey. * e **: nível de significância de $5 \%$ e $1 \%$ respectivamente. ns: não significativo.

\subsubsection{Amostragem realizada cinco meses após aplicação dos tratamentos}

Nas Tabelas 15 e 16 tem-se resultados da análise do solo amostrado na camada de $0-5 \mathrm{~cm}$. Houve diferença significativa para teores de enxofre $(\mathrm{S})$ e cálcio $(\mathrm{Ca})$. Os tratamentos T0 e T1 apresentaram maior teor de $\mathrm{S}$ em relação aos demais. Os tratamentos T5 e T6 apresentaram menores teores de S e não diferiram entre si (Tabela 15). Analisando teores de $\mathrm{Ca}$, verifica-se que maiores médias foram obtidas em T5 e provavelmente estejam relacionadas com aplicação de gesso juntamente coma a uréia.

Para teores de micronutrientes, grande número de repetições apresentaram valor zero na leitura de boro $(\mathrm{B})$ e cobre $(\mathrm{Cu})$. Isso fez com que o coeficiente de variação dos resultados obtidos para esses micronutrientes fosse muito elevado. Para os demais micronutrientes, não houve diferença significativa entre os diferentes tratamentos (Tabela 16). 
Tabela 15. Atributos químicos do solo amostrado cinco meses após aplicação dos tratamentos na profundidade de 0-5 cm.

\begin{tabular}{|c|c|c|c|c|c|c|c|c|c|c|c|c|c|}
\hline \multirow[t]{2}{*}{ Tratamento } & \multirow{2}{*}{$\begin{array}{c}\mathrm{pH} \\
\mathrm{CaCl}_{2}\end{array}$} & \multirow{2}{*}{$\begin{array}{l}\text { M.O. } \\
\mathrm{g} \mathrm{dm}^{3}\end{array}$} & $\mathrm{P}$ & $\mathrm{S}$ & \multirow[t]{2}{*}{$\mathrm{K}$} & \multirow[t]{2}{*}{$\mathrm{Ca}$} & \multirow[t]{2}{*}{$\mathrm{Mg}$} & \multirow{2}{*}{$\begin{array}{c}\mathrm{Al} \\
\mathrm{mmol}_{\mathrm{c}} \mathrm{dn}\end{array}$} & \multirow{2}{*}{$\begin{array}{l}\mathrm{H}+\mathrm{Al} \\
3\end{array}$} & \multirow[t]{2}{*}{ SB } & \multirow{2}{*}{$\begin{array}{r}\mathrm{T} \\
----\end{array}$} & \multirow{2}{*}{\multicolumn{2}{|c|}{$\begin{array}{ll}\mathrm{V} & \mathrm{m} \\
-----\end{array}$}} \\
\hline & & & \multicolumn{2}{|c|}{-------mg dm-3---- } & & & & & & & & & \\
\hline T0 & $4,4 \mathrm{a}$ & $16,8 \mathrm{a}$ & $8,6 \mathrm{a}$ & $12,4 \mathrm{a}$ & $2,5 \mathrm{a}$ & $14,8 \mathrm{ab}$ & $4,8 \mathrm{a}$ & $5,6 \mathrm{a}$ & $28,0 \mathrm{a}$ & $22,4 \mathrm{a}$ & $50,1 \mathrm{a}$ & $45,2 \mathrm{a}$ & $20,8 \mathrm{a}$ \\
\hline $\mathrm{T} 1$ & $4,2 \mathrm{a}$ & $16,6 \mathrm{a}$ & $7,8 \mathrm{a}$ & $11,4 \mathrm{ab}$ & $2,9 \mathrm{a}$ & $13,4 a b$ & $3,2 \mathrm{a}$ & $9,4 \mathrm{a}$ & $34,2 \mathrm{a}$ & $19,6 \mathrm{a}$ & $53,7 \mathrm{a}$ & $36,4 \mathrm{a}$ & $32,2 \mathrm{a}$ \\
\hline $\mathrm{T} 2$ & $4,2 \mathrm{a}$ & $15,6 \mathrm{a}$ & $9,0 \mathrm{a}$ & $9,8 \mathrm{~b}$ & $2,4 \mathrm{a}$ & $12,0 \mathrm{ab}$ & $3,4 \mathrm{a}$ & $9,0 \mathrm{a}$ & $35,8 \mathrm{a}$ & $17,8 \mathrm{a}$ & $53,6 \mathrm{a}$ & $34,2 \mathrm{a}$ & $34,2 \mathrm{a}$ \\
\hline $\mathrm{T} 5$ & $4,5 \mathrm{a}$ & $17,6 \mathrm{a}$ & $8,6 \mathrm{a}$ & $7,0 \mathrm{c}$ & $2,1 \mathrm{a}$ & $17,0 \mathrm{a}$ & $5,0 \mathrm{a}$ & $6,4 \mathrm{a}$ & $29,4 \mathrm{a}$ & $24,2 \mathrm{a}$ & $53,5 \mathrm{a}$ & $44,8 \mathrm{a}$ & $22,6 \mathrm{a}$ \\
\hline T6 & $4,1 \mathrm{a}$ & $17,2 \mathrm{a}$ & $9,0 \mathrm{a}$ & $7,8 \mathrm{c}$ & $1,8 \mathrm{a}$ & $7,8 \mathrm{~b}$ & $3,6 \mathrm{a}$ & $8,4 \mathrm{a}$ & $31,2 \mathrm{a}$ & $13,4 \mathrm{a}$ & $44,4 \mathrm{a}$ & $29,8 \mathrm{a}$ & $39,0 \mathrm{a}$ \\
\hline Valor F & $1,2 \mathrm{~ns}$ & $0,9 \mathrm{~ns}$ & $0,2 \mathrm{~ns}$ & $36,4 * *$ & $1,3 \mathrm{~ns}$ & $2,7 *$ & $0,7 \mathrm{~ns}$ & $0,7 \mathrm{~ns}$ & $0,8 \mathrm{~ns}$ & $2,0 \mathrm{~ns}$ & $1,6 \mathrm{~ns}$ & $0,2 \mathrm{~ns}$ & $2,2 \mathrm{~ns}$ \\
\hline $\mathrm{CV}(\%)$ & 5,8 & 9,9 & 24,3 & 7,2 & 29,2 & 29,5 & 47,2 & 49,0 & 21,2 & 28,3 & 12,0 & 24,4 & 56,1 \\
\hline
\end{tabular}

T0: Testemunha, T1: Uréia, T2: Uran, T3: Uréia + Sulfato de amônio, T4: Ajifer, T5: Uréia+Gesso, T6: Uréia incorporada. Médias de cinco repetições contidas em colunas, seguidas de mesma letra não diferem entre si pelo teste de Tukey. * e **: nível de significância de 5\% e $1 \%$ respectivamente. ns: não significativo. 
Tabela 16. Teores de micronutrientes no solo amostrado cinco meses após aplicação dos tratamentos na profundidade de $0-5 \mathrm{~cm}$.

\begin{tabular}{cccc}
\hline Tratamento & Fe & Mn & Zn \\
& & & \\
\hline T0 & $48,4 \mathrm{a}$ & $0,3 \mathrm{a}$ \\
T1 & $65,4 \mathrm{a}$ & $3,2 \mathrm{a}$ & $0,3 \mathrm{a}$ \\
T2 & $50,0 \mathrm{a}$ & $4,0 \mathrm{a}$ & $0,5 \mathrm{a}$ \\
T3 & $65,6 \mathrm{a}$ & $3,1 \mathrm{a}$ & $0,5 \mathrm{a}$ \\
T4 & $47,2 \mathrm{a}$ & $3,5 \mathrm{a}$ & $0,5 \mathrm{a}$ \\
T5 & $57,4 \mathrm{a}$ & $3,2 \mathrm{a}$ & $0,5 \mathrm{a}$ \\
T6 & $64,0 \mathrm{a}$ & $2,9 \mathrm{a}$ & $0,4 \mathrm{a}$ \\
Valor F & $1,3 \mathrm{~ns}$ & $4,0 \mathrm{a}$ & $2,1 \mathrm{~ns}$ \\
CV $(\%)$ & 28,4 & $0,6 \mathrm{~ns}$ & 34,6 \\
DMS & 32,9 & 35,4 & 0,3
\end{tabular}

T0: Testemunha, T1: Uréia, T2: Uran, T3: Uréia + Sulfato de amônio, T4: Ajifer, T5: Uréia+Gesso, T6: Uréia incorporada.

Médias de cinco repetições contidas em colunas, seguidas de mesma letra não diferem entre si pelo teste de Tukey. ${ }^{*}$ e **: nível de significância de 5\% e $1 \%$ respectivamente. ns: não significativo.

Analisando a Tabela 17, verifica-se que não houve diferença significativa entre tratamentos para teores de $\mathrm{C}, \mathrm{N}$-total e relação $\mathrm{C} / \mathrm{N}$ do solo. 
Tabela 17. Teores de carbono, nitrogênio total e relação $\mathrm{C} / \mathrm{N}$ do solo amostrado cinco meses após aplicação dos tratamentos na profundidade de $0-5 \mathrm{~cm}$.

\begin{tabular}{cccc}
\hline Tratamento & $\mathbf{C}$ & $\mathbf{N}$ & $\mathbf{C} / \mathbf{N}$ \\
& & & \\
\hline T0 & $9,3 \mathrm{a}$ & $23,6 \mathrm{a}$ \\
T1 & $9,2 \mathrm{a}$ & $0,4 \mathrm{a}$ & $22,4 \mathrm{a}$ \\
T2 & $8,7 \mathrm{a}$ & $0,4 \mathrm{a}$ & $21,4 \mathrm{a}$ \\
T3 & $9,8 \mathrm{a}$ & $0,4 \mathrm{a}$ & $21,4 \mathrm{a}$ \\
T4 & $9,4 \mathrm{a}$ & $0,5 \mathrm{a}$ & $23,0 \mathrm{a}$ \\
T5 & $9,8 \mathrm{a}$ & $0,4 \mathrm{a}$ & $25,7 \mathrm{a}$ \\
T6 & $9,6 \mathrm{a}$ & $0,4 \mathrm{a}$ & $22,5 \mathrm{a}$ \\
Valor F & $0,8 \mathrm{~ns}$ & $0,4 \mathrm{a}$ & $0,96 \mathrm{~ns}$ \\
CV $(\%)$ & 9,9 & $1,7 \mathrm{~ns}$ & 14,8 \\
DMS & 1,9 & 9,6 & 6,9
\end{tabular}

T0: Testemunha, T1: Uréia, T2: Uran, T3: Uréia + Sulfato de amônio, T4: Ajifer, T5: Uréia+Gesso, T6: Uréia incorporada.

Médias de cinco repetições contidas em colunas, seguidas de mesma letra não diferem entre si pelo teste de Tukey. ${ }^{*}$ e **: nível de significância de $5 \%$ e $1 \%$ respectivamente. ns: não significativo.

A Tabela 18 mostra resultados para a profundidade $5-10 \mathrm{~cm}$. Constata-se que houve diferença significativa para teores de matéria orgânica (M.O.) e de potássio (K). Teores de M.O. foram maiores em T5 e menores em T3 e T4, teores de K foram maiores em T1 e menores em T6. 
Tabela 18. Atributos químicos do solo amostrado cinco meses após aplicação dos tratamentos na profundidade de 5-10 cm.

\begin{tabular}{|c|c|c|c|c|c|c|c|c|c|c|c|c|c|}
\hline \multirow[t]{2}{*}{ Tratamento } & \multirow{2}{*}{$\begin{array}{c}\mathrm{pH} \\
\mathrm{CaCl}_{2}\end{array}$} & \multirow{2}{*}{$\begin{array}{l}\text { M.O. } \\
\mathrm{g} \mathrm{dm}^{3}\end{array}$} & $\mathrm{P}$ & $\mathrm{S}$ & \multirow[t]{2}{*}{$\mathrm{K}$} & \multirow[t]{2}{*}{$\mathrm{Ca}$} & \multirow[t]{2}{*}{$\mathrm{Mg}$} & \multirow{2}{*}{$\begin{array}{c}\mathrm{Al} \\
-\mathrm{mmol}_{\mathrm{c}} \mathrm{dm}\end{array}$} & $\mathrm{H}+\mathrm{Al}$ & \multirow[t]{2}{*}{ SB } & \multirow{2}{*}{$\begin{array}{r}\mathrm{T} \\
----\end{array}$} & \multirow{2}{*}{\multicolumn{2}{|c|}{$\begin{array}{ll}\mathrm{V} & \mathrm{m} \\
------\% & -----\end{array}$}} \\
\hline & & & \multicolumn{2}{|c|}{-------mg dm-3---- } & & & & & & & & & \\
\hline T0 & $4,6 a$ & $15,8 \mathrm{ab}$ & $8,4 \mathrm{a}$ & $12,4 \mathrm{a}$ & $1,2 \mathrm{ab}$ & $19,6 \mathrm{a}$ & $5,6 \mathrm{a}$ & $3,6 a$ & $27,2 \mathrm{a}$ & $26,4 \mathrm{a}$ & $53,6 \mathrm{a}$ & $49,4 \mathrm{a}$ & $12,6 a$ \\
\hline $\mathrm{T} 2$ & $4,3 \mathrm{a}$ & $16,2 \mathrm{ab}$ & $11,6 \mathrm{a}$ & $10,8 \mathrm{a}$ & $1,2 \mathrm{ab}$ & $14,2 \mathrm{a}$ & $4,0 \mathrm{a}$ & $10,2 \mathrm{a}$ & $32,6 \mathrm{a}$ & $19,4 \mathrm{a}$ & $52,0 \mathrm{a}$ & $36,6 \mathrm{a}$ & 37,4 \\
\hline $\mathrm{T} 3$ & $4,4 \mathrm{a}$ & $14,8 \mathrm{~b}$ & $11,2 \mathrm{a}$ & $13,4 \mathrm{a}$ & $1,2 \mathrm{ab}$ & $18,4 \mathrm{a}$ & $6,0 \mathrm{a}$ & $6,4 \mathrm{a}$ & $33,2 \mathrm{a}$ & $25,6 \mathrm{a}$ & 58,8 a & $45,0 \mathrm{a}$ & 20,8 \\
\hline $\mathrm{T} 5$ & $4,4 \mathrm{a}$ & $17,6 \mathrm{a}$ & $7,0 \mathrm{a}$ & $8,4 \mathrm{a}$ & $1,6 \mathrm{ab}$ & $16,0 \mathrm{a}$ & $4,4 \mathrm{a}$ & $5,4 \mathrm{a}$ & $28,4 \mathrm{a}$ & $21,8 \mathrm{a}$ & $50,2 \mathrm{a}$ & $44,0 \mathrm{a}$ & 21,0 \\
\hline T6 & $4,6 \mathrm{a}$ & $16,8 \mathrm{ab}$ & $6,2 \mathrm{a}$ & $7,8 \mathrm{a}$ & $0,8 \mathrm{~b}$ & $16,6 \mathrm{a}$ & $6,0 \mathrm{a}$ & $3,8 \mathrm{a}$ & $27,2 \mathrm{a}$ & $23,6 \mathrm{a}$ & $50,8 \mathrm{a}$ & $46,4 \mathrm{a}$ & 15,6 \\
\hline Valor F & $1,2 \mathrm{~ns}$ & $3,1^{*}$ & $0,6 \mathrm{~ns}$ & $0,9 \mathrm{~ns}$ & $2,4 *$ & $0,7 \mathrm{~ns}$ & 1,1 & $2,2 \mathrm{~ns}$ & $0,7 \mathrm{~ns}$ & $0,8 \mathrm{~ns}$ & $2,1 \mathrm{~ns}$ & $0,72 \mathrm{~ns}$ & $2,2 \mathrm{~ns}$ \\
\hline $\mathrm{CV}(\%)$ & 5,3 & 8,1 & 67,1 & 80,4 & 34,8 & 28,2 & 35,0 & 55,9 & 22,4 & 26,1 & 8,9 & 23,7 & 56,1 \\
\hline
\end{tabular}

T0: Testemunha, T1: Uréia, T2: Uran, T3: Uréia + Sulfato de amônio, T4: Ajifer, T5: Uréia+Gesso, T6: Uréia incorporada.

Médias de cinco repetições contidas em colunas, seguidas de mesma letra não diferem entre si pelo teste de Tukey. * e **: nível de significância de $5 \%$ e $1 \%$ respectivamente. ns: não significativo. 
Como foi relatado para teores de micronutrientes na camada de $0-5 \mathrm{~cm}$, o mesmo ocorreu na camada 5-10 cm. Grande número de repetições apresentaram valor zero na leitura de $\mathrm{B}$ e $\mathrm{Cu}$, fazendo com que o coeficiente de variação da análise de variância fosse muito elevado (Tabela 19).

Tabela 19. Teores de micronutrientes no solo amostrado cinco meses após aplicação dos tratamentos na profundidade de $5-10 \mathrm{~cm}$.

\begin{tabular}{|c|c|c|c|}
\hline Tratamento & $\mathbf{F e}$ & Mn & $\mathbf{Z n}$ \\
\hline & \multicolumn{3}{|c|}{ 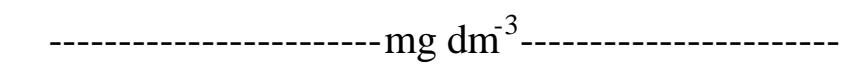 } \\
\hline T0 & $46,8 \mathrm{ab}$ & $3,7 \mathrm{a}$ & $0,4 \mathrm{a}$ \\
\hline $\mathrm{T} 1$ & $63,2 \mathrm{a}$ & $3,5 \mathrm{a}$ & $0,5 \mathrm{a}$ \\
\hline $\mathrm{T} 2$ & $57,2 \mathrm{ab}$ & $2,5 \mathrm{a}$ & $0,5 \mathrm{a}$ \\
\hline $\mathrm{T} 3$ & $53,8 a b$ & $3,1 \mathrm{a}$ & $0,5 \mathrm{a}$ \\
\hline $\mathrm{T} 4$ & $43,0 \mathrm{~b}$ & $2,7 \mathrm{a}$ & $0,8 \mathrm{a}$ \\
\hline T5 & $57,2 \mathrm{a}$ & $3,4 \mathrm{a}$ & $0,4 \mathrm{a}$ \\
\hline T6 & $52,8 \mathrm{ab}$ & $3,9 \mathrm{a}$ & $0,4 \mathrm{a}$ \\
\hline Valor F & $3,6^{*}$ & $0,8 \mathrm{~ns}$ & $0,6 \mathrm{~ns}$ \\
\hline $\mathrm{CV}(\%)$ & 14,9 & 39,6 & 72,6 \\
\hline DMS & 19,8 & 2,6 & 0,8 \\
\hline
\end{tabular}

T0: Testemunha, T1: Uréia, T2: Uran, T3: Uréia + Sulfato de amônio, T4: Ajifer, T5: Uréia+Gesso, T6: Uréia incorporada.

Médias de cinco repetições contidas em colunas, seguidas de mesma letra não diferem entre si pelo teste de Tukey. ${ }^{*}$ e ${ }^{* *}$ : nível de significância de $5 \%$ e $1 \%$ respectivamente. ns: não significativo.

A tabela 20 mostra diferença significativa para teores de $\mathrm{N}$-total e para relação C/N. O tratamento T5 apresentou maior teor de N-total e T3 e T4 apresentaram menores teores, não diferindo entre si. 
Tabela 20. Teores de carbono, nitrogênio total e relação $\mathrm{C} / \mathrm{N}$ do solo amostrado cinco meses após aplicação dos tratamentos, na profundidade de $5-10 \mathrm{~cm}$.

\begin{tabular}{cccc}
\hline Tratamento & $\mathbf{C}$ & $\mathbf{N}$ & $\mathbf{C} / \mathbf{N}$ \\
& & & \\
\hline T0 & $8,8 \mathrm{ab}$ & $0,4 \mathrm{a}$ & $21,7 \mathrm{ab}$ \\
$\mathrm{T} 1$ & $9,1 \mathrm{ab}$ & $0,4 \mathrm{a}$ & $20,7 \mathrm{ab}$ \\
$\mathrm{T} 2$ & $9,0 \mathrm{ab}$ & $0,4 \mathrm{a}$ & $20,2 \mathrm{ab}$ \\
T3 & $8,2 \mathrm{~b}$ & $0,4 \mathrm{a}$ & $21,2 \mathrm{ab}$ \\
T4 & $8,2 \mathrm{~b}$ & $0,5 \mathrm{a}$ & $17,6 \mathrm{~b}$ \\
T5 & $9,8 \mathrm{a}$ & $0,4 \mathrm{a}$ & $21,9 \mathrm{ab}$ \\
T6 & $9,3 \mathrm{ab}$ & $0,4 \mathrm{a}$ & $23,1 \mathrm{a}$ \\
Valor F & $3,1 *$ & $1,6 \mathrm{~ns}$ & $2,6 *$ \\
CV $(\%)$ & 8,1 & 12,9 & 11,5 \\
DMS & 1,5 & 0,1 & 4,9 \\
\hline
\end{tabular}

T0: Testemunha, T1: Uréia, T2: Uran, T3: Uréia + Sulfato de amônio, T4: Ajifer, T5: Uréia +Gesso, T6: Uréia incorporada.

Médias de cinco repetições contidas em colunas, seguidas de mesma letra não diferem entre si pelo teste de Tukey. ${ }^{*}$ e ${ }^{* *}$ : nível de significância de $5 \%$ e $1 \%$ respectivamente. ns: não significativo.

\subsubsection{Variações nos atributos químicos do solo nas diferentes épocas e profundidades de amostragem}

$\mathrm{Na}$ profundidade de 5-10 $\mathrm{cm}$ os valores de $\mathrm{pH}, \mathrm{Ca}, \mathrm{Mg}, \mathrm{SB}$ e $\mathrm{V} \%$ foram maiores em relação aos cinco primeiros centímetros de solo. Valores de $\mathrm{pH}, \mathrm{Ca}, \mathrm{Sb}$ e V\% foram maiores na segunda avaliação. As determinações de $\mathrm{H}+\mathrm{Al}, \mathrm{Al}$ e m\% apresentaram menores valores na profundidade de 5-10 cm e, na segunda amostragem, Al e m\% diminuíram.

A análise dos resultados de $\mathrm{pH}$ mostra que, nas amostragens realizadas aos três e aos cinco meses após aplicação dos tratamentos, maiores valores foram encontrados na camada de 5 a $10 \mathrm{~cm}$ de profundidade. Quanto aos resultados de matéria orgânica, 
quando comparado aos demais tratamentos, T0 apresentou menores teores na amostragem realizada aos três meses. Admitindo-se que o sistema radicular da cultura tenha influenciado nos teores de matéria orgânica do solo, os resultados indicam que a ausência de adubação nitrogenada comprometeu a formação de raízes e/ou radicelas.

A amostragem de solo realizada aos cinco meses apresentou menores teores de $\mathrm{S}$ quando comparada àquela realizada aos três meses. Após dois meses acentuou-se a diferença de teores desse nutriente nas profundidades de 0 a 5 e 5 a $10 \mathrm{~cm}$. 
Tabela 21. Valores de pH, M.O., P, S, V\% e m\% do solo em duas profundidades e épocas de amostragem.

\begin{tabular}{|c|c|c|c|c|c|c|c|c|c|c|c|c|c|}
\hline \multirow[t]{2}{*}{ Trat. } & \multirow[t]{2}{*}{$\begin{array}{l}\text { Prof. } \\
\text {--cm-- }\end{array}$} & & \multicolumn{2}{|c|}{$\begin{array}{c}M . O_{1} \\
-g_{d m}\end{array}$} & \multicolumn{2}{|c|}{$P$} & \multicolumn{2}{|c|}{$\overline{\mathrm{S}}$} & \multicolumn{3}{|c|}{$\mathrm{V}$} & \multirow{2}{*}{$\begin{array}{c}M \\
5\end{array}$} \\
\hline & & 3 & 5 & 3 & 5 & 3 & 5 & 3 & 5 & 3 & 5 & 3 & \\
\hline \multirow[t]{2}{*}{ T0 } & $0-5$ & 4,2 & 4,4 & 10,2 & 16,8 & 8,2 & 8,6 & 11,2 & 12,4 & 42,0 & 45,2 & 27,4 & 20,8 \\
\hline & $5-10$ & 4,4 & 4,6 & 8,4 & 15,8 & 6,6 & 8,4 & 18,8 & 12,4 & 42,6 & 49,4 & 18,6 & 12,6 \\
\hline \multirow[t]{2}{*}{$\mathrm{T} 1$} & $0-5$ & 4,0 & 4,2 & 16,4 & 16,6 & 7,0 & 7,8 & 11,6 & 11,4 & 26,0 & 36,4 & 43,8 & 32,2 \\
\hline & 5-10 & 4,3 & 4,3 & 15,2 & 16,4 & 7,0 & 10,8 & 12,2 & 12,4 & 41,6 & 43,2 & 24,8 & 20,6 \\
\hline \multirow[t]{2}{*}{ T2 } & $0-5$ & 4,1 & 4,2 & 16,0 & 15,6 & 8,2 & 9,0 & 11,6 & 9,8 & 35,6 & 34,2 & 32,6 & 34,2 \\
\hline & $5-10$ & 4,3 & 4,3 & 17,6 & 16,2 & 8,4 & 11,6 & 11,6 & 10,8 & 43,2 & 36,6 & 23,0 & 37,4 \\
\hline \multirow[t]{2}{*}{ T3 } & $0-5$ & 4,0 & 4,2 & 20,2 & 17,6 & 9,0 & 8,2 & 16,6 & 9,8 & 31,2 & 38,2 & 39,4 & 28,4 \\
\hline & $5-10$ & 4,3 & 4,4 & 19,6 & 14,8 & 6,8 & 11,2 & 16,2 & 13,4 & 42,2 & 45,0 & 20,4 & 20,8 \\
\hline \multirow[t]{2}{*}{$\mathrm{T} 4$} & $0-5$ & 4,0 & 4,3 & 18,8 & 17,0 & 7,8 & 8,6 & 14,6 & 9,8 & 28,0 & 38,2 & 38,4 & 26,8 \\
\hline & $5-10$ & 4,3 & 4,5 & 18,0 & 14,8 & 5,8 & 8,4 & 18,6 & 20,2 & 44,6 & 46,2 & 21,6 & 21,0 \\
\hline \multirow[t]{2}{*}{ T5 } & $0-5$ & 4,1 & 4,5 & 18,6 & 17,6 & 7,8 & 8,6 & 14,0 & 7,0 & 33,2 & 44,8 & 34,4 & 22,6 \\
\hline & 5-10 & 4,3 & 4,4 & 19,2 & 17,6 & 7,2 & 7,0 & 13,8 & 8,4 & 40,6 & 44,0 & 24,2 & 21,0 \\
\hline \multirow[t]{2}{*}{ T6 } & $0-5$ & 4,0 & 4,1 & 18,6 & 17,2 & 8,6 & 9,0 & 11,6 & 7,8 & 29,0 & 29,8 & 42,0 & 39,0 \\
\hline & $5-10$ & 4,3 & 4,6 & 17,0 & 16,8 & 7,0 & 6,2 & 11,4 & 7,8 & 39,6 & 46,4 & 26,0 & 15,6 \\
\hline
\end{tabular}

T: Testemunha, T1: Uréia, T2: Uran, T3: Uréia + Sulfato de amônio, T4: Ajifer, T5: Uréia + Gesso, T6: Uréia incorporada. 
Tabela 22. Valores de $\mathrm{K}, \mathrm{Ca}, \mathrm{Mg}, \mathrm{Al}, \mathrm{H}+\mathrm{Al}, \mathrm{SB}$ e $\mathrm{T}$ do solo amostrado em duas profundidades aos três e cinco meses após aplicação dos tratamentos.

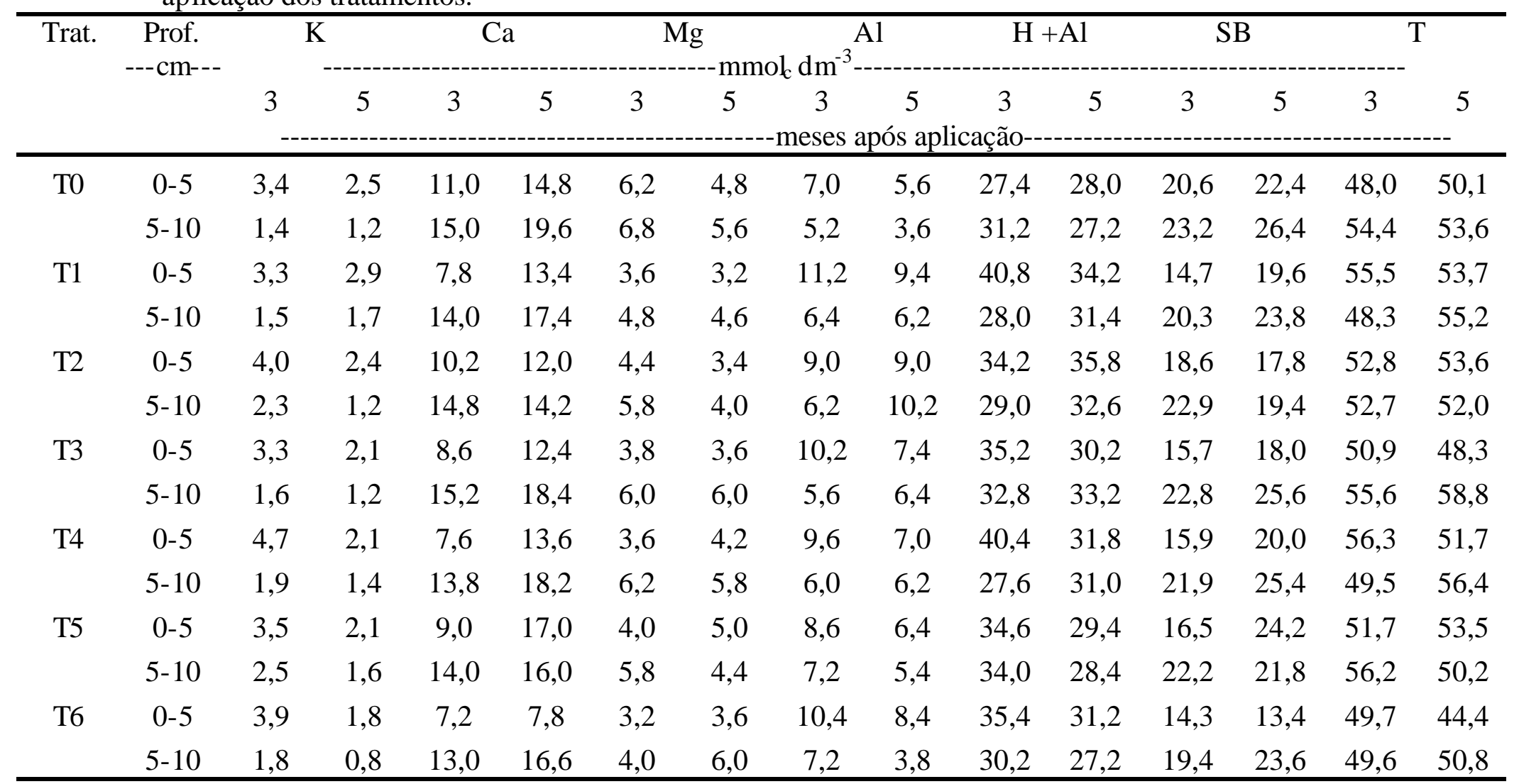

T: Testemunha, T1: Uréia, T2: Uran, T3: Uréia + Sulfato de amônio, T4: Ajifer, T5: Uréia + Gesso, T6: Uréia incorporada. 


\subsection{Avaliação da produtividade e dos atributos qualitativos da cana-de-açúcar}

Na Tabela 23 verifica-se que não houve diferença significativa dos atributos qualitativos entre os tratamentos. Verificou-se que a produção de colmos foi menor em T0, provavelmente devido a ausência de adubação nitrogenada. Nos tratamentos em que avaliou-se a volatilização, a produção de colmos foi inversamente proporcional às perdas ocorridas.

A maior produção de colmos por hectare observada no experimento foi de aproximadamente $50 \mathrm{t} \mathrm{ha}^{-1}$, enquanto que a produtividade anterior do talhão foi de $80 \mathrm{t}$ $\mathrm{ha}^{-1}$. Áreas em início de adoção do sistema de colheita de cana sem despalha a fogo têm apresentado redução na produtividade. Gava (1999) menciona que a diminuição da produtividade varia com o tempo de implantação do sistema de colheita de cana sem queima, com as condições climáticas e de manejo (compactação do solo, sanidade das plantas, variedade utilizada). Orlando Filho et al. (1994) verificaram que, após um ano, a presença da palha causou redução de $52 \%$ da produtividade em relação à cana colhida queimada.

A baixa produtividade também é explicada pelo fato da cana ter sido colhida aos dez meses de idade e pela falta de chuvas. As chuvas ocorridas em março e abril foram insuficientes e prejudicaram a produção de colmos pois a cana de oito a dez meses de idade apresenta aumento considerável na matéria seca de colmos e folhas (Silva e Casagrande, 1983). 
Tabela 23. Produtividade e atributos qualitativos obtidos para cada tratamento.

\begin{tabular}{ccccccccc}
\hline Tratamento & Brix & Pol & Pureza & PC & AR & Fibra & $\begin{array}{c}\text { ATR } \\
--k^{-1}--\end{array}$ & $\begin{array}{c}\text { Produtividade } \\
----- \text { ha }^{-1}----\end{array}$ \\
\hline T0 & $19,8 \mathrm{a}$ & $17,0 \mathrm{a}$ & $86,2 \mathrm{a}$ & $13,4 \mathrm{a}$ & $0,7 \mathrm{a}$ & $16,1 \mathrm{a}$ & $130,5 \mathrm{a}$ & $31,0 \mathrm{~b}$ \\
T1 & $19,7 \mathrm{a}$ & $17,0 \mathrm{a}$ & $86,3 \mathrm{a}$ & $13,5 \mathrm{a}$ & $0,7 \mathrm{a}$ & $15,7 \mathrm{a}$ & $131,0 \mathrm{a}$ & $39,6 \mathrm{ab}$ \\
T2 & $19,3 \mathrm{a}$ & $16,6 \mathrm{a}$ & $86,3 \mathrm{a}$ & $13,4 \mathrm{a}$ & $0,7 \mathrm{a}$ & $15,1 \mathrm{a}$ & $130,0 \mathrm{a}$ & $50,7 \mathrm{a}$ \\
T3 & $19,8 \mathrm{a}$ & $17,3 \mathrm{a}$ & $87,5 \mathrm{a}$ & $14,0 \mathrm{a}$ & $0,6 \mathrm{a}$ & $14,8 \mathrm{a}$ & $134,7 \mathrm{a}$ & $44,3 \mathrm{ab}$ \\
T4 & $19,8 \mathrm{a}$ & $16,9 \mathrm{a}$ & $85,4 \mathrm{a}$ & $13,5 \mathrm{a}$ & $0,8 \mathrm{a}$ & $15,3 \mathrm{a}$ & $132,1 \mathrm{a}$ & $51,5 \mathrm{a}$ \\
T5 & $20,1 \mathrm{a}$ & $17,6 \mathrm{a}$ & $87,6 \mathrm{a}$ & $14,1 \mathrm{a}$ & $0,6 \mathrm{a}$ & $15,1 \mathrm{a}$ & $135,9 \mathrm{a}$ & $45,0 \mathrm{ab}$ \\
T6 & $19,3 \mathrm{a}$ & $16,7 \mathrm{a}$ & $86,4 \mathrm{a}$ & $13,5 \mathrm{a}$ & $0,7 \mathrm{a}$ & $14,7 \mathrm{a}$ & $131,2 \mathrm{a}$ & $44,3 \mathrm{ab}$ \\
Valor F & $1,4 \mathrm{~ns}$ & $2,1 \mathrm{~ns}$ & $0,8 \mathrm{~ns}$ & $1,9 \mathrm{~ns}$ & $0,8 \mathrm{~ns}$ & $2,3 \mathrm{~ns}$ & $1,5 \mathrm{~ns}$ & $6,6^{* *}$ \\
CV $(\%)$ & 2,7 & 3,0 & 2,2 & 3,5 & 22,5 & 4,9 & 3,1 & 13,8 \\
DMS & 1,1 & 1,0 & 3,8 & 1,0 & 0,3 & 1,5 & 8,3 & 15,0 \\
\hline
\end{tabular}

T0: Testemunha, T1: Uréia, T2: Uran, T3: Uréia + Sulfato de amônio, T4: Ajifer, T5: Uréia+Gesso, T6: Uréia incorporada.

Médias de cinco repetições contidas em colunas, seguidas de mesma letra não diferem entre si pelo teste de Tukey. * e **: nível de significância de 5\% e 1\% respectivamente. ns: não significativo. 


\subsection{Estudo da decomposição da palha sem influência da adubação nitrogenada}

A massa seca de palha obtida dois meses após colheita da cana crua foi de $11 \mathrm{t}$ $\mathrm{ha}^{-1}$. Tal valor é baixo em relação ao obtido por outros autores (Herman et al., 1977, Ng kee Kwong et al, 1987 e Siqueira e Franco, 1988; Abramo Filho et al., 1993; Cantarella et al., 1998). Em área de cana colhida crua e mecanicamente, Orlando Filho et al. (1998) encontraram 21,3 $\mathrm{t} \mathrm{ha}^{-1}$ de palha com base em peso úmido e $15,1 \mathrm{t} \mathrm{ha}^{-1}$ com base no peso seco.

Os teores de $\mathrm{N}, \mathrm{P}, \mathrm{K}, \mathrm{Ca}, \mathrm{Mg}$ e $\mathrm{S}$ encontrados na palha $\left(\mathrm{kg} \mathrm{ha}^{-1}\right)$ foram $37 ; 1,1$; 4,$8 ; 18 ; 11$ e 6,0 respectivamente. Manechini (1997) encontrou que a palha de cana continha por hectare $55 \mathrm{~kg}$ de N, 4 de P, 76 de K, 55 de Ca, 26 de Mg e 15 de S. Como a amostragem inicial foi feita em época após ocorrência de chuvas, justifica-se os baixos teores de $\mathrm{K}$ encontrados.

Ao final do período de avaliação, encontrou-se $5 \mathrm{t} \mathrm{ha}^{-1}$ de palha caracterizando, ao final do período, redução de aproximadamente $55 \%$ da massa da palha. Urquiaga et al. (1991) observaram que, após cinco anos, das $74 \mathrm{t} \mathrm{ha}^{-1}$ de palha depositada sobre o solo, somente $6 \mathrm{t} \mathrm{ha}^{-1}$ ficaram como resíduo, indicando que o processo foi relativamente rápido, favorecido pela atividade biológica do solo. Abramo Filho et al. (1993) obtiveram em 11meses, redução de $60 \%$ da massa inicial da palha. Sob efeito da aplicação de nitrogênio e vinhaça, Penatti (2001) obteve redução média de $50 \%$ da massa de material seco da palha de uma safra para outra, atribuindo o observado à redução na quantidade dos carboidratos estruturais lignina, hemicelulose e celulose.

Tabela 24. Teor inicial e final de macronutrientes na palha.

\begin{tabular}{ccccccc}
\hline & $\mathrm{N}$ & $\mathrm{P}$ & $\mathrm{K}$ & $\mathrm{Ca}$ & $\mathrm{Mg}$ & $\mathrm{S}$ \\
& & & & \\
& & & & & \\
& & & & & & \\
Inicial & 3,4 & 0,1 & 0,44 & 1,60 & 0,98 & 0,58 \\
Final & 4,5 & 0,04 & 0,24 & 0,46 & 0,54 & 0,60 \\
\hline
\end{tabular}


No período não houve liberação de $\mathrm{N}$ pela palha, teores de $\mathrm{P}, \mathrm{K}$ e $\mathrm{Ca}$ diminuíram, enquanto que teores de $\mathrm{S}$ aumentaram. Penatti (2001) constatou que praticamente não houve liberação de nitrogênio da palha de cana. Oliveira et al. (1999) verificaram que a reciclagem de nutrientes imobilizados na palha da cultura no sistema de cana crua é mais lenta, sendo que apenas $20 \%$ da matéria seca e $18 \%$ do $\mathrm{N}$ são mineralizados, enquanto a totalidade do $\mathrm{P}$ e do $\mathrm{S}$ permanecem inalterados 12 meses após a colheita da cana crua. Yaday et al. (1987) estudaram a mineralização potencial dos restos culturais de cana-de-açúcar e verificaram que, num período de 120 dias, houve liberação de $70 \%$ de todo potássio existente nos restos culturais. Penatti (2001) concluiu que houve liberação de nutrientes da palha, principalmente de potássio, em média $80 \%$ de uma safra para outra. A liberação do $K$ deve-se ao fato do elemento não ser constituinte de nenhum composto existente na planta, estando presente na forma iônica, o que facilita sua saída da célula após rompimento da membrana plasmática (Malavolta et al., 1989).

Tabela 25. Teor inicial e final de micronutrientes e relações C/N, C/P e C/S na palha.

\begin{tabular}{ccccccccc}
\hline & $\mathrm{B}$ & $\mathrm{Cu}$ & $\mathrm{Fe}$ & $\mathrm{Mn}$ & $\mathrm{Zn}$ & $\mathrm{C} / \mathrm{N}$ & $\mathrm{C} / \mathrm{P}$ & $\mathrm{C} / \mathrm{S}$ \\
& ------------------ & & & & \\
\hline Inicial & 3,4 & 0,1 & 0,44 & 1,60 & 0,98 & 143 & 4860 & 845 \\
Final & 4,5 & 0,04 & 0,24 & 0,46 & 0,54 & 67 & 7575 & 505 \\
\hline
\end{tabular}

Houve redução nas relações C/N e C/S e aumento na relação C/P. Jadhav (1996) observou que, no início do experimento, a relação $\mathrm{C} / \mathrm{N}$ do resíduo de cana-de-açúcar era de 120:1 e, após decomposição, diminuiu para 20:1, ou seja, a relação C/N ficou próxima à dos microrganismos (12:1) e favoreceu a mineralização. Gava (1999) observou que, do início ao final do ensaio, houve redução da relação $\mathrm{C} / \mathrm{N}$ do resíduo de palha de cana-de-açúcar. Oliveira (1999) verificou que as relações $\mathrm{C} / \mathrm{N}, \mathrm{C} / \mathrm{P}$ e $\mathrm{C} / \mathrm{S}$ da palha de cana foram iguais a 97, 947 e 695 na palha recém colhida e passaram para 68, 552 e 455 na palha amostrada 12 meses após colheita da cana. 


\section{CONCLUSÕES}

Os resultados do presente estudo permitiram concluir que:

a) A mistura de uréia com sulfato de amônio, aplicada sobre a palha de canade-açúcar, não reduziu perdas de nitrogênio por volatilização de $\mathrm{N}-\mathrm{NH}_{3}$.

b) A adubação nitrogenada e as perdas por volatilização foram refletidas nos teores foliares de $\mathrm{N}$.

c) A produtividade das soqueiras variou com a adubação nitrogenada e foi inversamente proporcional às perdas ocorridas por volatilização de $\mathrm{N}-\mathrm{NH}_{3}$.

d) Ocorreu redução na massa seca da palhada durante um ciclo da cultura, entretanto não houve liberação de nutrientes pelo resíduo vegetal. 
ANEXOS 
ANEXO A

Tabela 26. Precipitação diária (D) e acumulada (A) da Fazenda São José da Jibóia 2000.

\begin{tabular}{|c|c|c|c|c|c|c|c|c|}
\hline \multirow[t]{3}{*}{ Dias } & \multirow{2}{*}{\multicolumn{2}{|c|}{ Setembro }} & \multirow{2}{*}{\multicolumn{2}{|c|}{ Outubro }} & \multicolumn{2}{|c|}{ Novembro } & \multicolumn{2}{|c|}{ Dezembro } \\
\hline & & & & reci & $\mathrm{o}(\mathrm{m}$ & & & \\
\hline & $\mathrm{D}$ & A & $\mathrm{D}$ & A & $\mathrm{D}$ & A & $\mathrm{D}$ & A \\
\hline 01 & 58 & 58 & 0 & 0 & 0 & 0 & 0 & 0 \\
\hline 02 & 22 & 80 & 0 & 0 & 0 & 0 & 0 & 0 \\
\hline 03 & 0 & 80 & 0 & 0 & 0 & 0 & 0 & 0 \\
\hline 04 & 0 & 80 & 0 & 0 & 0 & 0 & 45 & 45 \\
\hline 05 & 8 & 88 & 15 & 15 & 8 & 8 & 28 & 73 \\
\hline 06 & 0 & 88 & 0 & 15 & 0 & 8 & 0 & 73 \\
\hline 07 & 0 & 88 & 0 & 15 & 0 & 8 & 0 & 73 \\
\hline 08 & 0 & 88 & 0 & 15 & 0 & 8 & 0 & 73 \\
\hline 09 & 0 & 88 & 0 & 15 & 0 & 8 & 0 & 73 \\
\hline 10 & 0 & 88 & 0 & 15 & 18 & 26 & 5 & 78 \\
\hline 11 & 0 & 88 & 0 & 15 & 0 & 26 & 0 & 78 \\
\hline 12 & 17 & 105 & 0 & 15 & 32 & 58 & 0 & 78 \\
\hline 13 & 5 & 110 & 0 & 15 & 10 & 68 & 18 & 96 \\
\hline 14 & 0 & 110 & 0 & 15 & 30 & 98 & 0 & 96 \\
\hline 15 & 25 & 135 & 0 & 15 & 0 & 98 & 30 & 126 \\
\hline 16 & 0 & 135 & 0 & 15 & 0 & 98 & 35 & 161 \\
\hline 17 & 0 & 135 & 0 & 15 & 0 & 98 & 0 & 161 \\
\hline 18 & 0 & 135 & 3 & 18 & 28 & 126 & 0 & 161 \\
\hline 19 & 0 & 135 & 0 & 18 & 0 & 126 & 0 & 161 \\
\hline 20 & 0 & 135 & 0 & 18 & 12 & 138 & 0 & 161 \\
\hline 21 & 0 & 135 & 0 & 18 & 22 & 160 & 4 & 165 \\
\hline 22 & 0 & 135 & 0 & 18 & 0 & 160 & 0 & 165 \\
\hline 23 & 0 & 135 & 0 & 18 & 0 & 160 & 0 & 165 \\
\hline 24 & 8 & 143 & 0 & 18 & 30 & 190 & 30 & 195 \\
\hline 25 & 0 & 143 & 0 & 18 & 35 & 225 & 0 & 195 \\
\hline 26 & 0 & 143 & 0 & 18 & 0 & 225 & 22 & 217 \\
\hline 27 & 0 & 143 & 0 & 18 & 0 & 225 & 32 & 249 \\
\hline 28 & 0 & 143 & 0 & 18 & 42 & 267 & 22 & 271 \\
\hline 29 & 0 & 143 & 0 & 18 & 5 & 272 & 0 & 271 \\
\hline 30 & 0 & 143 & 0 & 18 & 45 & 317 & 25 & 296 \\
\hline 31 & 0 & 143 & 0 & 18 & 0 & 317 & 7 & 303 \\
\hline
\end{tabular}


ANEXO B

Tabela 27. Precipitação diária (D) e acumulada (A) da Fazenda São José da Jibóia 2001.

\begin{tabular}{|c|c|c|c|c|c|c|c|c|c|c|}
\hline \multirow[t]{2}{*}{ Dia } & \multicolumn{2}{|c|}{ Janeiro } & \multicolumn{2}{|c|}{ Fevereiro } & \multicolumn{2}{|c|}{ Março } & \multicolumn{2}{|c|}{ Abril } & \multicolumn{2}{|c|}{ Maio } \\
\hline & $\mathrm{D}$ & A & $\mathrm{D}$ & A & $\mathrm{D}$ & $\mathrm{A}$ & $\mathrm{D}$ & A & $\mathrm{D}$ & A \\
\hline 01 & 0 & 0 & 0 & 0 & 0 & 0 & 25 & 25 & 0 & 0 \\
\hline 02 & 0 & 0 & 0 & 0 & 0 & 0 & 0 & 25 & 0 & 0 \\
\hline 03 & 0 & 0 & 0 & 0 & 0 & 0 & 0 & 25 & 0 & 0 \\
\hline 04 & 0 & 0 & 4 & 4 & 0 & 0 & 0 & 25 & 7 & 7 \\
\hline 05 & 0 & 0 & 22 & 26 & 0 & 0 & 0 & 25 & 0 & 7 \\
\hline 06 & 0 & 0 & 44 & 70 & 12 & 12 & 0 & 25 & 0 & 7 \\
\hline 07 & 0 & 0 & 0 & 70 & 18 & 30 & 0 & 25 & 0 & 7 \\
\hline 08 & 0 & 0 & 32 & 102 & 25 & 55 & 0 & 25 & 0 & 7 \\
\hline 09 & 4 & 4 & 0 & 102 & 25 & 80 & 0 & 25 & 0 & 7 \\
\hline 10 & 0 & 4 & 18 & 120 & 0 & 80 & 0 & 25 & 0 & 7 \\
\hline 11 & 0 & 4 & 0 & 120 & 18 & 98 & 0 & 25 & 18 & 25 \\
\hline 12 & 60 & 64 & 24 & 144 & 0 & 98 & 0 & 25 & 30 & 55 \\
\hline 13 & 17 & 81 & 5 & 149 & 0 & 98 & 0 & 25 & 4 & 59 \\
\hline 14 & 0 & 81 & 2 & 151 & 0 & 98 & 0 & 25 & 0 & 59 \\
\hline 15 & 0 & 81 & 0 & 151 & 0 & 98 & 0 & 25 & 4 & 63 \\
\hline 16 & 0 & 81 & 22 & 173 & 0 & 98 & 0 & 25 & 18 & 81 \\
\hline 17 & 0 & 81 & 4 & 177 & 0 & 98 & 0 & 25 & 4 & 85 \\
\hline 18 & 41 & 122 & 8 & 185 & 0 & 98 & 0 & 25 & 0 & 85 \\
\hline 19 & 0 & 122 & 0 & 185 & 0 & 98 & 0 & 25 & 0 & 85 \\
\hline 20 & 8 & 130 & 0 & 185 & 4 & 102 & 0 & 25 & 0 & 85 \\
\hline 21 & 0 & 130 & 0 & 185 & 0 & 102 & 9 & 34 & 0 & 85 \\
\hline 22 & 0 & 130 & 0 & 185 & 0 & 102 & 4 & 38 & 0 & 85 \\
\hline 23 & 5 & 135 & 32 & 217 & 0 & 102 & 0 & 38 & 0 & 85 \\
\hline 24 & 45 & 180 & 0 & 217 & 0 & 102 & 0 & 38 & 0 & 85 \\
\hline 25 & 8 & 188 & 0 & 217 & 0 & 102 & 0 & 38 & 0 & 85 \\
\hline 26 & 0 & 188 & 0 & 217 & 0 & 102 & 0 & 38 & 0 & 85 \\
\hline 27 & 78 & 266 & 0 & 217 & 12 & 114 & 0 & 38 & 15 & 100 \\
\hline 28 & 118 & 384 & 0 & 217 & 13 & 127 & 0 & 38 & 0 & 100 \\
\hline 29 & 0 & 384 & 0 & 217 & 0 & 127 & 0 & 38 & 0 & 100 \\
\hline 30 & 0 & 384 & 0 & 217 & 0 & 127 & 0 & 38 & 0 & 100 \\
\hline 31 & 8 & 392 & 0 & 217 & 0 & 127 & 0 & 38 & 0 & 100 \\
\hline
\end{tabular}




\section{REFERÊNCIAS BIBLIOGRÁFICAS}

ABRAMO FILHO, J.; MATSUOKA, S.; SPERANDO, M.L.; RODRIGUES, R.C.D.; MARCHIETTI, L.L. Resíduo da colheita mecanizada da cana crua. Álcool e Açúcar, v. 13, n. 67, p. 23-25, 1993.

ACHORN, F.P. Liquid fertilizers and nitrogen solutions. In: INTERNATIONAL FERTILIZER DEVELOPMENT CENTER. Fertilizer manual. Alabama: Kluwer Academic, 2000. cap.10, p. 272-293.

ALEXANDER, A.G. Sugar sugar physiology: a comprehensive study of Saccharum souce-to-link system. Amsterdam: Elsevier, 1973. 752 p.

ALVAREZ, R.; DÍAZ, R.A.; BARBERO, N.; SANTANATOGLIA, O.J.; BLOTTA, R. Soil organic carbon, microbial biomass and $\mathrm{CO}_{2}-\mathrm{C}$ production from three tillage systems. Soil and Tillage Research, v. 33, p. 17-28, 1995.

BOLTON, J.K.; BROWN, R.H. Photosynthesis of grass especies differing in carbon dioxide fixation pathways. V. Response of Panicum maximum, Panicum milioides and tallfescue (Festuca arundinaceae) to nitrogen nutrition. Plant Physiology, v. 66, p. 97-100, 1980.

BOUYOUCOS, G.J. The hydrometer as a new and rapid method for determining the colloidal content of soil. Soil Science, v. 23, n. 4, p. 319-331, 1927. 
BRASIL. Leis, decretos, etc. Lei $\mathrm{n}^{0} 10.547 / 2000$ de 22 de junho de 2.001. Diário Oficial, 083 mai. 2000. Seção 1, p. 1-2. Dispões da proibição do emprego do fogo.

BUZOLIN, P.R.S. Efeitos da palha residual da colheita mecanizada associada a fontes de potássio e doses de nitrogênio, no solo e nas socas de cana-de-açúcar. Jaboticabal, 1997. 89 p. Dissertação (Mestrado) - Faculdade de Ciências Agrárias e Veterinárias, Universidade Estadual Paulista "Júlio de Mesquita Filho".

BYRNES, B.H. Liquid fertilizers and nitrogen solutions. In: INTERNATIONAL FERTILIZER DEVELOPMENT CENTER. Fertilizer manual. Alabama: Kluwer Academic, 2000. cap.2, p. 20-44.

CAMPBELL, C.A.; BIEDERBECK, V.O.; SCHNITZER, M.; SELLES, F.; ZENTNER, R.P. Effect of 6 years of zero tillage and $\mathrm{N}$ fertilizer management on changes in soil quality of an Orthic Brown Chernozen in Southwestern Saskatchewan. Soil and Tillage Research, v. 14, p. 39-52, 1989.

CANTARELlA, H. Adubação nitrogenada em sistema de cana crua. STAB. Açúcar, Álcool e Subprodutos, v.16, n.4. p.21-22, mar./abr. 1998.

CANTARELLA, H.; ROSSETO, R.; BARBOSA, W.; PENNA, M.J.; RESENDE, L.C.L Perdas de nitrogênio por volatilização da amônia e resposta da cana-de-açúcar à adubação nitrogenada, em sistema de colheita de cana sem queima prévia. STAB. Açúcar, Álcool e Subprodutos, v. 18, n. 1, p. 25, set./out., 1999.

CARNAÚBA, B.A.A. O nitrogênio e a cana-de-açúcar. STAB. Açúcar, Álcool e Subprodutos, v.8, n.3/4. p.24-41, jan./abr.1990. 
CLEMENTS, H.F.; MARTIN, S.P.; MORIGUCHI, S. Composition of sugar cane plants grown in deficiency nutrient solution. Hawaiian Planters' Record, n. 45, p. 227$239,1941$.

CONSELHO DOS PRODUTORES DE CANA-DE-AÇÚCAR, AÇÚCAR E ÁLCOOL DO ESTADO DE SÃO PAULO. Manual de instruções. Piracicaba, 1999. 92 p.

DAS, U.K. Nitrogen nutrition of sugarcane. Plant Physiology, v. 5, n. 11, p. 251-317, 1936.

DEANMEAD, O.T.; FRENEY, J.R.; JACKSON, A.V.; SMITH, J.W.B; SAFIGNA, P.G.; WOOD, A.W.; CHAPMAN, L.S. Volatilization of ammonia from urea and ammonium sulfate applied to sugarcane trash in North Queensland. Proceedings Australian Society of Sugar Cane Technologists, v. 12, n. 1, p. 72-78, 1990.

DILLEWIJN, C. van. Botany of sugarcane. Waltham: Chronica Botanica, 1952. 371p.

DÖBEREINER, J.; DAY, J.M.; DART, P.J. Nitrogenase activity in the rhizosphere of sugarcane and some other tropical grasses. Plant and Soil, v. 37, n. 4, p. 191-196, 1972.

EDMEADS, D.C.; JUDD, M.; SARATHCHANDRA, S.U. The effect of lime on nitrogen mineralization as measured by grass growth. Plant and Soil, v. 60, p. 177$186,1981$.

EMPRESA BRASILEIRA DE PESQUISA AGROPECUÁRIA. Centro Nacional de Pesquisa de Solos. Sistema brasileiro de classificação de solos. Rio de Janeiro, 1999. 412p. 
EPSTEIN, E. Nutrição mineral das plantas: princípios e perspectivas. Trad. de E. Malavolta. São Paulo: EDUSP; Rio de Janeiro: Livros Técnicos e Científicos, 1975. $341 \mathrm{p}$.

ESPIRONELLO, A. Aplicação de aquamônia, uréia, nitrato de amônio e cloreto de potássio em cinco níveis, em três socas de cana-de-açúcar. In: CONGRESSO NACIONAL DA SOCIEDADE DOS TÉCNICOS AÇUCAREIROS DO BRASIL, 4., Olinda, 1987. Anais. Piracicaba: STAB, 1987. p. 94-102.

FENN, L.B.; MIYAMOTO, S. Ammonia loss and associated reactions of urea in calcareous soils. Soil Science Society of America Journal, v. 45, p. 537-540, 1981.

FENN, L.B.; RICHARDS, J. Ammonia loss from surface applied urea-acid products. Fertilizer Research, v. 48, p. 578-582, 1984.

FNP CONSULTORIA \& COMÉRCIO. AGRIANUAL 2001: anuário da agricultura brasileira. São Paulo: Ed. Argos Comunicação, 2001. p.221-232: Cana-de-açúcar.

FREITAS, S.S.; CARDOSO, C.O.M.; CAMARGO, O.A.; LOPES, E.S. Mineralização e imobilização de nitrogênio em solo tratado com torta de filtro e carbonato de cálcio. Revista Brasileira de Ciência do Solo, v. 12, p. 243-248, 1988.

FRENEY, J.R.; LEUNING, R.; SIMPSON, J.R.; DENMEAD, O.T.; MUIRHEAD, W.A. Estimating ammonia volatilization from flooded rice fields by simplified methods. Soil Science Society of America Journal, v. 49, n. 4, p. 1049-1054, 1985. 
FRENEY, J.R.; DEANMEAD, O.T.; WOOD, A.W.; SAFFIGNA, P.G.; CHAPMAN, L.S.; HAM, G.J.; HURNEY, A.P.; STEWART, R.L. Factors controlling ammonia loss from trash covered sugarcane fields fertilized with urea. Fertilizer Research, v. 31, p. 341-349, 1992.

FURLANI NETO, V.L.; RIPOLI, T.C.; VILLA NOVA, N.A. Biomassa de cana-deaçúcar: energia contida no palhiço remanescente de colheita mecânica. STAB. Açúcar, Álcool e Subprodutos, v. 15, n. 4, p. 24-27, 1997.

GAVA, G.J.C. Utilização do nitrogênio da uréia $\left({ }^{15} \mathrm{~N}\right)$ e da palhada $\left({ }^{15} \mathrm{~N}\right)$ por soqueira de cana-de-açúcar no manejo sem despalha a fogo. Piracicaba, 1999. 81 p. Dissertação (Mestrado) - Centro de Energia Nuclear na Agricultura, Universidade de São Paulo.

GAVA, G.J.C.; TRIVELIN, P.C.O.; OLIVEIRA, M.W.; VITTI, A.C.; PENATTI, C.P. Perdas de amônia proveniente da mistura de vinhaça e uréia aplicada ao solo com e sem cobertura de palha de cana-de-açúcar. STAB. Açúcar, Álcool e Subprodutos, v. 19, n. 3, p. 40-42, jan./fev. 2001.

HARGROVE, W.L. Soil, environmental, and management factors influencing ammonia volatilization under field conditions. In: BOCK, B.R.; KISSEL, D.E. (Ed.) Ammonia volatilization from urea fertilizers. Alabama: NFDC, TVA, 1988. cap. 2, p.17-36.

HERMAN, W.A.; McGILL, W.B.; DORMAAR, J.F. Effects of initial chemical composition on decomposition of roots of three grass species. Canadian Journal of Soil Science, v. 57, p. 205-215, 1977.

JADHAV, S.B. Effect of incorporation of sugarcane trash on cane productivity and soil fertility. In: INTERNATIONAL SOCIETY OF SUGARCANE TECHNOLOGISTS CONGRESS, 22., Cartagena, 1995. Proceedings. Cali: Tecnicanã, 1996. r. 2 
JENKINSON, D.S.; AYANABA, A. Decomposition of carbon-14 labelled plant material under tropical conditions. Soil Science Society of America Journal, v. 41, p. 912-915, 1977.

JINGGUO, W.; BAKKEN, L.R. Competition for nitrogen during mineralization of plant residues in soil: microbial response to $\mathrm{C}$ and $\mathrm{N}$ availabitity. Soil Biology and Biochemistry, v. 29, p. 163-170, 1997.

JORNALCANA. http://www.canaweb.com.br (30 jun. 2001)

KIEHL, J.C. Nitrogênio: dinâmica e disponibilidade no solo. In: CURSO DE ATUALIZAÇÃO EM FERTILIDADE DO SOLO, 1., Ilha Solteira, 1987. Trabalhos apresentados. Campinas: Fundação Cargill, 1987. p. 139-157.

KIEHL, J.C. Emprego de sais inorgânicos no controle da volatilização de amônia decorrente da aplicação de uréia no solo. Piracicaba, 1989. 108 p. Tese (LivreDocência) - Escola Superior de Agricultura "Luiz de Queiroz", Universidade de São Paulo.

KILLHAM, K. Soil ecology. Cambridge: Cambridge University Press, 1994. 242 p.

KORNDORFER, G. H.; MARTINS, M. Importância da adubação na qualidade da canade-açúcar. STAB. Açúcar, Álcool e Subprodutos, v. 10, n. 3, p. 26-31, jan./fev. 1992.

KUNZ, K. The value of ammonium sulfate. /Apresentado ao Workshop sobre Manejo de Fertilizantes Nitrogenados e Sulfatados na Agricultura, Piracicaba, 2001/ 
LANE, J.H.; EYNON, L. Determination of reducing sugars by means of Fehling's solution with methylene blue as internal indicator. Journal Society Chemical Industry, v. 42, p. 32-37, 1934.

LARA CABEZAS. W.A.R.; TRIVELIN, P.C.O. Eficiência de um coletor semi-aberto estático na quantificação de $\mathrm{N}-\mathrm{NH}_{3}$ volatilizado da uréia aplicada ao solo. Revista Brasileira de Ciência do Solo, v. 14, p. 345-352, 1990.

LARA CABEZAS, W.A.R.; TRIVELIN, P.C.O.; BENDASSOLLI, D.G.S.; GASCHO, G.J. Calibration of a semi-open static collector for determination of ammonia volatilization from nitrogen fertilizers. Communications in Soil Science Plant Analysis, v. 30, n. 3 \& 4, p. 389-406, 1999.

LARA CABEZAS, W.A.R.; TRIVELIN, P.C.O.; SCHIAVINATO Jr., P.; BOARETTO, A.E. Perdas gasosas de nitrogênio de vinhaça e uréia em solos cultivados com canade-açúcar. Revista Brasileira de Ciência do Solo, v. 18, p. 463-469, 1994.

LARA CABEZAS, W.A.R.; TRIVELIN, P.C.O.; VICTÓRIA, R.L.; CAMARGO, P.B.; PICCOLO, M. C. Volatilização de amônia de uréia $-{ }^{15} \mathrm{~N}$ e aquamônia $-{ }^{15} \mathrm{~N}$ aplicadas na cultura da cana-de-açúcar em condições de campo. In: CONGRESSO NACIONAL DA SOCIEDADE DOS TÉCNICOS AÇUCAREIROS DO BRASIL, 4, Olinda, 1987. Anais. Piracicaba: STAB, 1987. p. 94-102.

MALAVOLTA, E. Nutrient and fertilizer management in sugarcane. Switzerland: International Potash Institute Bulletin, 1994. p. 34-35.

MALAVOLTA, E.; HAAG, N.P. Nutrição e adubação. In: MALAVOLTA, E. (Ed.) Cultura e adubação da cana -de-açúcar. São Paulo: Instituto Brasileiro da Potassa, 1964. p. 237-278. 
MALAVOlTA, E.; VITTI, G.C.; OLIVEIRA, S.A. de. Avaliação do estado nutricional das plantas. Piracicaba: POTAFOS, 1989. 201 p.

MALAVOLTA, E.; VITTI, G.C.; OLIVEIRA, S.A. de. Avaliação do estado nutricional das plantas: princípios e aplicações. 2.ed. Piracicaba: POTAFOS, 1997. 319p.

MANECHINI, C. Manejo da cana crua. In: SEMINÁRIO COPERSUCAR DE TECNOLOGIA AGRONÔMICA, 7., Piracicaba, 1997. Anais. Piracicaba: Copersucar, 1997. p. 309-327.

MARTIN, J.P.; HAIDER, K. Microbial degradation and stablization of ${ }^{14} \mathrm{C}$-labeled lignins, phenols, and phenolic polymers in relation to soil humus formation. In: KIRK, T.K.; HIGUCHI, T.; CHANG, H.M. (Ed.) Lignin biodegradation: microbiology, chemistry and potential applications. Boca Raton: CRC Press, 1980. v. 1, p. $77-100$.

MELGAR, R.; CAMOZZI, M.E.; FIGUEROA, M.M. Guia de fertilizantes, enmiendas y productos nutricionales. Buenos Aires: Instituto Nacional de Tecnologia Agropecuária, 1999. cap. 1, p. 13-25: Nitrogenados.

MELO, W.J. Matéria orgânica, nitrogênio e enxofre: curso de atualização em fertilidade do solo. Jaboticabal: ANDA, 1978. 66 p.

MINHONI, M.T.A.; EIRA, A.F.; BÜLL, L.T. Biomassa microbiana, liberação de $\mathrm{CO}_{2}$, fósforo disponível e $\mathrm{pH}$ em solo que recebeu glicose e fosfato de rocha. Revista Brasileira de Ciência do Solo, v. 20, n. 3, p. 387-392, 1996. 
MONESMITH, F.L. Mercado de fertilizantes nitrogenados: tendências internacionais e nacionais. /Apresentado ao Workshop sobre Manejo de Fertilizantes Nitrogenados e Sulfatados na Agricultura, Piracicaba, 2001/

MORAGHAN, J.T.; REGO, T.J.; BURESH, R.J.; VLEK, P.L.G.; BURFORD, J.R.; SINGH, S.; SAHRAWAT, K.L. Labeled nitrogen fertilizer research with urea in the semi-arid tropics. Plant and Soil, v. 80, n.1, p. 21-33, 1984.

NG KEE KWONG, K.F.; DEVILLE, J.; CAVALOT, P.C.; RIVIERE, V. Value of cane trash in nitrogen nutrition of sugarcane. Plant and Soil, v. 102, p. 79-83, 1987.

NÖNMIK, H. The effect of pellet size on the ammonia loss from urea applied to forest sois. Plant and Soil, v. 39, p. 309-318, 1973.

OLIVEIRA, M.W. Dinâmica do nitrogênio da uréia $\left({ }^{15} \mathrm{~N}\right)$ no sistema solo-cana-deaçúcar com ou sem queima da palhada. Piracicaba, 1999. 93 p. Tese (Doutorado) Escola Superior de Agricultura “Luiz de Queiroz”, Universidade de São Paulo.

OLIVEIRA, M.W.; TRIVELIN, P.C.O.; BENDASSOLLI, J.A. Volatilização de amônia da uréia $\left({ }^{15} \mathrm{~N}\right)$ aplicada ao solo com e sem cobertura de palhada em diferentes manejos na adubação de soqueiras de cana-de-açúcar. STAB. Açúcar, Álcool e Subprodutos, v. 18, n. 1, p. 26, 1999.

OLIVEIRA, M.W.; TRIVELIN, P.C.O., PENATTI, C.P.; PICCOLO, M.C. Decomposição e liberação de nutrientes da palhada de cana-de-açúcar em campo. Pesquisa Agropecuária Brasileira, v. 34, n. 12, p. 2359-2362, dez. 1999. 
OLIVEIRA, M.W.; GAVA, G.J.C.; VITTI, A.C.; BENDASSOLI, J.A.; TRIVELIN, P.C.O. Volatilização de amônia proveniente da uréia $\left({ }^{15} \mathrm{~N}\right)$ aplicada em solo cultivado com cana-de-açúcar. In: ENCONTRO CIENTÍFICO DE PÓSGRADUANDOS DO CENA - USP, 3., Piracicaba, 1997. Piracicaba: CENA, 1997. p. 28.

OLIVEIRA, S.A. Avaliação da mineralização e disponibilidade de nitrogênio para o trigo (Triticum aestivum L.) em solos do Distrito Federal. Piracicaba, 1987. 128 p. Tese (Doutorado) - Escola Superior de Agricultura "Luiz de Queiroz", Universidade de São Paulo.

ORLANDO FILHO, J.; HAAG, H.P.; ZAMBELLO JR, E. Crescimento e absorção de macronutrientes pela cana-de-açúcar variedade CB 41-76, em função da idade, em solos do Estado de São Paulo. Boletim Técnico Planalsucar, v. 2, n. 1, p. 1-128, fev. 1980 .

ORLANDO FILHO, J.; CARMELLO, Q.A.C.; PEXE, C.A.; GLÓRIA, A.N. Adubação de soqueira de cana-de-açúcar sob dois tipos de despalha: cana crua $\mathrm{x}$ cana queimada. STAB. Açúcar, Álcool e Subprodutos, v. 12, n. 4, p. 7-11, 1994.

ORLANDO FILHO, J.; ROSSETO, R.; MURAOKA, T.; ZOTELLI, H.B. Efeitos do sistema de despalha (cana crua $\mathrm{X}$ cana queimada) sobre algumas propriedades do solo. STAB. Açúcar, Álcool e Subprodutos, v. 16, n. 6, p. 30-33, 1998.

PAVAN, M.A. Alumínio em solos ácidos do Paraná: Relação entre o alumínio não trocável, trocável e solúvel, com o pH, porcentagem de saturação de $\mathrm{Al}$ e matéria orgânica. Revista Brasileira de Ciência do Solo, v. 7, p. 39-46, 1983. 
PENATTI, C.P.; DONZELLI, J.L. Avaliação nutricional em cana colhida sem a queima da palha. Piracicaba: COPERSUCAR, 2001. 18 p. (Relatório Final do Projeto $n^{\circ} 620$ - Fase P1 safras 99/00 e 00/01).

PRAMMANEE, P.; SAFFIGNA, P.G.; WOOD, A.W. Loss of nitrogen from urea and ammonium sulfate applied to sugar cane crop residues. In: AUSTRALIAN SOCIETY OF SUGARCANE TECHNOLOGISTS, 11., Mackay, 1989. Proceedings. Mackay: Watson Fergunson, 1989. p. 76-84.

PRIMAVESI, A. Manejo ecológico do solo. São Paulo: Nobel, 1987. p. 108-135: A matéria orgânica .

RAIJ, B. van. Fertilidade do solo e adubação . Piracicaba: Ceres; POTAFOS, 1991. $343 \mathrm{p}$.

RAIJ, B. van; QUAGGIO, J.A; CANTARELLA, H.; FERREIRA, M.E.; LOPES, A.S.; BATAGLIA, O.C. Análise química do solo para fins de fertilidade. Campinas: Fundação Cargill, 1987. 170p.

RASHID, G.H. The volatilization loss of nitrogen from added urea in some soils of Bangladesh. Plant and Soil, v. 48, n.3, p. 549-556, 1977.

REYNOLDS, C.M.; WOLF, D.C.; ARMBRUSTER, J.A. Factors related to urea hydrolysis in soils. Soil Science Society America Journal, v.49. p. 104-108, 1987.

RIPOLI, T.C.; PARANHOS, S.B. Colheita. In: PARANHOS, S.B. (Ed.) Cana-deaçúcar: cultivo e utilização. Campinas: Fundação Cargill, 1987. v. 2, p. 517-597. 
RODRIGUES, M.B.; KIEHL, J.C. Volatilização de amônia após o emprego de uréia em diferentes doses e modos de aplicação. Revista Brasileira de Ciência do Solo, v. 10, n. 1, p. 37-43, 1986.

RODRIGUES, M.B.; KIEHL, J.C. Distribuição e nitrificação da amônia proveniente da uréia aplicada ao solo. Revista Brasileira de Ciência do Solo, v. 16, p. 403-408, 1992.

ROSSIELLO, R.O.P. Bases fisiológicas da acumulação de nitrogênio e potássio em cana-de-açúcar (Saccharum spp, cv. NA 56-79) em resposta à adubação nitrogenada em cambissolo. Piracicaba, 1987. 172 p. Tese (Doutorado) - Escola Superior de Agricultura "Luiz de Queiroz", Universidade de São Paulo.

SALLAWAY, M.M. Trash retention as a soil Techinique. In: CONFERENCE OF AUSTRALIAN SOCIETY OF SUGAR TECHNOLOGISTS, Mackay, 1979. Proceedings. Brisbane: BSES, 1979. p. 89-93.

SAMPAIO, E.V.S.B. Dinâmica de nitrogênio em solos de Pernambuco, especialmente em solo de tabuleiro cultivado com cana-de-açúcar. Recife, 1991. 115 p. Tese (Titular) - Universidade Federal de Pernambuco.

SAMPAIO, E.V.S.B.; SALCEDO, I.H.; LIMA Jr., M.A.; BETTANY, J. Decomposição de palha de milho $\left({ }^{14} \mathrm{C}-\mathrm{N}^{15}\right)$ incorporada a três profundidades em um Latossolo vermelho-amarelo de Pernambuco. Revista Brasileira de Ciência do Solo, v. 14 , n.3, p. 269-276, 1990.

SAN, C.K. The simple open soil method of measuring urea volatilization losses. Plant and Soil, v. 92, n.1, p. 73-79, 1986. 
SAS INSTITUTE. SAS/STAT guide for personal computers. Version 6. Cary,1987. $1 \mathrm{v}$.

SAVANT, N.K.; JAMES, A.F.; MCCLELEAN, G.H. Effect of amounts and sequence of additions of urea and water on hydrolysis of surface-applied granular urea in unsaturated soils. Fertilizer Research, v. 11, p. 231-234, 1987.

SCHARF, P.C.; ALLEY, M.M. Nitrogen loss pathways and nitrogen loss inhibitors: a review. Journal of Fertilizer Issues, v. 5, n. 4, p. 141-144, 1988.

SCHNEIDER, F. (Ed.) Sugar analysis ICUMSA metods. Mackay: BSES, 1979. 265 p.

SENGIK, E.; KIEHL, J.C. Controle da volatilização de amônia em terra tratada com uréia e turfa pelo emprego de sais inorgânicos. Revista Brasileira de Ciência do Solo, v. 19, n. 3, p. 329-492, 1995.

SILVA, L.C.F. da; CASAGRANDE, J.C. Nutrição mineral da cana-de-açúcar (macronutrientes). In: ORLANDO FILHO, J. Nutrição e adubação da cana-deaçúcar no Brasil. Piracicaba: Instituto do açúcar e do álcool, 1983. cap. 4, p. 77-97: Nutrição mineral da cana-de-açúcar (macronutrientes).

SILVEIRA, J.A.G. Aspectos bioquímicos e fisiológicos da relação K:N em cana-deaçúcar (Saccharum spp) cv. NA 56-79 cultivada em solução nutritiva. Piracicaba, 1980. 127 p. Dissertação (Mestrado) - Escola Superior de Agricultura "Luiz de Queiroz”, Universidade de São Paulo.

SIQUEIRA, J.O.; FRANCO, A.A. Biotecnologia do solo: fundamentos e perspectivas. Brasília: ABEAS; MEC; ESAL, FAEPE, 1988. 236 p. 
SUBIRÓS, J.F.; BERTSCH, F. Utilizacion de fertilizantes líquidos nitrogenados en tres ciclos de produccion comercial de caña de azúcar en Guanacaste. Agronomia Costarricense, v. 22, n. 1, p. 89-98, 1998.

TEDESCO, M.J.; GIANELLO, C.; BISSANI, C.A.; BOHNEN, H.; VOLKWEISS, S.J. Análise de solo, plantas e outros materiais. 2.ed. Porto Alegre: UFRGS, Depto. de Solos, $1995.174 \mathrm{p}$.

TRIVELIN, P.C.O.; BENDASSOLLI, J.A.; OLIVEIRA, M.W. Potencialidade da mistura de aquamônia com vinhaça na fertilização de canaviais colhidos sem despalha a fogo. Parte I: Estabilidade química da mistura. STAB. Açúcar, Álcool e Subprodutos, v. 16, n. 2, p. 26-29, 1997.

TRIVELIN, P.C.O.; STEFANUTTI, R.; LIMA FILHO, O.F.; TZIBOY, E.A.T.; OLIVEIRA, J.A.; BENDASSOLLI, J.A. Volatilização de amônia do solo associada à aplicação superficial de solução nitrogenada com uréia e nitrato de amônio (compact disc). In: CONGRESSO LATINO AMERICANO DE CIÊNCIA DO SOLO, 13., Águas de Lindóia, 1996. Anais. Águas de Lindóia: SLACS, 1996.

URQUIAGA, S.; BODDEY, R.M.; OLIVEIRA, O.C.; LIMA, E.; GUIMARÃES, D.H.V. Importância de não queimar a palha da cana-de-açúcar. Seropédica: Embrapa, CNPAB, 1991. 12 p. (Comunicado Técnico, 5).

VARGAS, L.K.; SCHOLLES, D. Biomassa microbiana e produção de $\mathrm{C}_{-} \mathrm{CO}_{2}$ e N mineral de um Podzólico Vermelho-Escuro submetido a diferentes sistemas de manejo. Revista Brasileira de Ciência do Solo, v. 24, n. 1, p. 35-42, jan./mar. 2000. 
VITTI, A.C. Utilização pela cana-de-açúcar (cana planta) do nitrogênio da uréia $\left({ }^{15} \mathrm{~N}\right)$ e do mineralizado no solo em sistemas de manejo com ou sem a queima. Piracicaba, 1998. 93 p. Dissertação (Mestrado) - Centro de Energia Nuclear na Agricultura, Universidade de São Paulo.

VITTI, G.C. Avaliação e interpretação do enxofre no solo e na planta. Jaboticabal: FUNEP, 1988. $37 \mathrm{p}$.

VITTI, G.C.; COSTA, M.C.G. Manejo de fertilizantes nitrogenados na culturas de canade-açúcar e café. /Apresentado ao Workshop sobre Manejo de Fertilizantes Nitrogenados e Sulfatados na Agricultura, Piracicaba, 2001/

VITTI, G.C.; MALAVOLTA, E.; COUTINHO, E.L.M. Uso de fertilizantes nitrogenados e portadores de enxofre. In: SIMPÓSIO BRASILEIRO SOBRE FERTILIZANTES NA AGRICULTURA BRASILEIRA, Brasília, 1984. Anais. Brasília, Embrapa, 1984. p. 215.

VITTI, G.C.; TAVARES Jr., J.E.; LUZ, P.H.C.; COSTA, M.C.G.; FAVARIN, J.L. Características físicas e químicas da mistura entre uréia e sulfato de amônio . In: CONGRESSO BRASILEIRO DE CIÊNCIA DO SOLO, 18., Londrina, 2001. Anais. Londrina: SBCS, 2001. p. 312.

VOLK, M.G. Volatile loss of ammonia following surface application of urea to turf of bare soils, Agronomy Journal, v. 51, p.746-749, 1959.

WENG, T.H.; LI, S.W. Nitrogen mineralization potencial and rate in soil. Taiwan Sugar, v. 39, n. 3, p. 8-11, May/June 1992.

WILLCOX, T. Prosepine growers develop new fertilizers applicators. BSES Bulletin, v. 29, n. 32, p. 20-21, 1990. 
WOOD, A.W. Management of crops residues following green harvesting of sugarcane in north Queensland. Soil \& Tillage Research, v. 20, p. 69-85, 1991.

YADAY, D.V.; TODI, S.; SRIVASTAVA, A.R. Recycling of nutrients in trash with N for higher cane yield. Biological Wastes, v. 20, p. 133-141, 1987.

ZAMBELLO Jr., E.; ORLANDO FILHO, J. A adubação da cana-de-açúcar na região centro-sul do Brasil. Boletim Técnico Planalsucar, v. 3, n.3, p. 15, mar. 1981. 